US Army Corps

of Engineers ${ }_{\circledast}$

Engineer Research and

Development Center

Navigation Systems Research Program

\title{
Corrosion Induced Loss of Capacity and Development of a Guided Wave Condition Assessment Method for Multistrand Anchor Systems Used in Corps Projects
}

Richard W. Haskins, James A. Evans, and Robert M. Ebeling

August 2014
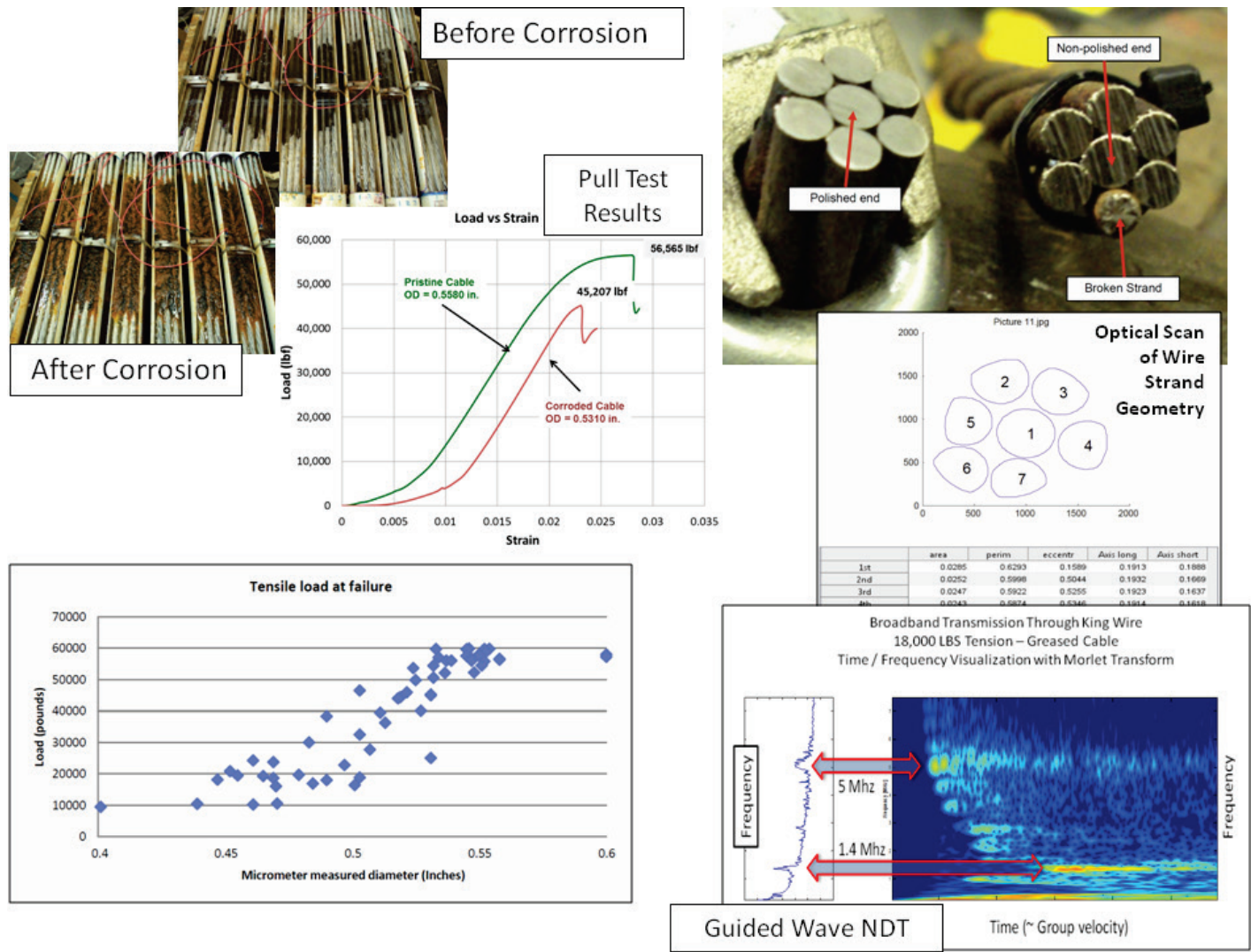
The US Army Engineer Research and Development Center (ERDC) solves the nation's toughest engineering and environmental challenges. ERDC develops innovative solutions in civil and military engineering, geospatial sciences, water resources, and environmental sciences for the Army, the Department of Defense, civilian agencies, and our nation's public good. Find out more at www.erdc.usace.army.mil.

To search for other technical reports published by ERDC, visit the ERDC online library at http://acwc.sdp.sirsi.net/client/default. 


\section{Corrosion Induced Loss of Capacity and Development of a Guided Wave Condition Assessment Method for Multistrand Anchor Systems Used in Corps Projects}

Richard W. Haskins, James A. Evans, and Robert M. Ebeling Information Technology Laboratory US Army Engineer Research and Development Center 3909 Halls Ferry Road

Vicksburg, MS 39180-6199

Final report

Approved for public release; distribution is unlimited.

Prepared for US Army Corps of Engineers 441 G Street

Washington, DC 20314-1000 


\section{Abstract}

Over the past three decades, the US Army Corps of Engineers (USACE) has worked to upgrade its projects by installing high-capacity, post-tensioned foundation anchors. These stressed steel tendons have been used to strengthen hydraulic concrete structures and to improve their serviceability and structural stability. Substantial improvements to protect multistrand anchor systems from corrosion have been made since they were first used in Corps projects more than 50 years ago, but the corrosion of older multistrand anchor systems is still a major concern. As a result of these needs, researchers at the US Army Engineer Research and Development Center (ERDC) are developing engineering procedures to estimate the current state of load-carrying capacity and to estimate the remaining service life of these tendons. These tools also aim to establish the rate of deterioration of anchorage capacity (with time), so costly replacement of ground anchorage can be delayed until absolutely needed. Analytical, laboratory, and fieldtesting efforts will be used to develop a methodology and analytical models to predict deterioration and loss of strength. Probabilistic procedures will be used to quantify uncertainties for the primary variable resulting in loss of strength of the post tensioned tendon. These uncertainty parameters will be carried into the risk-based analytical model. Procedures to extend the life of deteriorating multistrand tendons will be investigated.

This report discusses ERDC's recent advances in the initial phase of a laboratory testing program to estimate seven strand wire cable strength as a function of cross sectional material loss. Cable strength is measured by performing a pull test to failure on corroded specimens, as well as specimens with manufactured defects. An innovative morphological procedure using digital photography was developed for quantifying the geometrical properties of cables near their failure locations. Fundamental research into nondestructive testing (NDT) methods to assess the condition of posttensioning seven strand wire cables is also discussed, with a focus on the guided wave approach.

DISCLAIMER: The contents of this report are not to be used for advertising, publication, or promotional purposes. Citation of trade names does not constitute an official endorsement or approval of the use of such commercial products. All product names and trademarks cited are the property of their respective owners. The findings of this report are not to be construed as an official Department of the Army position unless so designated by other authorized documents. 


\section{Contents}

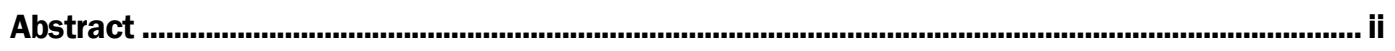

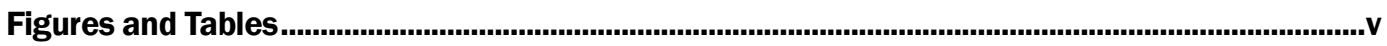

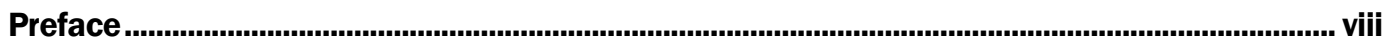

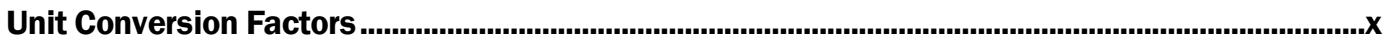

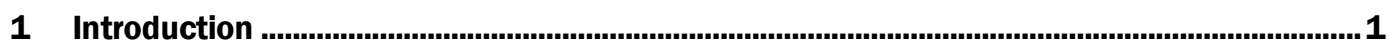

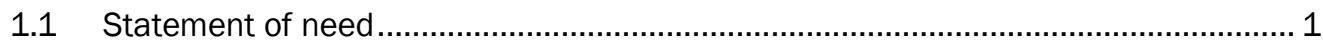

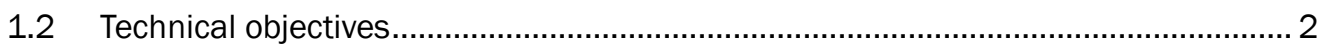

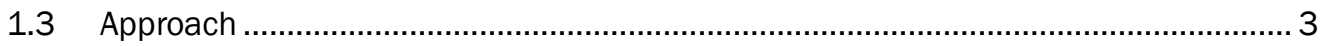

1.4 Observations made in the first multistrand research and development

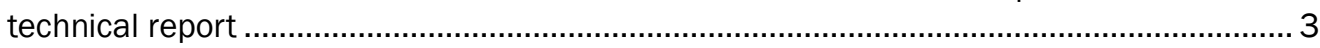

2 Estimating Seven Strand Wire Cable Strength as a Function of Cross-Sectional

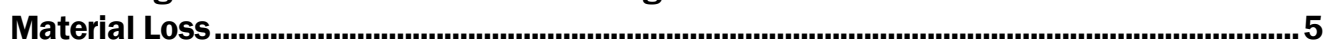

2.1 Reduction of cross-sectional area …………............................................... 5

2.1.1 The corrosion process................................................................................. 5

2.1.2 Manufactured defect process ............................................................................ 6

2.2 Target corrosion levels and sample counts ........................................................ 7

2.3 Assessment of the condition of seven strand wire cables during corrosion

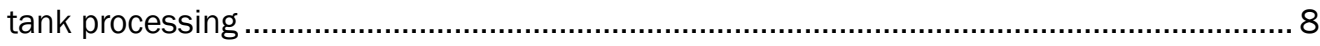

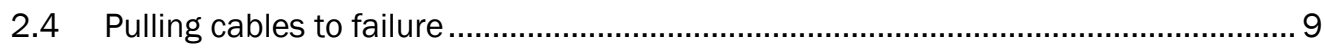

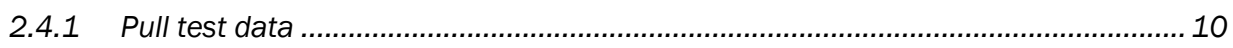

2.4.2 Accurately characterizing the weakest cross-sectional area................................. 10

2.4.3 Overview of the morphological processing of cable failure points ........................... 11

2.4.4 Mechanical preparation of broken strands for imaging.........................................13

2.4.5 Collection of image data .............................................................................. 14

2.4.6 Operation of image processing software ........................................................... 15

2.4.7 Image processing method used for automated cable segmentation........................ 18

2.5 Development of Deterioration Database:................................................................. 24

3 NDT Methods to Access the Condition of Post-Tension Seven Strand Wire Cables..............31

3.1 Need within the Corps for Seven Strand Post Tension Cable Inspection .................. 31

3.2 Boundary Conditions for Field Inspection in Mass Concrete ....................................32

3.3 NDT Technologies in General for Seven Strand Wire Cable Inspection.....................32

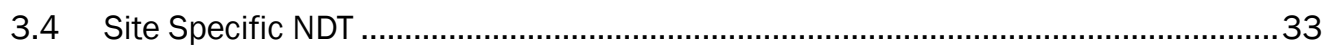

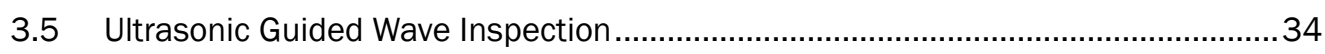

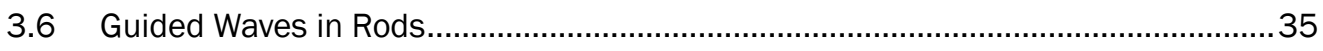

3.7 Guided Wave Inspection of Cables ................................................................. 37

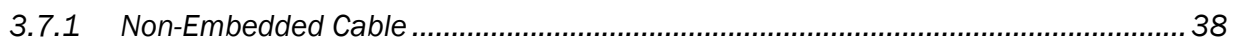

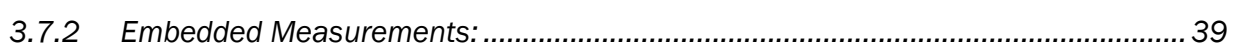

3.8 Test Fixtures and Loading Mechanisms ........................................................... 43 
3.9 Current system configuration and optimizations..............................................50

3.10 NDT Results and Conclusions .................................................................. 51

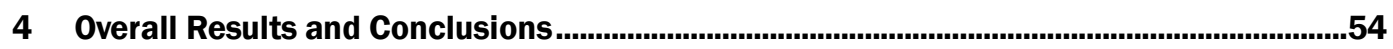

4.1 Summary of NDT Findings to Date .................................................................. 54

4.2 Summary of progress relating cable condition to performance ..............................55

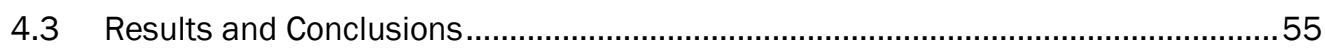

References .............................................................................................................................57

Appendix A: Cable End View Imager Code (MATLAB IMAGE PROCESSING \#2 code).................59

Appendix B: Axial Scanner Theory and Operation......................................................................65

Report Documentation Page 


\section{Figures and Tables}

\section{Figures}

Figure 1. Schematic representation of corrosion chamber for controlled deterioration of cables.

Figure 2. Photographs of corrosion tanks and corroded seven strand wire cables. ......................... 7

Figure 3. Orientation of the caliper measurements used when tracking material losses

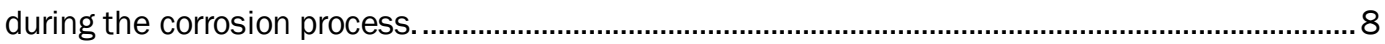

Figure 4. Pull test results used to determine micrometer readings for pull criteria. .......................... 9

Figure 5. Pull criteria used to hit target strength reductions.............................................................

Figure 6. Curve comparing a strength reduction of $25 \%$ to a pristine cable. ...................................10

Figure 7. Typical output of data from image analysis.....................................................................12

Figure 8. Tracing deformation with string measurement to locate the failure point in unbroken wires.

Figure 9. Saw (left) and sander (right) application used to finish seven strands at the

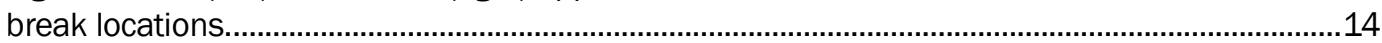

Figure 10. Cross-sectional imaging frame used for cable and calibration imaging........................15

Figure 11. Computer capture with cable installed in imaging frame.............................................15

Figure 12. Binary image of 3/4-inch diameter calibration sticker......................................................16

Figure 13. Cropping of cable cross-section image. .........................................................................16

Figure 14. Original image (left), threshold set too low (center), and proper threshold

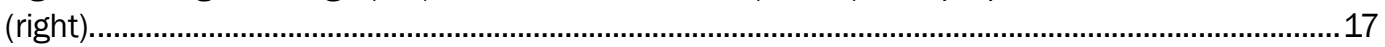

Figure 15. Morphological failure image indicating poor segmentation.............................................17

Figure 16. Last resort approach of manual segmentation using mouse-based freehand cutting.

Figure 17. Resulting mask from inverting and thinning binary image from thresholding (pixels enlarged for illustration). 19

Figure 18. Difference between two different levels of spur removal.

Figure 19. (Left) Branch points, (Right) Composite showing branch points, spurs, and object perimeters

Figure 20. Linear error of spur points contained between neighboring spur points. .......................21

Figure 21. Continuous line form connecting spur points with acceptable error................................21

Figure 22. Added segment and linear test points for all branch points. .........................................22

Figure 23. Composite cut mask from thinning mask combined with the segment masks.............22

Figure 24. Before segmentation with mask, the mask used, and the segmented result

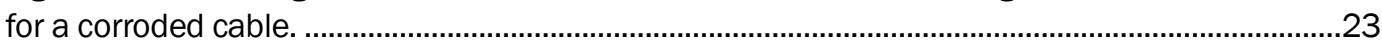

Figure 25. Morphological results from automatic segmentation. ...................................................24

Figure 26. Masks formation and application for a poorly oriented strand with artifacts.................24

Figure 27. A distribution of pull test results from laboratory corroded samples...............................25

Figure 28. Pull test load failure points plotted against micrometer measured diameter................25 
Figure 29. Low-loss modes existing between centralization of guided wave energy at higher frequency and lower material attenuation at lower frequencies.

Figure 30. (Left)-Energy velocity curves showing compression and torsional modes.

(Right)-Reverberation of high frequency low-loss modes and the associated A-scan.

Figure 31. Narrow band spectral reflections a .18-inch-deep cut and the rod end of a 1.31-inch-diameter grease embedded trunion anchor rod with concrete termination.

Figure 32. $441 \mathrm{Khz}$ narrow band signal propagating in a non-embedded and non-loaded strand.

Figure 33. Continuous wave based low order spectral response for coiled cable test.

Figure 34. Cut detection in free strand using individual wire coupling

Figure 35. Comparison of high frequency modes for embedded cable and rod (no tension).

Figure 36. Phase detected 5.6 MHz Ultrasonic Pulse Echo using magnetically coupled transducer on embedded cable.

Figure 37. Helical (perimeter) wire embedded in potting compound.................................................... 41

Figure 38. Embedded helical wire echo results from various gates. .................................................42

Figure 39. Spectral shifts observed between perimeter helical wire and center king wires.............42

Figure 40. A 15-foot concrete test bed after form removal. ...............................................................43

Figure 41. Tensioner being used on concrete cable test bed. .............................................................44

Figure 42. Small hydraulic load frame with fine control of applied tension........................................44

Figure 43. Low order modes and approximately 1.4 MHz mode in a tensioned cable.....................46

Figure 44. Reflection of approximately $1.4 \mathrm{MHz}$ mode through 5-foot cable section. .......................46

Figure 45. Time-frequency visualization of propagation in a tensioned and grease embedded cable.

Figure 46. Alternate time-frequency visualization from the same data in Figure 45.

Figure 47. Comparison of un-tensioned energy velocity from broadband stimulation (impact - bottom) and narrowband (Ritec sweep - top) in center wire propagation.

Figure 48. Suppression of extraneous ultrasound by grease embedment $(18,000 \mathrm{lbs}$ tension)

Figure 49. Attenuation increase with tension due to inter-wire coupling.

Figure 50. Scan of $1.4 \mathrm{MHz}$ mode at $27,000 \mathrm{lbs}$ of tension with grease embedment.....................49

Figure 51. Optimal system configuration of Ritec and TCG components..........................................51

Figure 52. TCG application to reverberation in a 2-foot section of grouted cable...............................51

Figure B.1. Camera image obtained by projecting a plane laser onto a stranded cable. ..................66

Figure B.2. Camera image obtained in a darkened room. .................................................................66

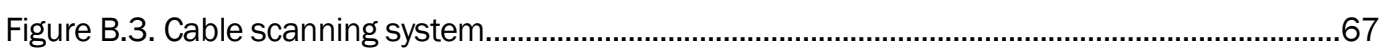

Figure B.4. Camera and plane laser aligned to scan a stranded cable. ..........................................68

Figure B.5. Rotation Method of Scanning..........................................................................................69

Figure B.6. 3-D display of data obtained while rotating stranded Cable 47A about the longitudinal axis.

Figure B.7. Surface magnitude variations along a single line of a cable strand. ...............................70

Figure B.8. 3-D representation of data obtained with a non-rotational scan of Cable 47A............... 71

Figure B.9. Surface displacement mapping of a non-rotational scan of Cable 47A.........................72 
Figure B.10. Surface displacements measured at pixel row 618 along the length of a section of Cable 47A as compared to a pristine cable section..............................................................72

\section{Tables}

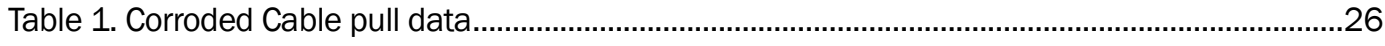

Table 2. System Requirements. .................................................................................................52

Table 3. Challenges of the NDT system development of seven strand wire cables...........................53 


\section{Preface}

This technical report adds to the authors' findings from the first report, ERDC TR-13-3, by discussing the US Army Engineer Research and Development Center's (ERDC) recent advances in the initial phase of a laboratory testing program to estimate seven strand wire cable strength as a function of cross-sectional material loss. Cable strength is measured by performing a pull test to failure on corroded specimens, as well as specimens with manufactured defects. An innovative morphological procedure using digital photography was developed for quantifying the geometrical properties of cable near the failure locations. Fundamental research into nondestructive testing (NDT) methods to assess the condition of post-tensioning seven strand wire cables is also discussed, with a focus on the guided wave approach.

The investigation and report was authorized by Headquarters, US Army Corps of Engineers (HQUSACE), and was performed from October 2012 to September 2013. It was published under the Navigation Systems Research Program, Work Unit "Probabilistic Assessment of the Reduced Capacity of Multistrand Post Tensioned Ground Anchorage Due to Tendon Corrosion." Jeff McKee was the HQUSACE Navigation Business Line Manager. The Program Manager for the Navigation Systems Research Program was Charles Wiggins, Coastal and Hydraulics Laboratory (CHL), US Army Engineer Research Development Center (ERDC). Jeff Lillycrop was Technical Director, CHL-ERDC. The research investigation was led by Dr. Robert M. Ebeling, Information Technology Laboratory (ITL), under the general supervision of Dr. Reed L. Mosher, Director, ITL; Patti S. Duett, Deputy Director, ITL; and Dr. Robert M. Wallace, Chief, Computational Science and Engineering Division (CSED), ITL. Dr. Ebeling was Principle Investigator of the "Probabilistic Assessment of the Reduced Capacity of Multistrand Post-Tensioned Ground Anchorage Due to Tendon Corrosion" work unit. Special thanks is given to Dr. Robert Mosher, Geotechnical and Structures Laboratory (GSL), for the insight and collaborative efforts he provided on this project; Ken Switzer (ITL) for his efforts with the accelerated corrosion and pulling (to failure) of the cables, as well as cutting and polishing of the pulled cables; Dr. Dan Wilson (GSL) for his supporting efforts with the cable pulling, and his knowledge and expertise with the equipment; and Lee Miller (ITL) was instrumental in the imaging of the cables used in the project. 
This report was authored by Richard W. Haskins, James A. Evans, both of the Sensor Integration Branch (SIB), ITL, and by Dr. Ebeling, ITL.

At the time of publication, COL Jeffrey R. Eckstein was Commander of ERDC, and Dr. Jeffery P. Holland was Director of ERDC. 


\section{Unit Conversion Factors}

\begin{tabular}{|l|c|l|}
\hline Multiply & By & To Obtain \\
\hline feet & 0.3048 & meters \\
\hline inches & 0.0254 & meters \\
\hline kips & 1,000 & pounds \\
\hline knots & 0.5144444 & meters per second \\
\hline miles (nautical) & 1,852 & meters \\
\hline miles (U.S. statute) & $1,609.347$ & meters \\
\hline miles per hour & 0.44704 & meters per second \\
\hline pounds (force) & 4.448222 & newtons \\
\hline pounds (mass) & 0.45359237 & kilograms \\
\hline slugs & 14.59390 & kilograms \\
\hline tons (force) & $8,896.443$ & newtons \\
\hline tons (force) per square foot & 95.76052 & kilopascals \\
\hline tons (long) per cubic yard & $1,328.939$ & kilograms per cubic meter \\
\hline tons (2,000 pounds, mass) & 907.1847 & kilograms \\
\hline tons (2,000 pounds, mass) per square foot & $9,764.856$ & kilograms per square meter \\
\hline
\end{tabular}




\section{Introduction}

Stressed steel tendons have been used to strengthen hydraulic structures and improve their serviceability and stability. Since they were first used in Corps projects more than 50 years ago, there have been substantial improvements in the corrosion resistance of new construction; however, corrosion of older multistrand installations is a major concern. Observation of strand condition or performance in navigation structures is typically limited due to its mass concrete embedment. At best, only one anchorage end can be observed in most installations. Details on these systems, field observations, potential testing methods, and other information have been previously reported in a Technical note by Ebeling et al. (2012) and a Technical report by Ebeling et al. (2013). These deterioration problems are generally attributable to moisture migration occurring between the anchorages, and no suitable solutions have been implemented for monitoring or estimating strand condition at the time of this report.

\subsection{Statement of need}

In an effort to achieve structural stability of hydraulic concrete structures and/or to remediate cracked concrete monoliths, the Corps has installed at many of its projects high-capacity, post-tensioned foundation anchors. These anchors typically are embedded in the monolith, meaning only the top anchor head can be inspected. Corps Districts report that several of the early installed anchors have inadequate corrosion protection and do not meet current standards. Some of the older anchors are showing deterioration and corrosion. Reports indicate that some even have broken strands. The fundamental structural issues are that the current load-carrying capacity and the remaining life of the anchors are both unknown. Consequently, structural engineers are unable to make accurate stability assessments of concrete monoliths with these damaged or corroded ground anchorages.

Some engineers have proposed using lift-off tests to help determine the condition of aged and deteriorated anchors. These tests are expensive and potentially dangerous. Also, lift-off tests cannot be performed on all types of anchorage, such as those that are grouted for corrosion protection (a Corps requirement for new ground anchorage, HQUSACE 2005). In the 
past, testing deteriorated anchors has been avoided because of the greater danger of breaking these older anchorages. Lift-off testing usually is conducted on good anchors. Testing the good anchors exclusively provides only a capacity value (current time) that is biased toward the high end.

Load testing of newly installed anchorage in the field will never involve loading to failure. Post-tensioned anchors used as ground anchors for the support of excavations, slopes, landslide stabilization, and tie-downs are proof tested at the time of anchorage installation. These proof tests take the form of either short-term (1) performance testing or (2) proof testing, and possibly (3) extended creep testing. A description of the various testing methods used for foundation-type anchors can be found in Strom and Ebeling (2002).

Engineers and planners need new tools and methods to evaluate the effectiveness and remaining service life of at risk post tension systems in navigation structures. While this same need exists in other structures, such as buildings and bridges, the structural response and access constraints inherent in mass concrete construction indicate that future industry solutions being pursued are likely to translate poorly to the assessment of lock and dams.

\subsection{Technical objectives}

The primary objectives of this research are as follows:

1. Develop guidelines to estimate the rate of corrosion of the anchorage assembly.

2. Conduct fundamental research that will lead to the development of a nondestructive testing (NDT) tool that has the capability of nondestructively determining the amount of corrosion that has occurred to the tendon.

3. Investigate methods to estimate the current state of load-carrying capacity of the ground anchorage.

4. Investigate methods to estimate the deterioration rate and remaining service life of the anchorage, so costly replacements of ground anchorages can be delayed until absolutely needed.

5. Investigate and develop a procedure to extend the life of deteriorating multistrand tendons.

The Corps has no deterministic- or probabilistic-based methodology in place to assess corrosion damage or progression and its impact. Therefore, 
the Corps cannot determine in a stability assessment the current reserve capacity of hydraulic concrete structural monoliths with deteriorated ground anchorage nor can it establish when a deteriorated ground anchorage will need to be replaced.

\subsection{Approach}

In order to develop a method to estimate the remaining capacity of the load-carrying ground anchorages, a research project was initiated at ERDC in FY12 (2012) within the Navigation Systems R\&D program. Within this work unit research program, the following steps were undertaken:

1. An extensive literature research on
a. Corrosion deterioration in anchorage tendons (seven wire cable) FY12; and
b. Loss of anchorage capacity of post tensioned ground anchorages at existing sites (John Day Lock and Dam) FY12.

2. Field investigation of anchorage at John Day Lock and Dam. The results of this investigation were reported in Technical Note ERDC/CHL CHETN-IX-28 (Ebeling et al. 2012).

3. Test bed designed and built (FY13).

4. Corrosion chambers designed and built (FY13).

\subsection{Observations made in the first multistrand research and development technical report}

As pointed out in the approach section, the FY13 report built on the previously detailed efforts from FY12. In FY12, using machining processes, simulated defects were examined by controlling defect parameters such as depth, distance from wedge, wire location, etc. In FY13, an actual laboratory corrosion chamber was constructed and used to deteriorate specimens to varying degrees. The corroded specimens were evaluated in pull test experiments to determine their mechanical properties. Post failure specimen analysis based on image processing methods was then used to determine various cross-sectional properties at the failure points. These processes and efforts are described in more detail in Chapter 2 of this report. In the next (FY14) efforts, the cross-sectional properties will be correlated with the pull test results to better determine the relationship between cable system performance and deterioration. Chapter 3 details the ultrasonic guided wave inspection system development effort progress 
made in FY13. This work successfully builds on efforts made by others in this field for testing embedded seven strand post tension cables.

Ultrasonic guided wave influence from load, embedment, anchorage, and other field variables were evaluated across a range of frequencies and propagation modes. Key challenges and candidate inspection modes were identified for future development efforts. 


\section{Estimating Seven Strand Wire Cable Strength as a Function of Cross-Sectional Material Loss}

In order to estimate the remaining life of an anchor, it was decided to develop in the laboratory a correlation between the cross-sectional properties of deteriorated seven strand wire cables and their ultimate capacity.

\subsection{Reduction of cross-sectional area}

The laboratory testing program has considered two methods to reduce the cables cross-section.

An accelerated corrosion process and an intentionally damaged defect method were both investigated as the best method to achieve a defined reduction in cross-sectional area. Of the two methods, the corrosion method was preferred due to its tendency to simulate the natural on-site corrosion process. The corrosion process, however, is inherently more difficult to characterize. To solve the challenge of corrosion characterization, optical methods based on morphological image analysis at the break location were developed.

\subsubsection{The corrosion process}

The corrosion system works by using a destructive electrochemical process, which liberates iron from the steel surface. A salt solution serves to both carry the electrical potential and introduce destructive chlorides. The additional catalysts of heat and aeration further accelerate the process. This system shown schematically in Figure 1 consists of the following components:

- direct current power supply with positive lead attached to cables and negative lead attached to submerged stainless steel grid,

- water heater,

- reservoir tank with brine solution,

- pump for circulation and aeration, and

- a spacer to separate cables and a node from contact. This system has the capacity to corrode 44 cables simultaneously. 
Figure 1. Schematic representation of corrosion chamber for controlled deterioration of cables.

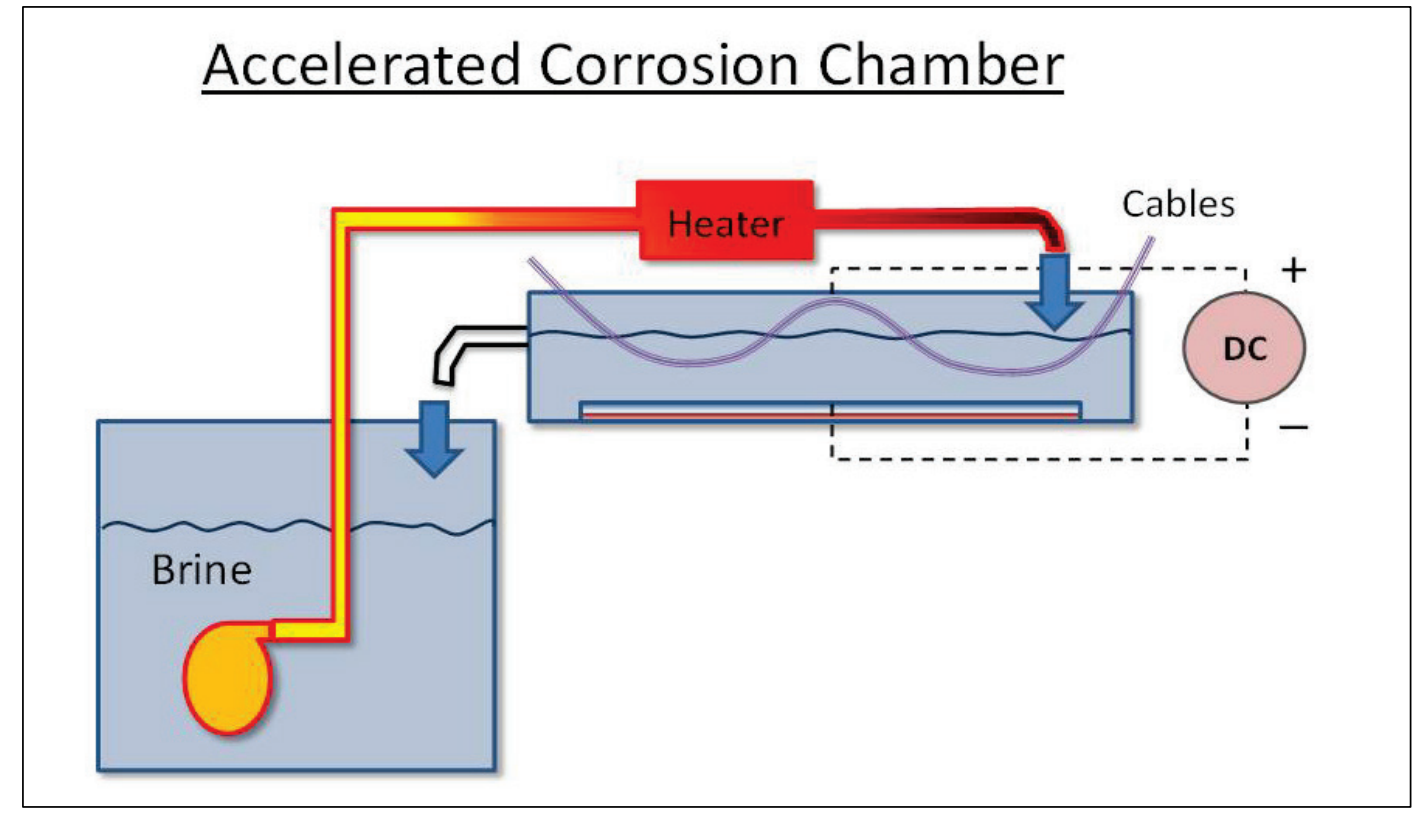

In some of the more severely corroded cables, non-uniform corrosion was observed. This non-uniformity manifested itself as a deeper pitting on one side of the cable, sometimes near mid-span but more commonly at the waterline. The mid-span pits were thought to be a result of iron buildup in the bottom of the cable tank, and was addressed by more frequent inspection and cleanout. The waterline pits were thought to be a result of salt precipitation and higher oxygen levels. These pits were handled by protecting the cable in this area with a rust preventative spray paint, which was covered by corrosion inhibiting grease and sealed in heat shrink tubing. Initial investigations for corrosion system development indicated that the circulation process produced relatively smoother deterioration and that static tanks with high salt concentrations (precipitated) produced more aggressive pitting and higher losses for the same exposure times. The top two photographs in Figure 2 show two different views of one of the cable tanks, the lower two photographs show cables just removed from the bath (left) and after drying (right).

\subsubsection{Manufactured defect process}

In some instances, defective cables were created by using a hacksaw to open up a single wire within the cable. This method resulted in sharp corners within the defect area, which allowed for the initiation of material tears in the sample cable. In later production, manufactured defects were produced by placing the sample cable within the chuck of a lathe and using 
Figure 2. Photographs of corrosion tanks and corroded seven strand wire cables.
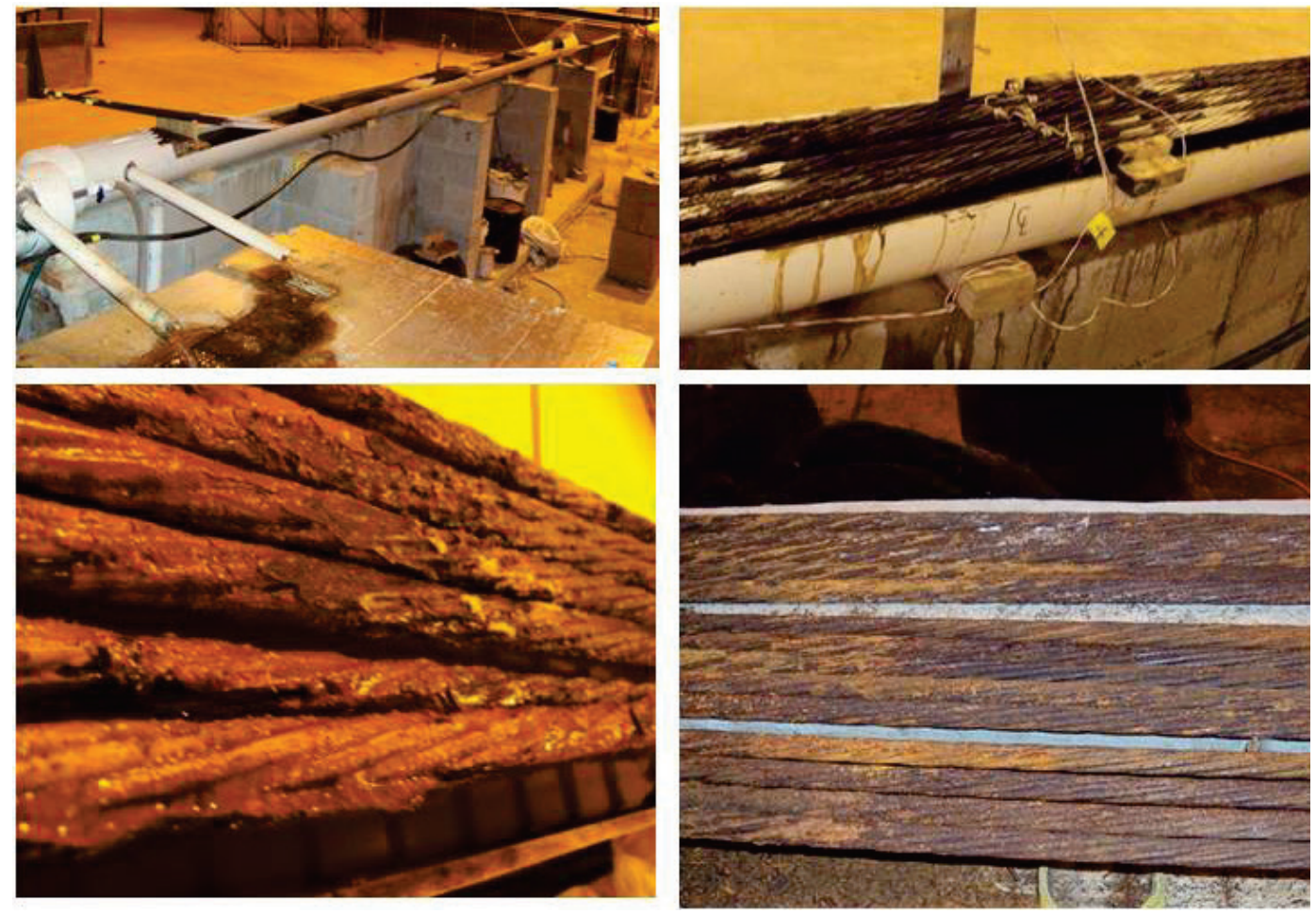

a file to create the defect area. This resulted in a rounded indentation on the circumference of the cable without the sharp edges. The production of defective cables by manufacturing the defects was not the primary method used because the resulting cross-sectional loss was unlike that made by corrosion of the stranded members.

\subsection{Target corrosion levels and sample counts}

Target corrosion levels or bins were selected by considering expected loads due to influences such as strand relaxation, installation errors, and multistrand load reductions from partially failed cables. An extreme point was also included so that the testing range extended beyond expected field load levels. Selected targets for cable reduction in strength due to corrosion are $0,10,18,25,40,55$, and 75 percent. A target count of 22 samples per bin was selected based on the following considerations:

- Clarity of the expected distribution function,

- Limitation on a practical number of cables that could be corroded, characterized, and tested, and

- Resolution limits of the pull test machine. 


\subsection{Assessment of the condition of seven strand wire cables during corrosion tank processing}

The cables within the corrosion tanks (Figure 2) were continuously monitored, along with the fluids, temperature, and current flowing through the system.

A procedure was developed to remove cables from the corrosion system at approximately the target corrosion levels. This was done by determining a rapid and repeatable measurement that could be performed while the cables were in the corrosion process. This was done by measuring the cables diameter with a caliper as it rested on four of the six outside strands. This orientation is shown in Figure 3. For each cable, six readings were made and the lowest taken as the corrosion state, since it represented the smallest area and most likely the failure point. In the next step, four cables were initially corroded to various degrees, pull tests were performed on those specimens, and the caliper readings were used to fit a curve for estimating the target strength reduction levels.

Figure 3. Orientation of the caliper measurements used when tracking material losses during the corrosion process.

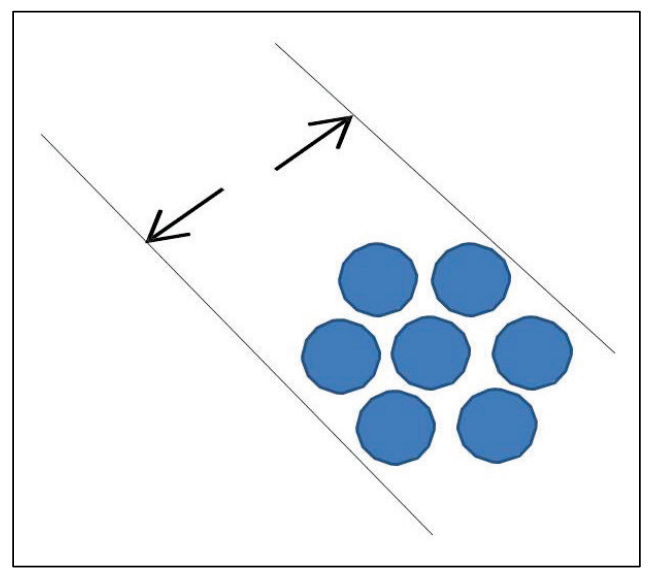

The strength data used for mapping target bins to the micrometer reading is shown in Figure 4. Lastly, the resulting caliper readings are shown in Figure 5. Cables are pulled from the corrosion system when periodic measurements of the corroded cables come close to these targets; cables and samples are needed in that bin range. 
Figure 4. Pull test results used to determine micrometer readings for pull criteria.

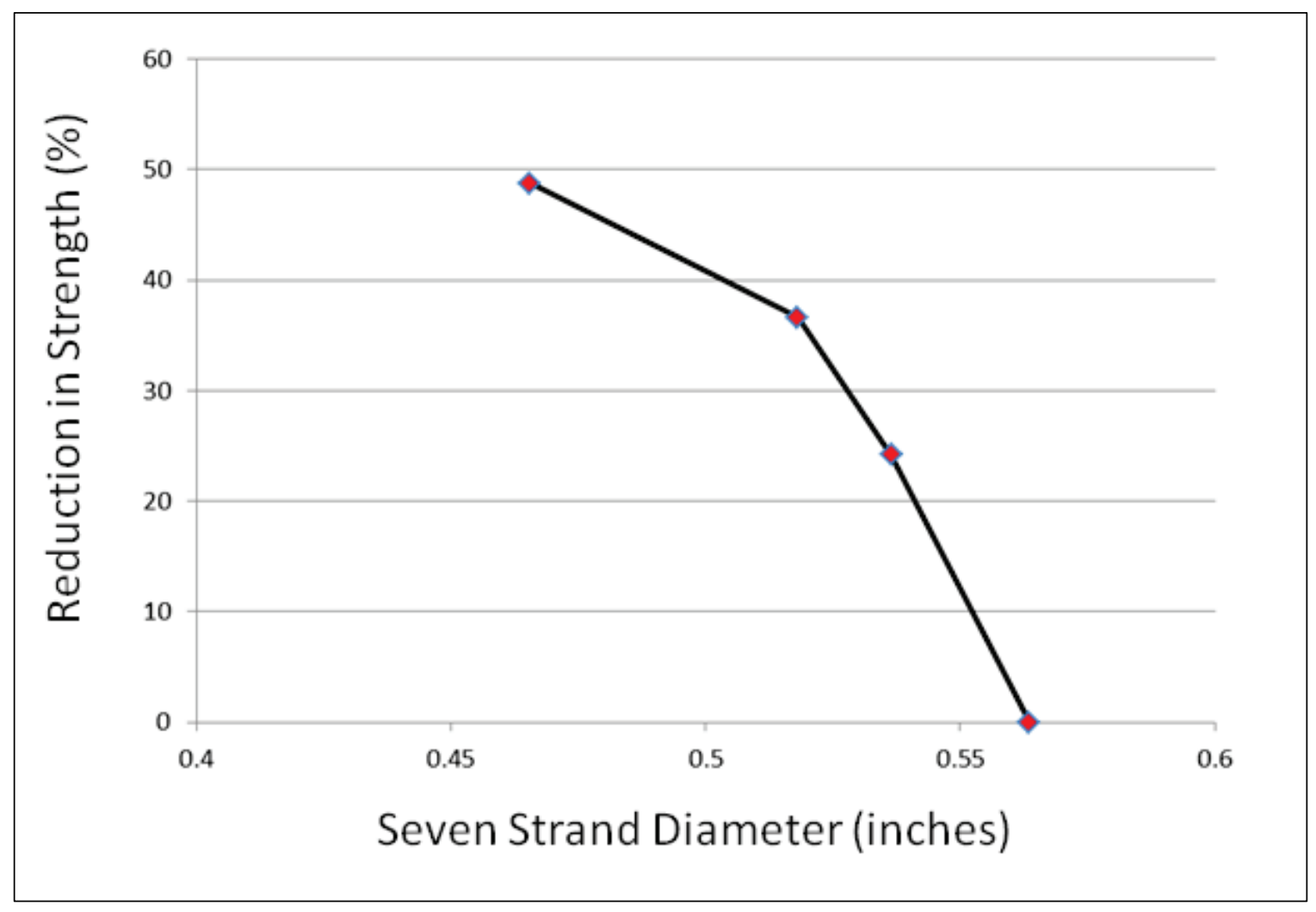

Figure 5. Pull criteria used to hit target strength reductions.

\begin{tabular}{|l|l|}
\hline $\begin{array}{l}\text { Strength Reduction Target, } \\
(\%)\end{array}$ & $\begin{array}{l}\text { Cross section min diaTargets, } \\
\text { (in.) }\end{array}$ \\
\hline 0 & .563 (pristine) \\
\hline 10 & .5523 \\
\hline 18 & .5433 \\
\hline 25 & .5366 \\
\hline 40 & .503347 \\
\hline 55 & .4383 \\
\hline
\end{tabular}

\subsection{Pulling cables to failure}

Once the cross-section of the cable has been reduced by corrosion (or manufactured defects), the cable is pulled using the Baldwin 440,00o lbs Universal Testing Machine (see page 48, Ebeling et al. 2013). The broken cable is then cut at the point where the break occurred and a measurement of the remaining cross-sectional area is made. An "End-of-cable imaging system" was developed for accurately determining the cross-sectional area at the point of cable breakage. 


\subsubsection{Pull test data}

A pull test using a modified Baldwin 440,00o lbs compression/tension loading system was used in an arrangement described in Ebeling et al. (2013). As cables reaching high force levels were found to stick in the grip wedges, a modification involving slotting the end was made so that failed cables could be more easily removed. The cables were tested in lengths of 70 inches and 35.5 inches and loaded at a rate of 0.0075 inches/second until initial failure occurred. Figure 6 is an example of the pull test data. The two curves in this figure compare a pristine cable's condition to one that has been deteriorated to a target strength reduction of 25 percent.

Figure 6. Curve comparing a strength reduction of $25 \%$ to a pristine cable.

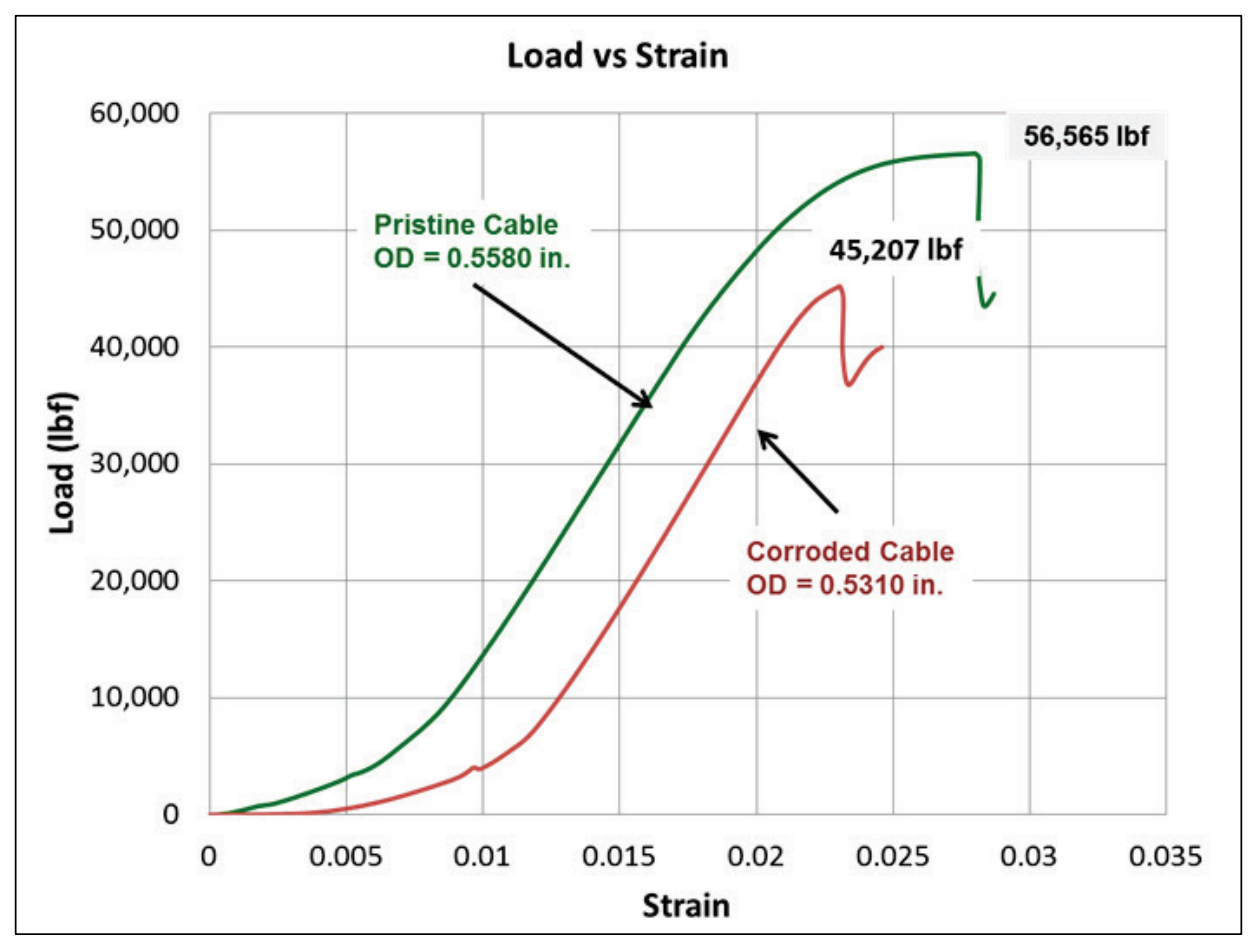

\subsubsection{Accurately characterizing the weakest cross-sectional area}

The caliper measurements provide only a crude estimation of the corrosion condition of the cables. In order to improve the estimation of corrosion levels, an additional measurement tool was developed. The measurement tool was a 3-D laser line scanner that uses a process common in machine vision applications that monitors extrusion processes, and a secondary method aimed at capturing area near the failure point. The laser scanner must hold the cable straight and rotate it as the camera moves down the cable's length. Small surface displacements of the cables surface cause the 
projected laser line to move left or right depending on the direction of the surface displacement. Higher laser/camera angles give more displacement resolution as the expanse of increased shadowing appeared in the images. The cable scanner was not developed in time to provide data to this project, and therefore is included in Appendix B.

To remove the corrosion product and image the structural steel, two approaches were evaluated. The first process was electrolysis in a baking soda solution and the second was a chemical rust remover that targets the rust oxides. Both approaches provided good performance but the chemical approach provided a quicker and more thorough performance. The chemical method provides a secondary benefit of leaving a protective finish which prevented re-rusting of the bare metal. EVAPO-RUST ${ }^{1}$ was selected as the chemical rust remover; its characteristics are stated as watersoluble, ph-neutral, biodegradable, non-toxic, non-corrosive, and skinsafe. All cables were soaked for at least 24 hours.

\subsubsection{Overview of the morphological processing of cable failure points}

Since seven strand post tension cable failures are highly dependent on their cross-sectional geometries, an image analysis task to quantify the geometrical properties of the cables near their failure locations was performed. The basic components of this process are described in the remainder of this section.

First, the cables were carefully cut and finished at a point near the failure location to form a clean smooth orthogonal cross section for imaging. Attention was paid here to avoid imaging the ductile necking region (typically one to two millimeters long) at the break location. The cut and processed strand was loaded in a mounting rig, which optimizes alignment with the camera and avoids the capture of and focus on undesired background components. After adjusting focus and alignment, a calibration dot was placed on the end of the cable. This dot was a known area and allowed for automatic generation of a calibration scale between observed pixels and length and area dimensions. After removing the calibration dot, lighting via a small LED light was adjusted to best illuminate the end of the cable, while minimizing background from the helical twist. Once lighting was considered correct, an image was captured and saved with the appropriate cable description label. The images were post processed using

${ }^{1}$ Harris International Laboratories, Springdale, Arkansas, www.evapo-rust.com. 
an ERDC developed morphological analysis code. The results of this code are the individual wire properties of area, perimeter, eccentricity, long axis length, and short axis length. Also captured and saved were the statistical properties of seven wires (mean, total, and standard deviation) as well as a labeled image where the strands were numbered in order of decreasing area and mapped to their geometrical measurements. These properties were imported into the database to provide future mechanisms for statistical analysis of the cable losses due to corrosive material loss. The repeatability of the system was greater than 99 percent and the length error after calibration was less than .003 inches. An example of the output data is shown in Figure 7. The following sections describe in more detail the steps and the process required in going from the broken cable to the desired geometrical properties. The image analysis operation was performed on both sides of the failure point, which produced a second dataset such as shown in Figure 7 for each broken cable. The integration process for these two datasets will be determined in the next phase of (FY14) efforts.

Figure 7. Typical output of data from image analysis.

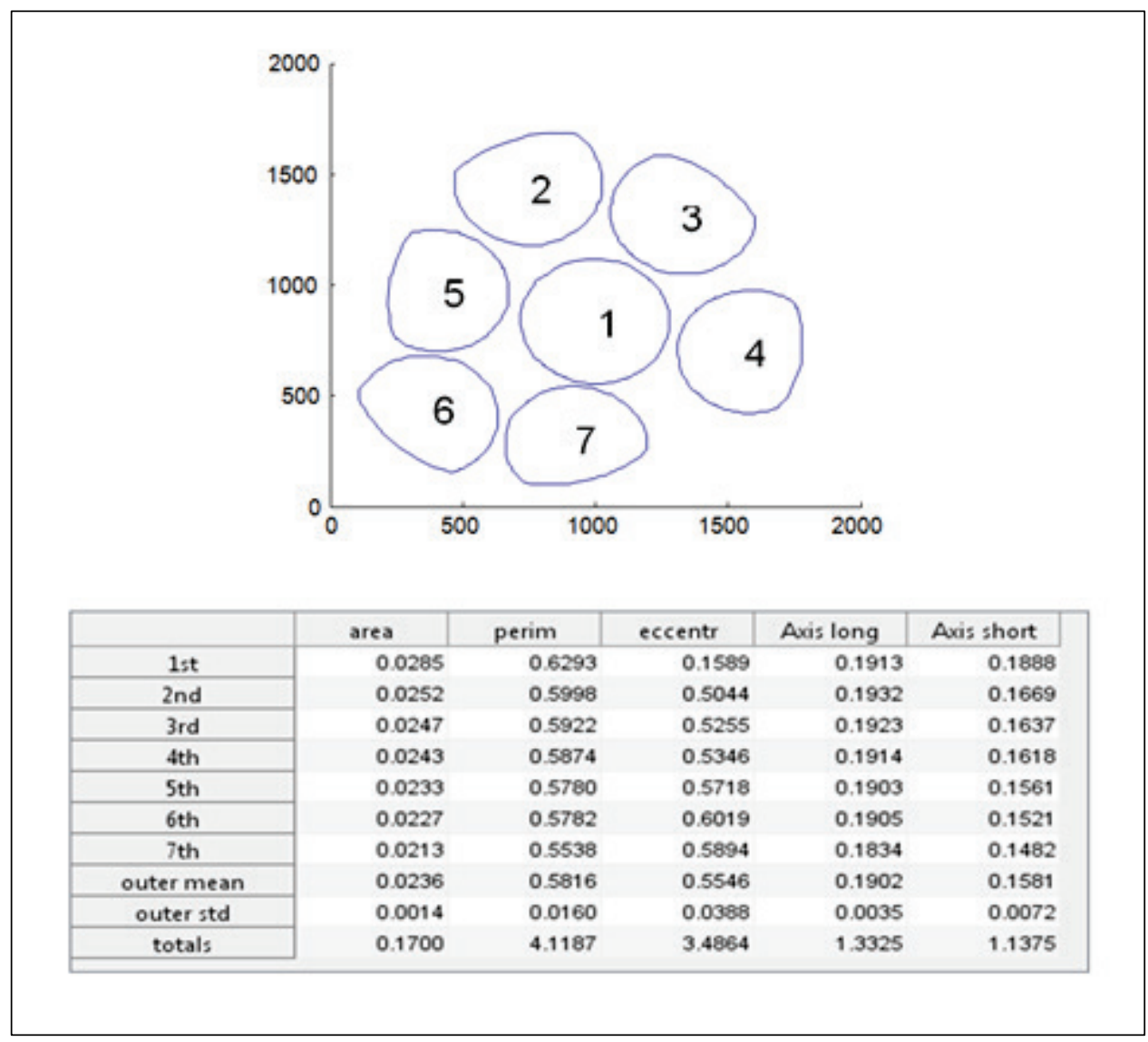




\subsubsection{Mechanical preparation of broken strands for imaging}

In order to arrive at a good cross-sectional representation, care must be taken in preparing the broken cables. Typically, one to three wires will break at failure, the wires with the ductile necking are considered the initial failures and the other failed wires are thought to break due to the sudden release of energy or the remaining load level being redistributed. Most often a number of wires are left that did not fail. After failure, it is typical for the broken wires to "bird cage" or deform elastically away from the failure point. This can happen on one or both sides of the failure point. When both sides birdcage, it is necessary to retrace the separated wires back to the original point of failure so that the remaining wires in the seven strand bundle can be cut at the appropriate location. A simple process has been devised by tracking a string along the length of the bird cage wire and then to re-track that same section of string along an under formed wire. If this is done from both sides, a good approximation of the failure point can be determined. Figure 8 shows the tracing of a string along a section of deformed wire. As mentioned previously, some ductile failure is often seen in the broken wires.

Figure 8. Tracing deformation with string measurement to locate the failure point in unbroken wires.

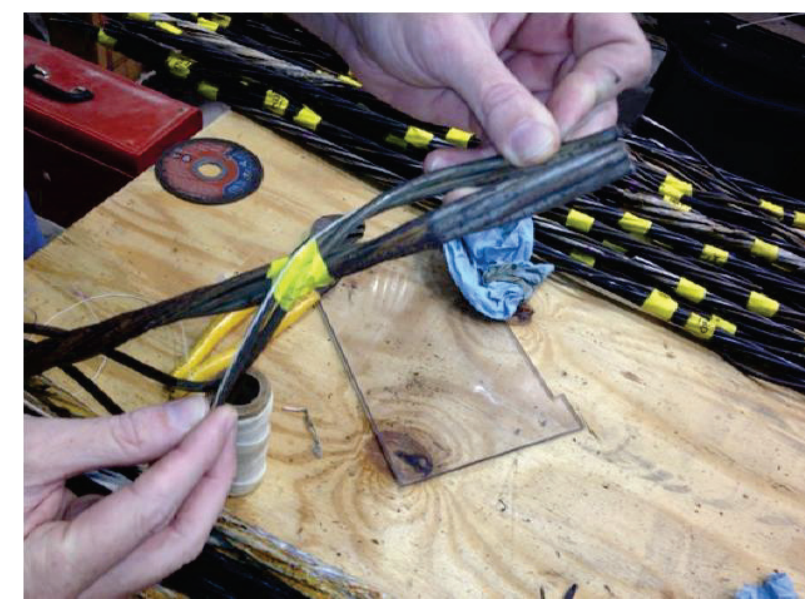

To avoid imaging this failure related reduced cross section as part of the corrosion induced cross-section loss, the cables are cut just beyond this necking region which is typically a few millimeters. A cut-off saw is used to perform the initial cutting of the seven wire strands. It is important to clamp the strands together as shown in Figure 9 (left) or the cut off wheel of the saw will separate the wires during cutting and deposit undesired material into the intestinal region of the cable. This material creates 
undesired reflective artifacts in the imaging process. Deformed wires that were displaced should be put back in place so that the machining of the strand occurs on seven wires simultaneously in the correct plane. To provide the final finishing, a table based sanding wheel is used with a notched mount to produce a smooth and orthogonal finish as shown in Figure 9 (right).

Figure 9. Saw (left) and sander (right) application used to finish seven strands at the break locations.
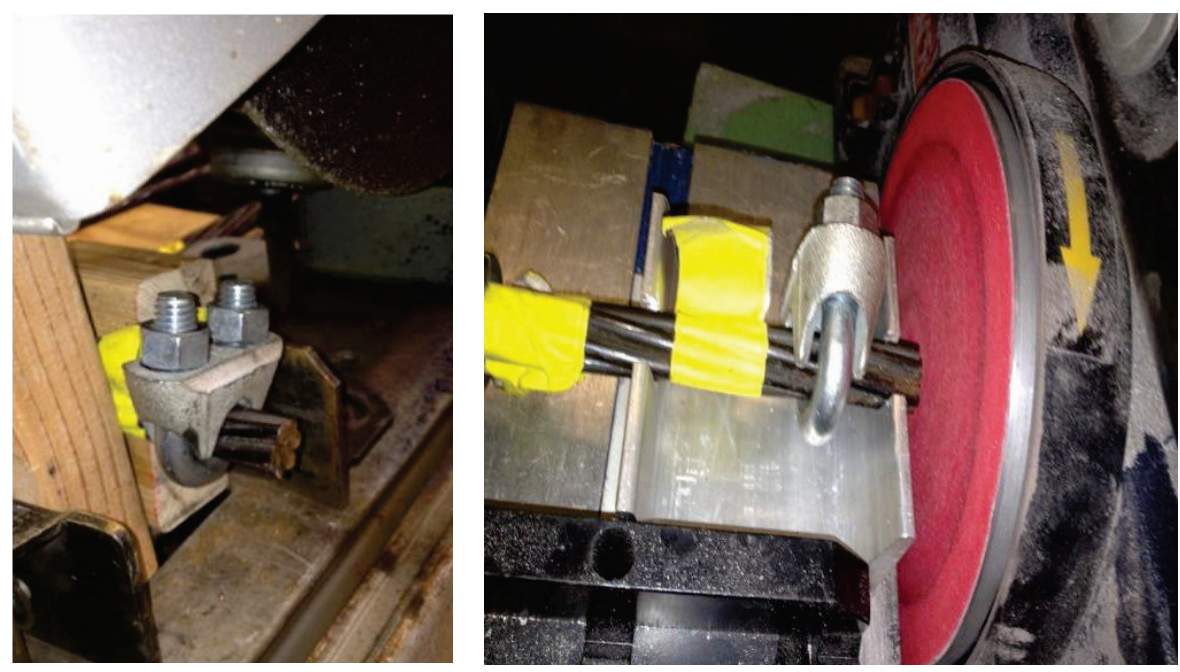

\subsubsection{Collection of image data}

After broken wires are prepared and labeled, they can be loaded into the imaging frame. The imaging frame shown in Figures 10 and 11, uses a wedge to orthogonally hold and center the seven wires within a tapered black tube. The tapering and black surface help minimize background object detection and focusing by the autofocus mechanism of the camera. The strand should be placed in the mount so that it is just flush with the edge of the containing tube, which is accomplished by placing the wedge approximately 4 inches from the machined surface. After inserting the strand, the USB camera can be installed and slid forward to the closest focusing range as shown in Figure 10B. The focusing range can be checked in the autofocus range screen of the web cam software. The highest possible camera resolution setting for the camera used was 15 megapixels. The software settings are manually optimized for best image collection of each strand, but in general the gain and exposure settings are set high, color intensity is set low, and the contrast and brightness are varied to show the front of the cable with the highest contrast to the background. This should be done with the LED lighting in place. Ideally, the LED light 
shines back toward the camera as shown in Figure 10B. The background spiraling of the cable should not be captured if possible. The camera height and angle are adjusted to center the cable image and maintain a parallel plane between the front of the cable and the camera face. After all adjustments are made, the calibration dot (an Avery sticker) can be placed on the front of the wire surface as shown in Figure 10C. After lighting is optimized for the cable, the calibration image of the reference dot is collected and named appropriately. The next step is to carefully remove the sticker, recheck proper lighting, and collect and name the cable image. These files are stored for later processing with image analysis software. The imaging frame is shown in operation with the collection software in Figure 11 (note the light source is not shown in this image).

Figure 10. Cross-sectional imaging frame used for cable and calibration imaging.

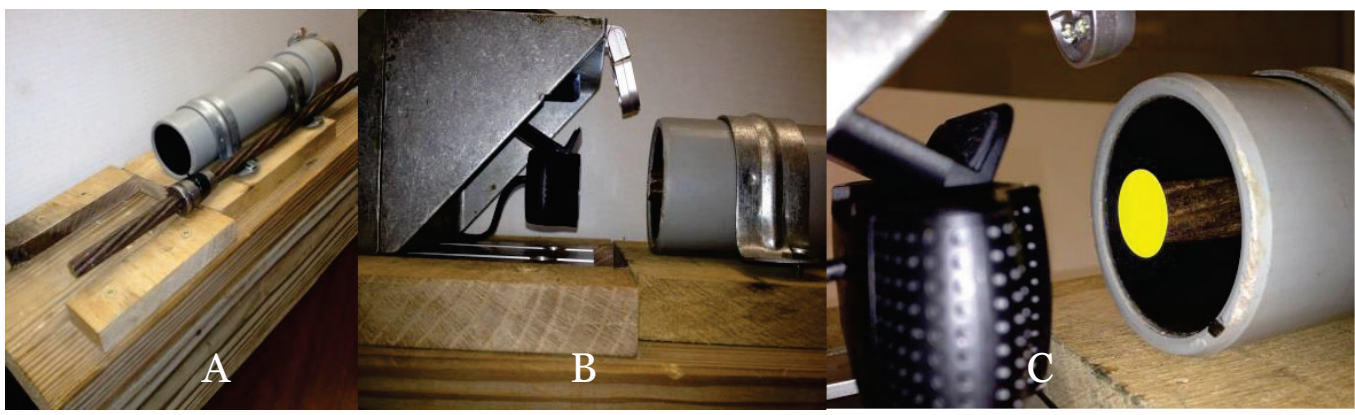

Figure 11. Computer capture with cable installed in imaging frame.

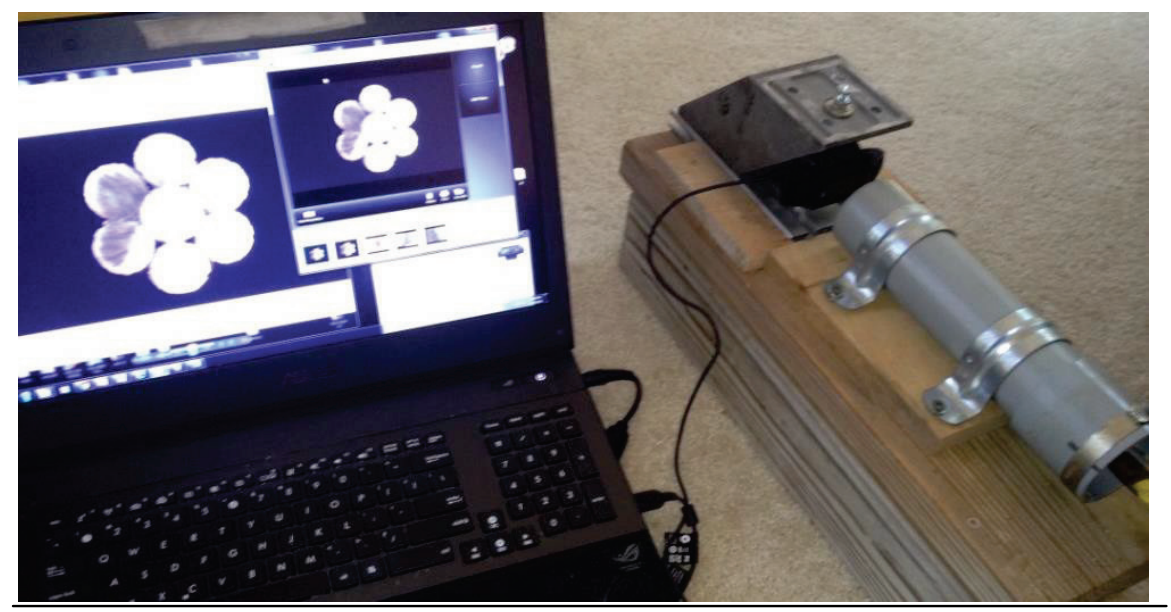

\subsubsection{Operation of image processing software}

The cable cross-sectional imaging software utilizes a graphical user interface to prompt the user for the necessary actions and options. The first step involves selecting and loading the associated calibration image file of the .75-inch-diameter reference dot. Figure 12 shows a collected calibration 
image. Each cable cross-sectional image has its own calibration dot image to account for range, zoom, and alignment issues unique to each cable's installation in the mounting frame. The dot is morphologically separated from the background by automatic thresholding and perimeter noise removal. The pixel count is collected to generate a mapping from observed pixels to engineering units. After pressing any key to confirm a good calibration file was loaded, the user is given another file load GUI for the cable image file. The mouse is used to position a cropping frame to size the analysis window and roughly center the cable. A background margin around the cable's perimeter as shown in Figure 13 and should be left in the cropping process. The next window will automatically pop up and will allow for selection of the lower thresholding limit. Slide the upper range to a point near the lower range (within 10 or 20 levels) and then slide the lower threshold upwards until the cable stands out from the background and no background contamination is seen (Figure 14 shows a starting image as well as a bad and good lower threshold setting). Once the threshold is

Figure 12. Binary image of $3 / 4$-inch diameter calibration sticker.

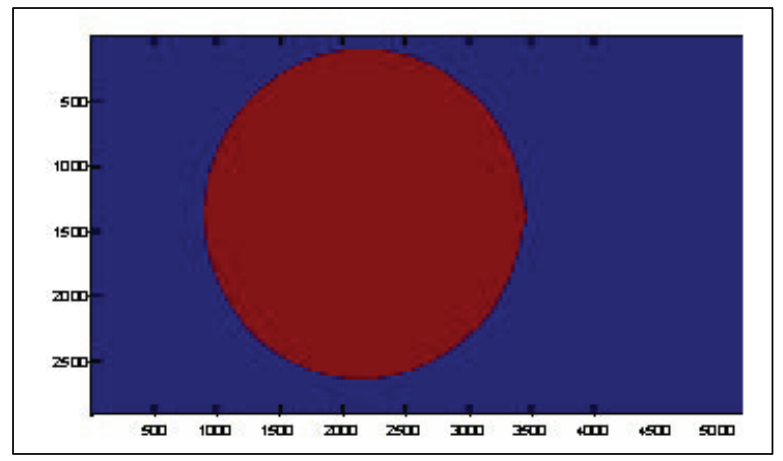

Figure 13. Cropping of cable cross-section image.

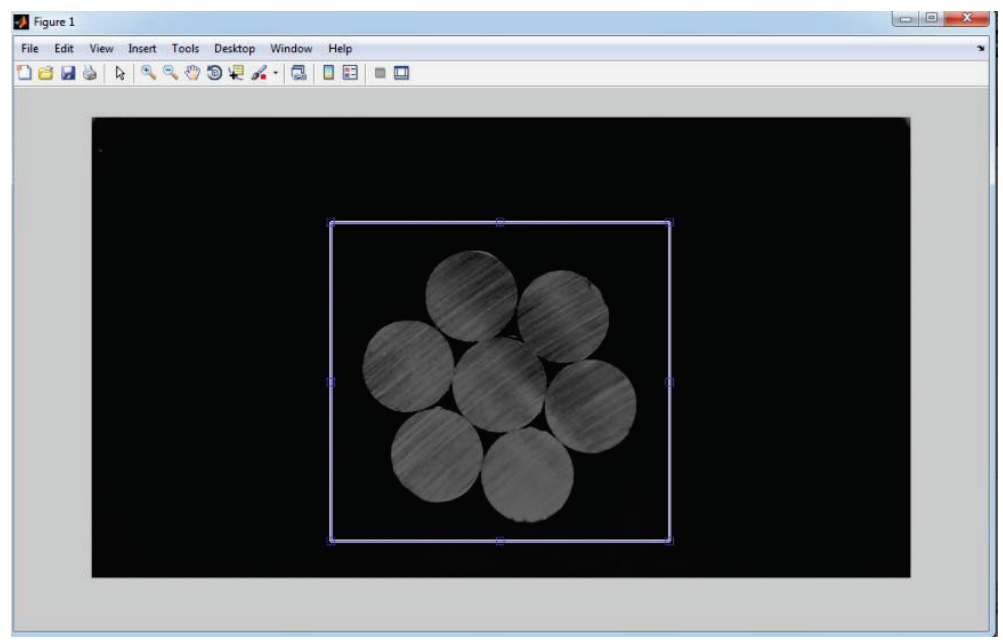


Figure 14. Original image (left), threshold set too low (center), and proper threshold (right).

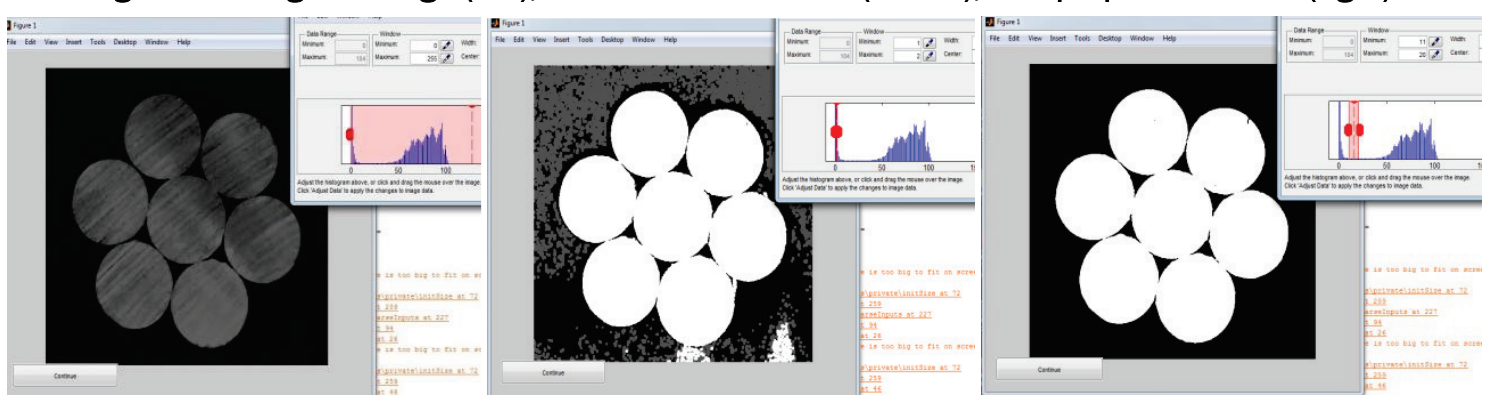

correct, hit the continue button in the lower left corner of the imaging window. If the processing software can segment the image in the first stage, it will automatically display and save the output data files. If it cannot detect seven objects of the appropriate size, as shown in Figure 15, it will immediately prompt the user with the option to run automatic segmentation using a custom designed morphological process (described in the next section). If the user selects ' $n$ ' for no (default), he will be prompted to manually segment the image using the image zoom control and mousebased object cutting. This cutting process is shown in Figure 16. Multiple cuts can be sequentially executed and pushing the center mouse button will cause the software to cut and check if proper segmentation has yet been achieved. Once the image is segmented properly, the geometrical properties of the strand and individual wires will be automatically displayed and saved in the same file name prefix as the calibration image. Exported to the drive are an enhanced metafile for document and presentation purposes as well as a tabular comma delimited file for import into the database.

Figure 15. Morphological failure image indicating poor segmentation.

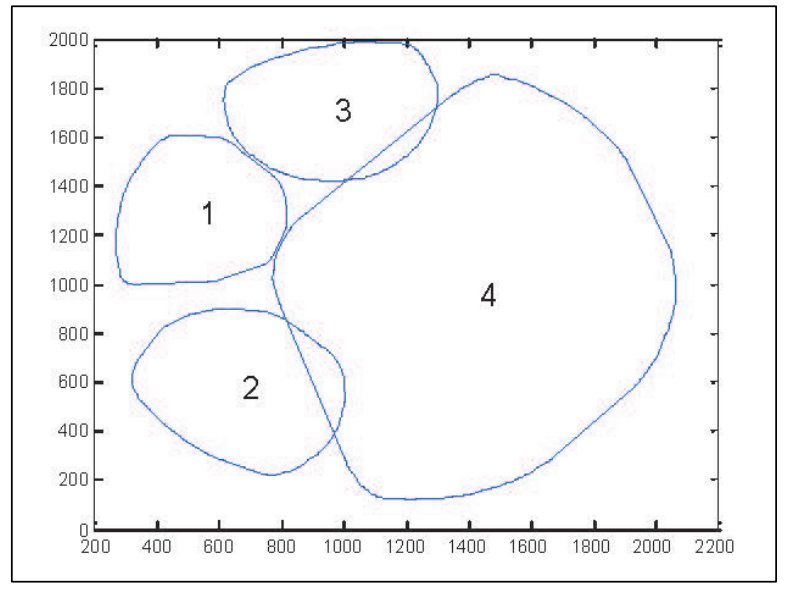


Figure 16. Last resort approach of manual segmentation using mouse-based freehand cutting.

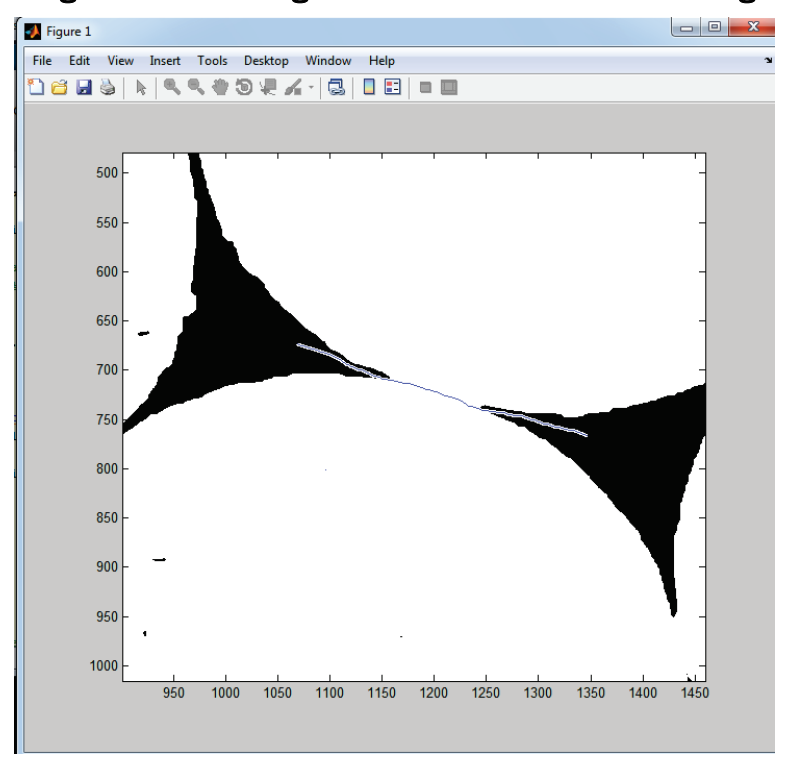

\subsubsection{Image processing method used for automated cable segmentation}

Separating touching objects for image analysis is a common and difficult problem in image analysis. The common method of watershed analysis was attempted under several preprocessing approaches without achieving adequate and robust performance. Additionally, other approaches based on dilation and skeletonization showed promise but proved to be too slow and performed poorly when less than perfect images were used. The method described below has been tested and shown to be robust across a wide variety of input conditions. In general, this approach appears to be applicable to touching objects which are round and non-overlapping. Unlike the skeletonization based approach, the method described here is also practical in terms of processing time. The goal of this routine was to generate binary cut lines between touching objects which cannot be separated by simple methods such as edge enhancement and grayscale thresholding. The code itself is presented in Appendix A.

Prior to running the segmentation routine described below, first stage processing is performed and a segmentation check is performed. In some cases, the objects' edges are visually contrasting enough so that no additional processing or operations are performed. The segmentation criteria check is that there are at least seven objects detected and that no object is greater than .3 inches at its maximum length. The first stage processing consists of bottom hat filtering, which enhances/sharpens edges and then grayscale morphological opening with a structural element 
consisting of a 10 pixel diameter disk. This step serves to smooth internal object contrast while preserving edge details. Lastly, the cropped image is thresholded by the manual level set in the GUI before being sent to the morphological routine for object detection and classification. If the image fails to meet the segmentation criteria, the user is prompted to execute the automated segmentation process described below.

Due to the smooth planar metallic surface, grayscale morphological processing presented little to no benefit. For this reason, the grayscale image is converted to a binary image and the morphological processing is binary instead of intensity based. When the thresholded binary image is inverted and infinite thinning of the structures is performed, the image shown in Figure 17 can be obtained. The disconnected line segments in this image represent regions where the objects are touching each other, and cannot be morphologically segmented. The objective here is to robustly connect these disconnected "lines" and then use them as a binary mask for cutting the touching objects.

Figure 17. Resulting mask from inverting and thinning binary image from thresholding (pixels enlarged for illustration).

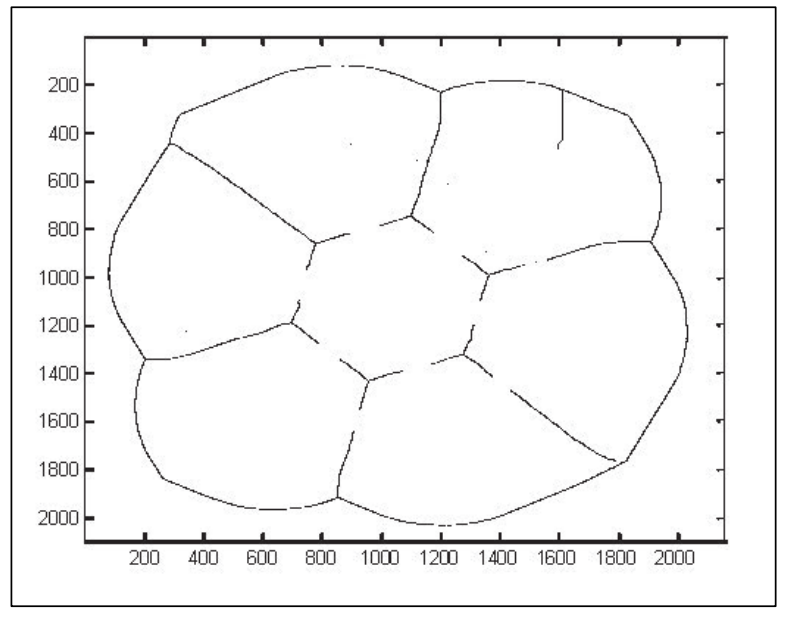

The next step is to run a routine that literately removes spurs. Spurs are open line segments such as those appearing near the points where the individual wires touch. If spur removal is run at two different levels of iteration and the difference in these two images is taken, we can look at the points that are being removed in the spur trimming process. These spur points are shown enlarged for clarity in Figure 18. In the next step, branch points are identified. Branch points are points where three or more lines come together. Branch points are shown in the left panel of Figure 19. 
Figure 18. Difference between two different levels of spur removal.

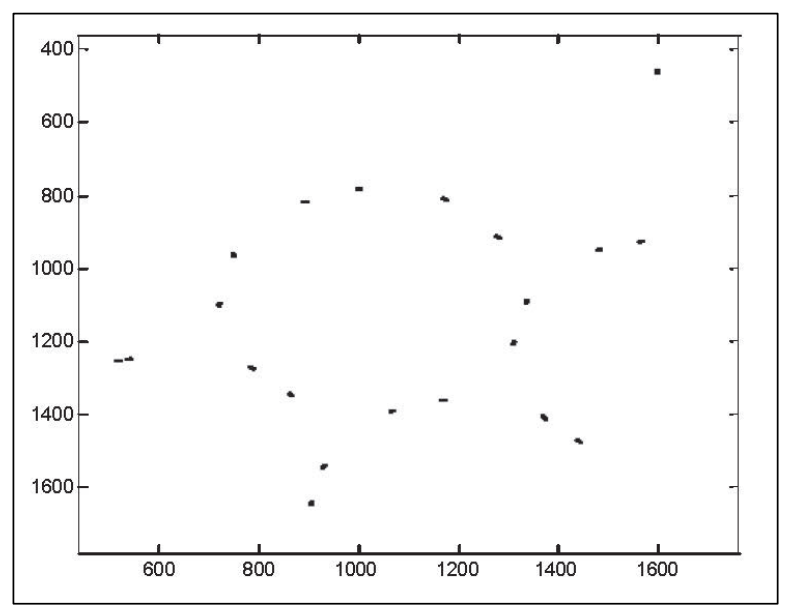

Figure 19. (Left) Branch points, (Right) Composite showing branch points, spurs, and object perimeters.

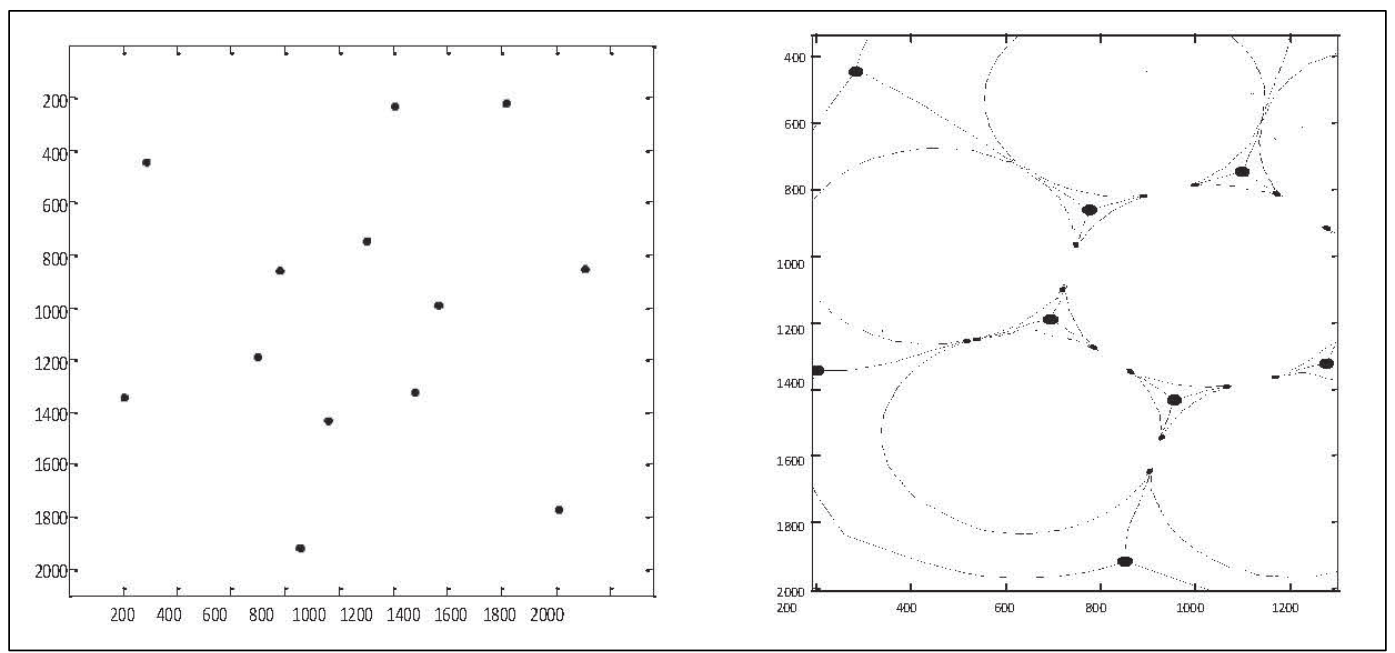

The right panel of Figure 19 shows the composite of the objects, spurs, and end points. The fact that the missing mask segments (and spur points) are approximately in a line with the detected branch points formed the basis for the mask generation process described below. A statistical based search routine was executed, which found the closest six neighbors for each branch point in the image. The next routine steps through the branch point neighbors and evaluates regional spur point errors relative to a line between the branch points. Figure 20 illustrates points which fit the line equation as red circles and trimmed spur points as blue plus marks. A normalized error equation was developed, which summed the distances from the line and divided the total by the spur points contained between the $\mathrm{x}$ and $\mathrm{y}$ limits between the branch points (i.e., $200<x<700,1340<y<1180$ for the data in 
Figure 20). If the error is less than 1000, then the points are considered proper and a line continuous in $\mathrm{x}$ and $\mathrm{y}$ pixels is formed between the spur points. An example of continuous linear fitting between regional spur points is shown in Figure 21.

Figure 20. Linear error of spur points contained between neighboring spur points.

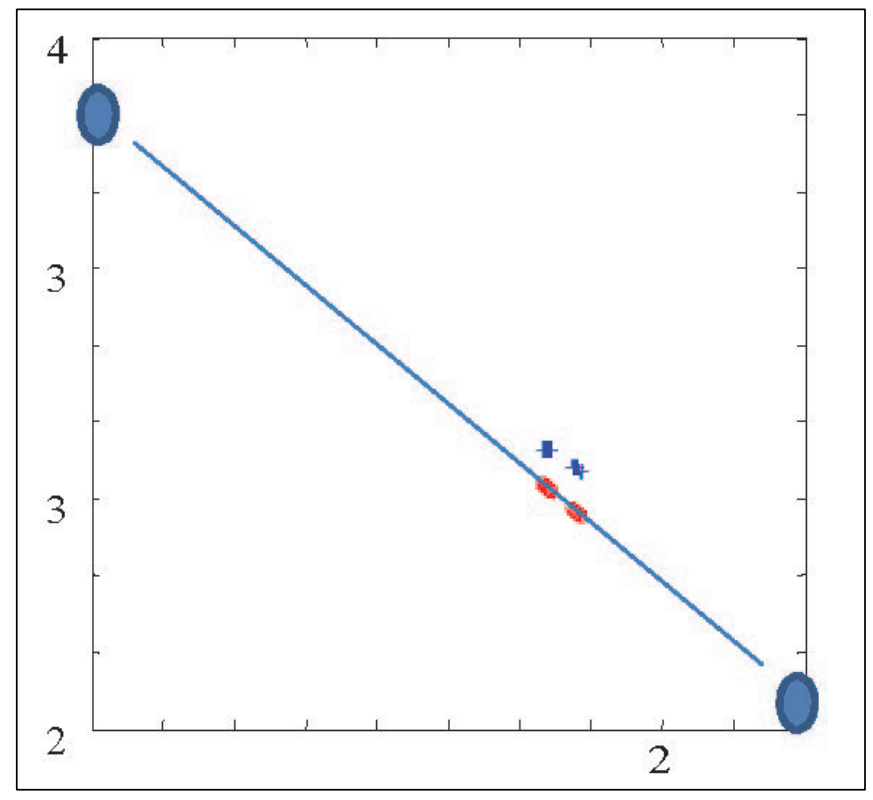

Figure 21. Continuous line form connecting spur points with acceptable error.

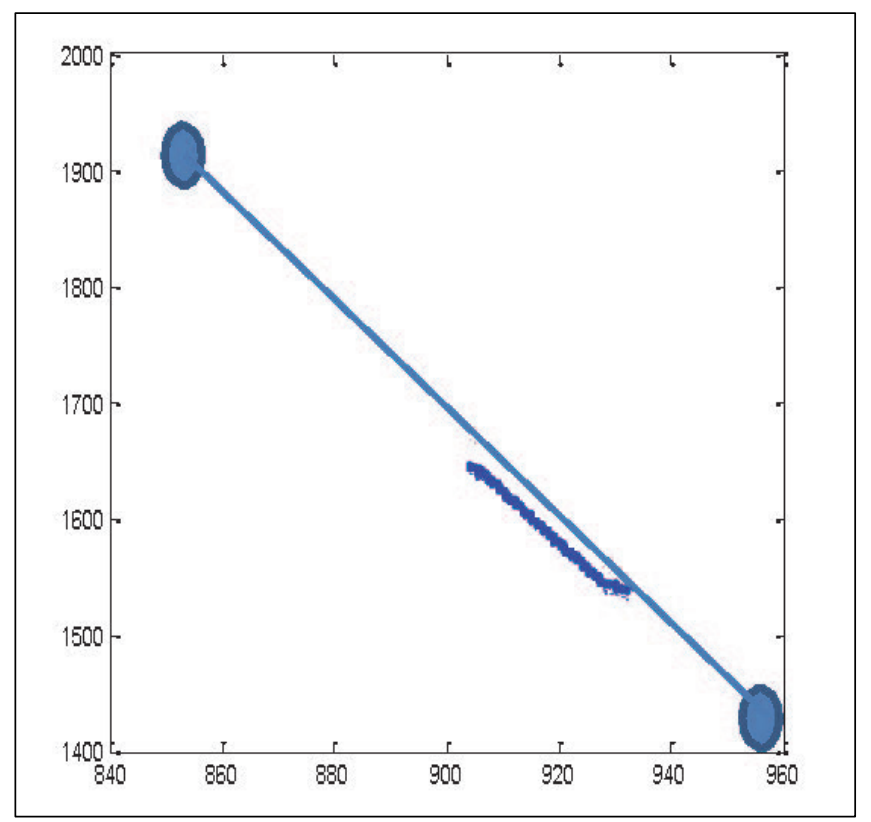


In Figure 22, all test points are shown for the cases where spur points were detected between the neighboring branch points. These test points are shown as red circles and the added segments which passed the linear error test are shown in blue. If we combine the line segments to the mask determined by the initial thinning in Figure 17 with the added segments shown in Figure 21, we arrive at a continuous composite mask like the one shown in Figure 23. Notice that in this particular mask image there are a few artifact spurs which can be removed by infinite skeletonization. This process, however, is computationally time consuming and can be omitted with little issue.

Figure 22. Added segment and linear test points for all branch points.

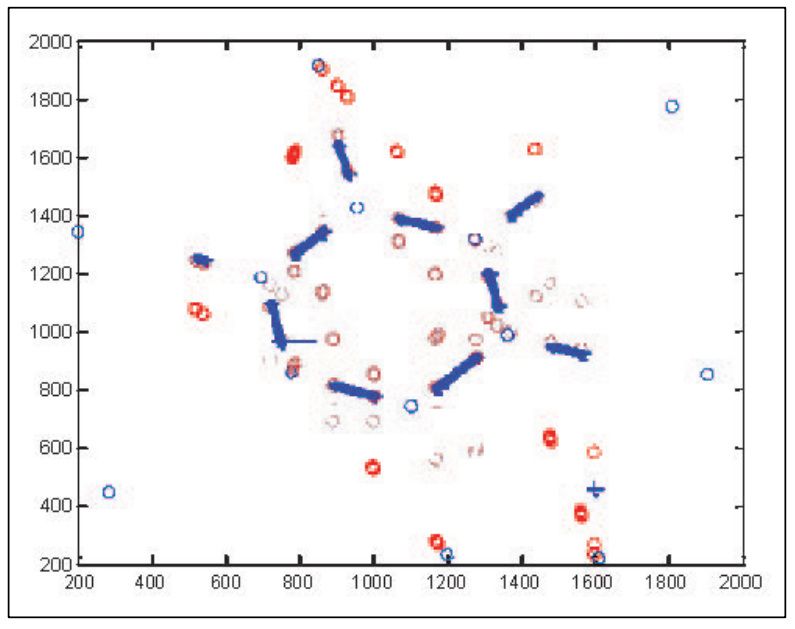

Figure 23. Composite cut mask from thinning mask combined with the segment masks.

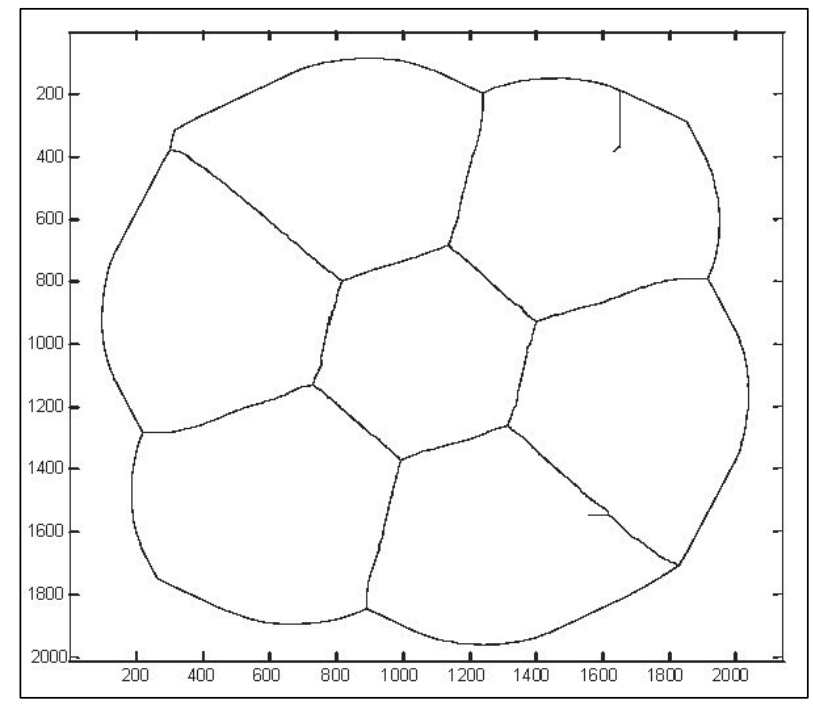


This process was tested on a number of test cases for robustness and performed very well. The test cases included cables where the wires were not strictly round due to machining or corrosion, and cases where the spacing, position, and alignment of the strands were highly varied. A few example masks and results are presented below. A partial image is shown in Figure 24, where a corroded cable was automatically segmented with the masks in the center image. The left pane shows the before image where objects were connected and the right plane shows the result after segmentation.

Figure 24. Before segmentation with mask, the mask used, and the segmented result for a corroded cable.

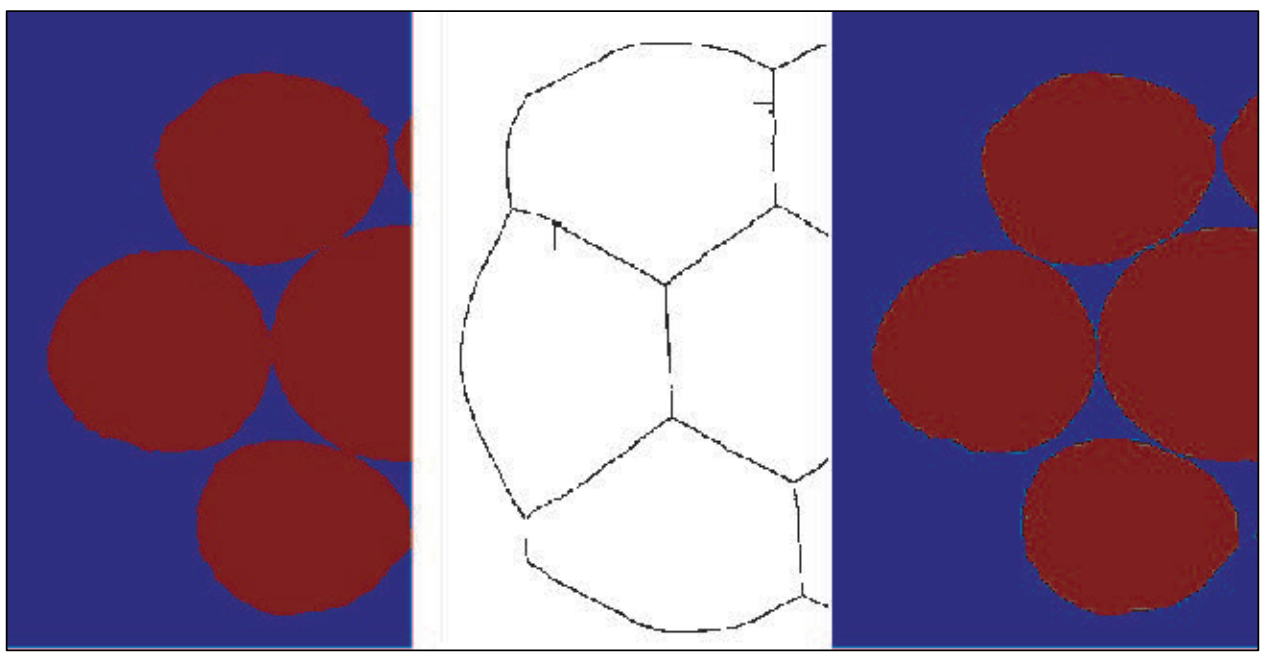

The results of morphological analysis of the corroded cable segmented in Figure 24 is shown in Figure 25. In Figure 26, the strands indicated by the arrows in the mask were connected in the poorly aligned cable. The mask was applied for successful segmentation of these strands.

It should be pointed out that the reason the individual wires were not physically separated for machining and imaging from the bundle is the inherent difficulty of realigning the cut helical wires and maintaining proper orientation with the original cable axis and cut planes. Mechanical variations on this approach were tried initially with poor results and repeatability.

The imaging software described in this section of the report will be applied to corroded cables recently broken in pull test evaluations for the purpose of improved characterization of their deterioration condition and an improved understanding of the strand factors affecting capacity. 
Figure 25. Morphological results from automatic segmentation.

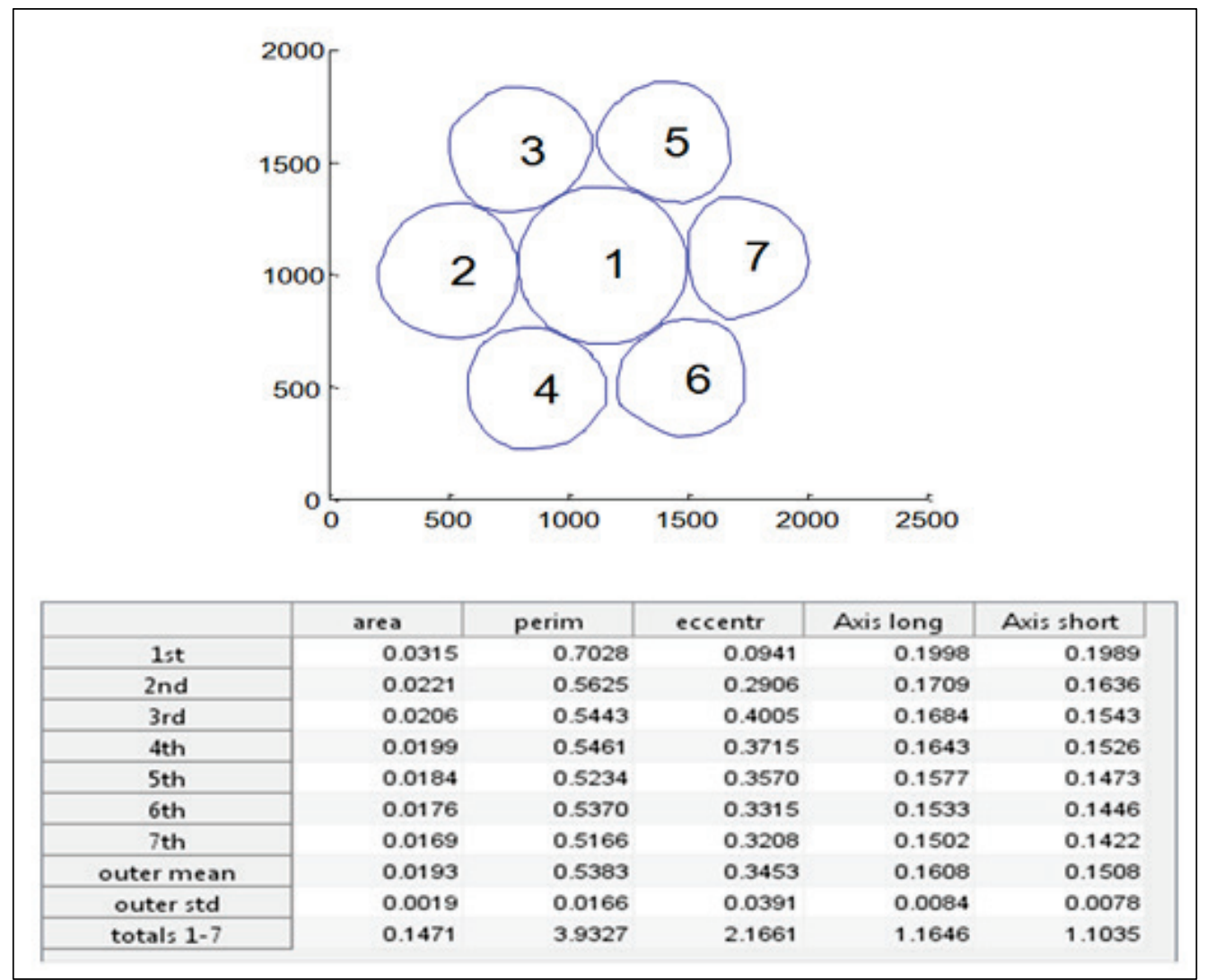

Figure 26. Masks formation and application for a poorly oriented strand with artifacts.

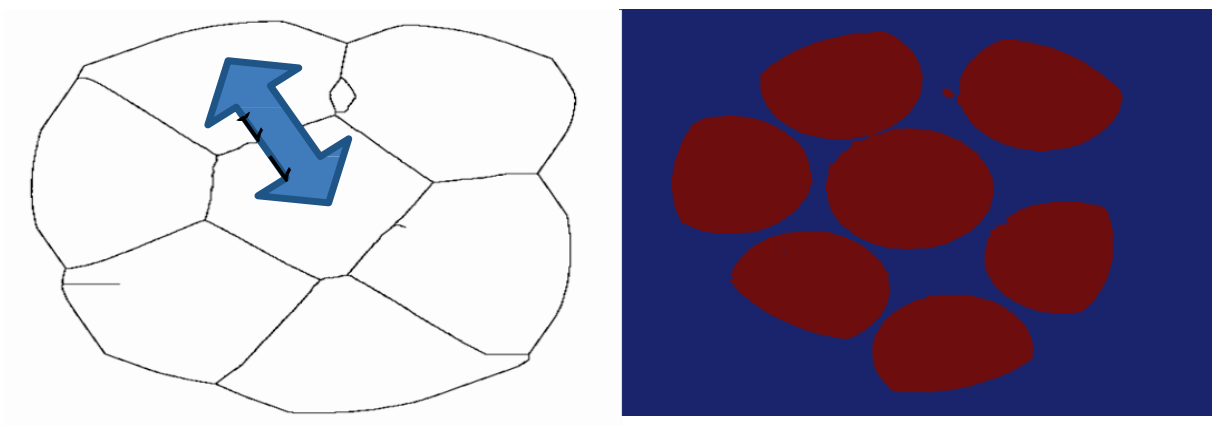

\subsection{Development of Deterioration Database:}

To manage and organize the inventory of cables being deteriorated and evaluated, a database with file linking was developed. This database includes a cable labeling system, dates of corrosion and testing, corrosion chamber and post failure analysis, pictures, pull test data, and other relevant comments and information. An example of data gathering from the database is shown in a distribution of strength curves (Figure 27) and data plot vs. caliper readings of the minimal cable diameter (Figure 28). 
Figure 27. A distribution of pull test results from laboratory corroded samples.

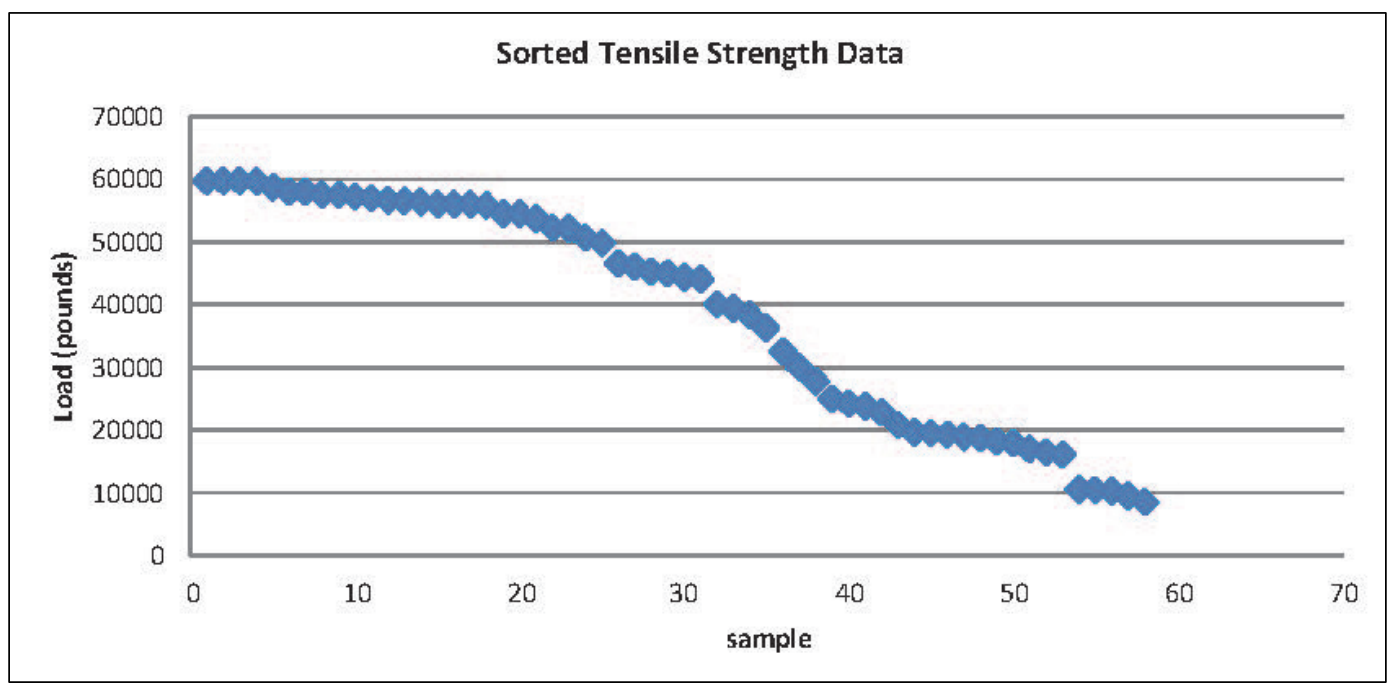

Figure 28. Pull test load failure points plotted against micrometer measured diameter.

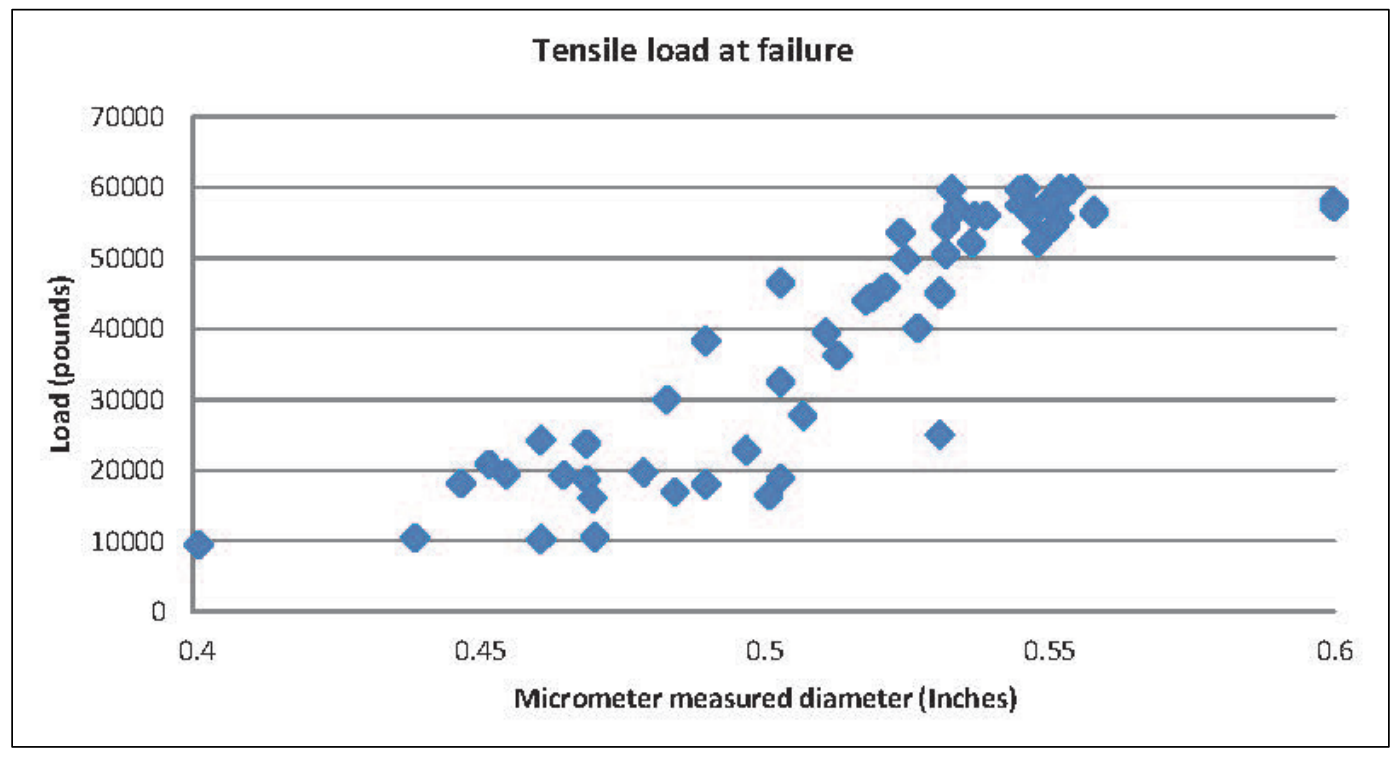

Some of the extracted data from the database is shown in Table 1. Note that the diameters recorded here are from the caliper measurements and not from the image analysis effort, which was still being processed at the time of this report being written. The image analysis effort, database update, and data interpretation will all conclude in FY14, and it will be reported in the next publication. 
Table 1. Corroded Cable pull data

Diameter at various locations (Inches)

\begin{tabular}{|l|l|l|l|l|l|l|l|l|l|l|l|l|l|l|l|}
\hline Cable ID & $\begin{array}{l}\text { Start } \\
\text { Dia (in) }\end{array}$ & $\begin{array}{l}\text { Gage } \\
\text { (in) }\end{array}$ & $\begin{array}{l}\text { Peak } \\
\text { (lbs) }\end{array}$ & Avg (in) & Min (in) & loss (in) & L1-1 & L1-2 & L1-3 & L2-1 & L2-2 & L2-3 & L3-1 & L3-2 & L3-3 \\
\hline 26A & 0.5625 & 72.5 & 59849 & 0.5485 & 0.546 & 0.0165 & 0.546 & 0.547 & 0.548 & 0.55 & 0.551 & 0.549 & & \\
\hline 24B & 0.5595 & 71 & 59770 & 0.5588 & 0.554 & 0.0055 & 0.558 & 0.558 & 0.561 & 0.554 & 0.562 & 0.56 & & \\
\hline M20 & 0.527 & 38.25 & 59767 & 0.5460 & 0.543 & -0.016 & 0.546 & 0.549 & 0.543 & & & & & & \\
\hline 25A & 0.56 & 70.5 & 59732 & 0.5538 & 0.533 & 0.027 & 0.558 & 0.559 & 0.554 & 0.556 & 0.5555 & 0.556 & 0.533 & 0.56 & 0.553 \\
\hline 26B & 0.5625 & 70 & 59726 & 0.5557 & 0.552 & 0.0105 & 0.557 & 0.559 & 0.555 & 0.552 & 0.556 & 0.555 & & & \\
\hline 27A & 0.5605 & 73.5 & 59670 & 0.5472 & 0.545 & 0.0155 & 0.549 & 0.545 & 0.546 & 0.546 & 0.548 & 0.549 & & & \\
\hline 28A & & 67.75 & 58691 & 0.5566 & 0.5525 & 0.012 & 0.5525 & 0.557 & 0.556 & 0.557 & 0.557 & 0.5605 & & & \\
\hline M22 & 0.527 & 36.75 & 58518 & 0.5403 & 0.538 & -0.011 & 0.542 & 0.541 & 0.538 & & & & & & \\
\hline 18B & 0.562 & 69.5 & 58011 & 0.5553 & 0.55 & 0.012 & 0.553 & 0.55 & 0.557 & 0.556 & 0.558 & 0.558 & & & \\
\hline M21 & 0.527 & 37 & 57908 & 0.5373 & 0.535 & -0.008 & 0.538 & 0.539 & 0.535 & & & & & & \\
\hline 28B & 0.562 & 70.5 & 57629 & 0.5525 & 0.55 & 0.012 & 0.555 & 0.552 & 0.552 & 0.553 & 0.55 & 0.553 & & & \\
\hline 27A (1st & 0.5605 & 72 & 57537 & 0.5472 & 0.545 & 0.0155 & 0.549 & 0.545 & 0.546 & 0.546 & 0.548 & 0.549 & & & \\
\hline 1 & 0.5625 & 84 & 57232 & 0.5365 & 0.5365 & 0.026 & 0.5365 & & & & & & & & \\
\hline 9A & 0.5695 & 69.5 & 57009 & 0.5452 & 0.534 & 0.0355 & 0.551 & 0.545 & 0.534 & 0.545 & 0.555 & 0.542 & 0.536 & 0.56 & 0.539 \\
\hline 29A & 0.564 & 70.5 & 56661 & 0.5522 & 0.547 & 0.017 & 0.547 & 0.547 & 0.552 & 0.551 & 0.559 & 0.557 & & & \\
\hline Pristine & 0.5605 & 68.25 & 56565 & 0.5595 & 0.558 & 0.0025 & 0.558 & 0.5605 & 0.56 & & & & & & \\
\hline A2 & 0.561 & 30.75 & 56449 & 0.5560 & 0.556 & 0.005 & 0.556 & & & & & & & & \\
\hline 18A & 0.562 & 68.5 & 56334 & 0.5595 & 0.558 & 0.004 & 0.5585 & 0.558 & 0.559 & 0.561 & 0.562 & 0.559 & & & \\
\hline 17A & 0.5595 & 69 & 56031 & 0.5480 & 0.537 & 0.0225 & 0.5525 & 0.554 & 0.552 & 0.551 & 0.5535 & 0.552 & 0.537 & 0.538 & 0.542 \\
\hline
\end{tabular}




\begin{tabular}{|c|c|c|c|c|c|c|c|c|c|c|c|c|c|c|c|}
\hline \multirow[b]{2}{*}{ Cable ID } & \multirow[b]{2}{*}{\begin{tabular}{|l|} 
Start \\
Dia (in)
\end{tabular}} & \multirow[b]{2}{*}{$\begin{array}{l}\text { Gage } \\
\text { (in) }\end{array}$} & \multirow[b]{2}{*}{$\begin{array}{l}\text { Peak } \\
\text { (lbs) }\end{array}$} & \multirow[b]{2}{*}{ Avg (in) } & \multirow[b]{2}{*}{ Min (in) } & \multirow[b]{2}{*}{ loss (in) } & \multicolumn{5}{|c|}{ Diameter at various locations (Inches) } & \multirow[b]{2}{*}{ L2-3 } & \multirow[b]{2}{*}{ L3-1 } & \multirow[b]{2}{*}{ L3-2 } & \multirow[b]{2}{*}{ L3-3 } \\
\hline & & & & & & & L1-1 & L1-2 & L1-3 & L2-1 & L2-2 & & & & \\
\hline $29 B$ & 0.564 & 69.25 & 56005 & 0.5542 & 0.547 & 0.017 & 0.555 & 0.553 & 0.547 & 0.556 & 0.557 & 0.557 & & & \\
\hline $25 B$ & 0.56 & 69.5 & 56002 & 0.5523 & 0.539 & 0.021 & 0.552 & 0.539 & 0.563 & 0.542 & 0.548 & 0.546 & 0.556 & 0.552 & 0.573 \\
\hline M5 & 0.559 & 35.75 & 55967 & 0.5395 & 0.531 & 0.028 & 0.536 & 0.531 & 0.532 & 0.559 & & & & & \\
\hline 3 & 0.564 & 65 & 55796 & 0.5527 & 0.552 & 0.012 & 0.5535 & 0.5525 & 0.552 & & & & & & \\
\hline $\mathrm{H} 2$ & 0.571 & 32.5 & 55271 & 0.5443 & 0.542 & 0.029 & 0.542 & 0.544 & 0.547 & & & & & & \\
\hline $30 \mathrm{~B}$ & 0.567 & 70.5 & 54474 & 0.5552 & 0.551 & 0.016 & 0.553 & 0.557 & 0.551 & 0.555 & 0.553 & 0.562 & & & \\
\hline $9 B$ & 0.5695 & 70 & 54406 & 0.5373 & 0.532 & 0.0375 & 0.5385 & 0.541 & 0.537 & 0.542 & 0.5395 & 0.536 & 0.533 & 0.532 & 0.537 \\
\hline M9 & 0.557 & 37 & 54251 & 0.5313 & 0.521 & 0.036 & 0.521 & 0.523 & 0.524 & 0.557 & & & & & \\
\hline M11 & 0.559 & 36.75 & 53795 & 0.5260 & 0.512 & 0.047 & 0.515 & 0.512 & 0.518 & 0.559 & & & & & \\
\hline $24 \mathrm{~A}$ & 0.5595 & 71.75 & 53667 & 0.5450 & 0.524 & 0.0355 & 0.524 & 0.549 & 0.553 & 0.549 & 0.548 & 0.547 & & & \\
\hline F2 & 0.561 & 36.5 & 52642 & 0.5227 & 0.521 & 0.04 & 0.521 & 0.525 & 0.522 & & & & & & \\
\hline E1 & 0.564 & 37 & 52546 & 0.5343 & 0.521 & 0.043 & 0.555 & 0.527 & 0.521 & & & & & & \\
\hline $27 \mathrm{~B}$ & 0.5605 & 70.5 & 52227 & 0.5525 & 0.548 & 0.0125 & 0.552 & 0.554 & 0.548 & 0.552 & 0.553 & 0.556 & & & \\
\hline $10 \mathrm{~A}$ & 0.576 & 67.5 & 52113 & 0.5422 & 0.5365 & 0.0395 & 0.5445 & 0.539 & 0.5365 & 0.542 & 0.5505 & 0.5405 & & & \\
\hline M4 & 0.557 & 36.25 & 51228 & 0.5203 & 0.505 & 0.052 & 0.512 & 0.505 & 0.507 & 0.557 & & & & & \\
\hline F3 & 0.566 & 39 & 51174 & 0.5140 & 0.506 & 0.06 & 0.519 & 0.517 & 0.506 & & & & & & \\
\hline F1 & 0.558 & 37 & 50732 & 0.5203 & 0.519 & 0.039 & 0.52 & 0.519 & 0.522 & & & & & & \\
\hline E2 & 0.562 & 37 & 50657 & 0.5250 & 0.52 & 0.042 & 0.52 & 0.532 & 0.523 & & & & & & \\
\hline $14 \mathrm{~B}$ & 0.5715 & 67.25 & 50626 & 0.5506 & 0.532 & 0.0395 & 0.555 & 0.557 & 0.558 & 0.554 & 0.555 & 0.556 & 0.549 & 0.539 & 0.532 \\
\hline M7 & 0.559 & 37 & 50608 & 0.5160 & 0.5 & 0.059 & 0.502 & 0.503 & 0.5 & 0.559 & & & & & \\
\hline
\end{tabular}




\begin{tabular}{|c|c|c|c|c|c|c|c|c|c|c|c|c|c|c|c|}
\hline \multirow[b]{2}{*}{ Cable ID } & \multirow[b]{2}{*}{\begin{tabular}{|l|} 
Start \\
Dia (in)
\end{tabular}} & \multirow[b]{2}{*}{$\begin{array}{l}\text { Gage } \\
\text { (in) }\end{array}$} & \multirow[b]{2}{*}{\begin{tabular}{|l} 
Peak \\
(lbs)
\end{tabular}} & \multirow[b]{2}{*}{ Avg (in) } & \multirow[b]{2}{*}{ Min (in) } & \multirow[b]{2}{*}{ loss (in) } & \multicolumn{5}{|c|}{ Diameter at various locations (Inches) } & \multirow[b]{2}{*}{ L2-3 } & \multirow[b]{2}{*}{ L3-1 } & \multirow[b]{2}{*}{ L3-2 } & \multirow[b]{2}{*}{ L3-3 } \\
\hline & & & & & & & L1-1 & L1-2 & L1-3 & L2-1 & L2-2 & & & & \\
\hline G1 & 0.564 & 37.25 & 50382 & 0.5140 & 0.513 & 0.051 & 0.514 & 0.513 & 0.515 & & & & & & \\
\hline G3 & 0.557 & 37 & 50275 & 0.5170 & 0.514 & 0.043 & 0.516 & 0.514 & 0.521 & & & & & & \\
\hline $10 \mathrm{~B}$ & 0.576 & 68.25 & 49835 & 0.5296 & 0.525 & 0.051 & 0.526 & 0.527 & 0.526 & 0.533 & 0.529 & 0.525 & 0.532 & 0.542 & 0.526 \\
\hline $50 \mathrm{~A}$ & 0.558 & 71.25 & 49300 & 0.5327 & 0.529 & 0.029 & 0.529 & 0.535 & 0.534 & & & & & & \\
\hline H3 & 0.565 & 31 & 49075 & 0.5113 & 0.508 & 0.057 & 0.512 & 0.508 & 0.514 & & & & & & \\
\hline $53 \mathrm{~A}$ & 0.556 & 70 & 48416 & 0.5360 & 0.524 & 0.032 & 0.524 & 0.542 & 0.542 & & & & & & \\
\hline $51 \mathrm{~A}$ & 0.56 & 71.5 & 47751 & 0.5413 & 0.539 & 0.021 & 0.546 & 0.539 & 0.539 & & & & & & \\
\hline E3 & 0.561 & 37 & 47341 & 0.5070 & 0.501 & 0.06 & 0.507 & 0.501 & 0.513 & & & & & & \\
\hline M17 & 0.557 & 37 & 47251 & 0.5095 & 0.479 & 0.078 & 0.479 & 0.495 & 0.507 & 0.557 & & & & & \\
\hline $30 \mathrm{~A}$ & 0.567 & 71.5 & 46650 & 0.5492 & 0.536 & 0.031 & 0.556 & 0.536 & 0.543 & 0.553 & 0.557 & 0.55 & & & \\
\hline $22 \mathrm{~A}$ & 0.5615 & 58.75 & 46519 & 0.5125 & 0.503 & 0.0585 & 0.503 & 0.514 & 0.517 & 0.512 & 0.516 & 0.513 & & & \\
\hline G2 & 0.564 & 36.5 & 46485 & 0.5003 & 0.496 & 0.068 & 0.496 & 0.504 & 0.501 & & & & & & \\
\hline $14 \mathrm{~A}$ & 0.5715 & 68 & 45961 & 0.5366 & 0.5215 & 0.05 & 0.537 & 0.5215 & 0.539 & 0.547 & 0.534 & 0.541 & & & \\
\hline 4 & 0.5605 & 67 & 45207 & 0.5348 & 0.531 & 0.0295 & 0.531 & 0.5375 & 0.536 & & & & & & \\
\hline $11 \mathrm{~A}$ & 0.5665 & 68.25 & 44953 & 0.5358 & 0.531 & 0.0355 & 0.537 & 0.531 & 0.539 & 0.536 & 0.539 & 0.533 & & & \\
\hline $21 \mathrm{~A}$ & 0.5655 & 66 & 44421 & 0.5247 & 0.519 & 0.0465 & 0.536 & 0.521 & 0.521 & 0.524 & 0.519 & 0.527 & & & \\
\hline D3 & 0.557 & 37.5 & 44367 & 0.4937 & 0.491 & 0.066 & 0.491 & 0.494 & 0.496 & & & & & & \\
\hline $11 \mathrm{~B}$ & 0.5665 & 68 & 44015 & 0.5333 & 0.518 & 0.0485 & 0.545 & 0.518 & 0.559 & 0.528 & 0.524 & 0.526 & & & \\
\hline D2 & 0.557 & 36 & 43621 & 0.5173 & 0.515 & 0.042 & 0.515 & 0.518 & 0.519 & & & & & & \\
\hline $48 \mathrm{~B}$ & 0.559 & 70.5 & 42492 & 0.5200 & 0.517 & \begin{tabular}{|l|}
0.042 \\
\end{tabular} & 0.517 & 0.521 & 0.522 & & & & & & \\
\hline
\end{tabular}




\begin{tabular}{|c|c|c|c|c|c|c|c|c|c|c|c|c|c|c|c|}
\hline \multirow[b]{2}{*}{ Cable ID } & \multirow[b]{2}{*}{\begin{tabular}{|l|} 
Start \\
Dia (in)
\end{tabular}} & \multirow[b]{2}{*}{$\begin{array}{l}\text { Gage } \\
\text { (in) }\end{array}$} & \multirow[b]{2}{*}{$\begin{array}{l}\text { Peak } \\
\text { (lbs) }\end{array}$} & \multirow[b]{2}{*}{ Avg (in) } & \multirow[b]{2}{*}{ Min (in) } & \multirow[b]{2}{*}{ loss (in) } & \multicolumn{5}{|c|}{ Diameter at various locations (Inches) } & \multirow[b]{2}{*}{ L2-3 } & \multirow[b]{2}{*}{ L3-1 } & \multirow[b]{2}{*}{ L3-2 } & \multirow[b]{2}{*}{ L3-3 } \\
\hline & & & & & & & L1-1 & L1-2 & L1-3 & L2-1 & L2-2 & & & & \\
\hline $54 \mathrm{~B}$ & 0.5595 & 73.5 & 42113 & 0.5237 & 0.517 & 0.0425 & 0.517 & 0.535 & 0.519 & & & & & & \\
\hline $\mathrm{C} 2$ & 0.565 & 31.5 & 42030 & 0.4960 & 0.494 & 0.071 & 0.494 & 0.5 & 0.494 & & & & & & \\
\hline M19 & 0.559 & 38 & 40865 & 0.4788 & 0.451 & 0.108 & 0.451 & 0.454 & 0.451 & 0.559 & & & & & \\
\hline 16B & 0.561 & 68.5 & 40085 & 0.5339 & 0.527 & 0.034 & 0.53 & 0.527 & 0.5315 & 0.537 & 0.543 & 0.536 & 0.535 & 0.527 & 0.539 \\
\hline $53 B$ & 0.563 & 71.5 & 39561 & 0.5340 & 0.531 & 0.032 & 0.531 & 0.539 & 0.532 & & & & & & \\
\hline $16 \mathrm{~A}$ & 0.561 & 71 & 39429 & 0.5322 & 0.511 & 0.05 & 0.538 & 0.536 & 0.536 & 0.541 & 0.5455 & 0.547 & 0.511 & 0.522 & 0.514 \\
\hline $13 \mathrm{~A}$ & 0.5875 & 59.25 & 38268 & 0.5035 & 0.49 & 0.0975 & 0.508 & 0.498 & 0.501 & 0.532 & 0.492 & 0.49 & & & \\
\hline $54 \mathrm{~A}$ & 0.5595 & 71.5 & 37148 & 0.5327 & 0.524 & 0.0355 & 0.529 & 0.524 & 0.545 & & & & & & \\
\hline $17 \mathrm{~B}$ & 0.5595 & 71.25 & 36211 & 0.5338 & 0.513 & 0.0465 & 0.52 & 0.513 & 0.519 & 0.552 & 0.56 & 0.539 & & & \\
\hline $52 \mathrm{~A}$ & 0.5615 & 71.5 & 35975 & 0.5387 & 0.538 & 0.0235 & 0.539 & 0.538 & 0.539 & & & & & & \\
\hline $51 \mathrm{~B}$ & 0.569 & 71.75 & 32844 & 0.5047 & 0.5 & 0.069 & 0.506 & 0.508 & 0.5 & & & & & & \\
\hline $12 \mathrm{~B}$ & 0.577 & 69 & 32472 & 0.5121 & 0.503 & 0.074 & 0.509 & 0.503 & 0.5053 & 0.523 & 0.5125 & 0.52 & & & \\
\hline $34 \mathrm{~B}$ & 0.56 & 67.75 & 29976 & 0.5100 & 0.483 & 0.077 & 0.511 & 0.545 & 0.483 & 0.51 & 0.505 & 0.506 & & & \\
\hline D1 & 0.562 & 38 & 29926 & 0.4353 & 0.433 & 0.129 & 0.433 & 0.437 & 0.436 & & & & & & \\
\hline $52 B$ & 0.56 & 71.25 & 28565 & 0.5060 & 0.504 & 0.056 & 0.507 & 0.507 & 0.504 & & & & & & \\
\hline $43 B$ & 0.556 & 71 & 28557 & 0.5123 & 0.492 & 0.064 & 0.492 & 0.521 & 0.524 & & & & & & \\
\hline $12 \mathrm{~A}$ & 0.577 & 67.5 & 27724 & 0.5098 & 0.507 & 0.07 & 0.509 & 0.507 & 0.512 & 0.517 & 0.507 & 0.507 & & & \\
\hline $15 \mathrm{~A}$ & 0.5505 & 69 & 25002 & 0.5350 & 0.531 & 0.0195 & 0.5345 & 0.5335 & 0.5365 & 0.531 & 0.537 & 0.5375 & & & \\
\hline $21 B$ & 0.55 & 69.5 & 24257 & 0.5300 & 0.461 & 0.089 & 0.531 & 0.542 & 0.529 & 0.532 & 0.533 & 0.541 & 0.461 & 0.551 & 0.55 \\
\hline $22 B$ & 0.559 & 65.5 & 23738 & 0.5174 & 0.469 & 0.09 & 0.5205 & 0.516 & 0.503 & 0.521 & 0.5105 & 0.5065 & 0.551 & 0.469 & 0.559 \\
\hline
\end{tabular}




\begin{tabular}{|c|c|c|c|c|c|c|c|c|c|c|c|c|c|c|c|}
\hline \multirow[b]{2}{*}{ Cable ID } & \multirow[b]{2}{*}{$\begin{array}{l}\text { Start } \\
\text { Dia (in) }\end{array}$} & \multirow[b]{2}{*}{$\begin{array}{l}\text { Gage } \\
\text { (in) }\end{array}$} & \multirow[b]{2}{*}{$\begin{array}{l}\text { Peak } \\
\text { (lbs) }\end{array}$} & \multirow[b]{2}{*}{ Avg (in) } & \multirow[b]{2}{*}{ Min (in) } & \multirow[b]{2}{*}{ loss (in) } & \multicolumn{5}{|c|}{ Diameter at various locations (Inches) } & \multirow[b]{2}{*}{ L2-3 } & \multirow[b]{2}{*}{ L3-1 } & \multirow[b]{2}{*}{ L3-2 } & \multirow[b]{2}{*}{ L3-3 } \\
\hline & & & & & & & L1-1 & L1-2 & L1-3 & L2-1 & L2-2 & & & & \\
\hline 13B & 0.5875 & 62 & 22786 & 0.5187 & 0.497 & 0.0905 & 0.53 & 0.556 & 0.521 & 0.501 & 0.507 & 0.497 & & & \\
\hline $43 \mathrm{~A}$ & 0.564 & 71.25 & 22677 & 0.4440 & 0.418 & 0.146 & 0.418 & 0.473 & 0.441 & & & & & & \\
\hline $19 \mathrm{~A}$ & 0.5665 & 67.5 & 20795 & 0.4775 & 0.452 & 0.1145 & 0.456 & 0.4815 & 0.4985 & 0.488 & 0.452 & 0.489 & & & \\
\hline $33 B$ & 0.5595 & 68.25 & 19636 & 0.5147 & 0.479 & 0.0805 & 0.565 & 0.479 & 0.486 & 0.513 & 0.533 & 0.512 & & & \\
\hline $32 B$ & 0.5605 & 68.5 & 19476 & 0.5087 & 0.455 & 0.1055 & 0.455 & 0.53 & 0.499 & 0.49 & 0.544 & 0.534 & & & \\
\hline $34 \mathrm{~A}$ & 0.56 & 67 & 19257 & 0.5135 & 0.465 & 0.095 & 0.511 & 0.512 & 0.512 & 0.465 & 0.565 & 0.516 & & & \\
\hline $20 B$ & 0.5685 & 67.25 & 18846 & 0.5105 & 0.503 & 0.0655 & 0.503 & 0.51 & 0.508 & 0.506 & 0.513 & 0.523 & & & \\
\hline $35 \mathrm{~A}$ & 0.56 & 69.5 & 18151 & 0.5022 & 0.447 & 0.113 & 0.513 & 0.474 & 0.447 & 0.526 & 0.523 & 0.53 & & & \\
\hline $13 \mathrm{~A}$ (1st & 0.5875 & 64.5 & 17977 & 0.5035 & 0.49 & 0.0975 & 0.508 & 0.498 & 0.501 & 0.532 & 0.492 & 0.49 & & & \\
\hline $23 B$ & 0.566 & 65.5 & 16908 & 0.4948 & 0.4845 & 0.0815 & 0.5 & 0.502 & 0.4845 & 0.494 & 0.4935 & 0.4915 & 0.491 & 0.495 & 0.5025 \\
\hline $31 B$ & 0.559 & 69.5 & 16409 & 0.5387 & 0.501 & 0.058 & 0.587 & 0.55 & 0.518 & 0.532 & 0.544 & 0.501 & & & \\
\hline $33 \mathrm{~A}$ & 0.5595 & 68 & 16034 & 0.4913 & 0.47 & 0.0895 & 0.488 & 0.508 & 0.476 & 0.512 & 0.494 & 0.47 & & & \\
\hline $23 A$ & 0.566 & 67.5 & 10512 & 0.5316 & 0.4705 & 0.0955 & 0.4705 & 0.559 & 0.5635 & 0.528 & 0.526 & 0.5395 & 0.531 & 0.534 & 0.5325 \\
\hline $35 B$ & 0.56 & 68 & 10408 & 0.5070 & 0.439 & 0.121 & 0.56 & 0.497 & 0.439 & 0.506 & 0.554 & 0.486 & & & \\
\hline $20 \mathrm{~A}$ & 0.5685 & 63.5 & 10217 & 0.4959 & 0.461 & 0.1075 & 0.461 & 0.524 & 0.474 & 0.522 & 0.496 & 0.504 & 0.506 & 0.498 & 0.478 \\
\hline $31 \mathrm{~A}$ & 0.559 & 69 & 9466 & 0.4793 & 0.401 & 0.158 & 0.505 & 0.451 & 0.484 & 0.513 & 0.401 & 0.522 & & & \\
\hline 6 & 0.5635 & 72 & 8476 & 0.3822 & 0.305 & 0.2585 & 0.392 & 0.362 & 0.305 & 0.385 & 0.474 & 0.375 & & & \\
\hline
\end{tabular}




\section{NDT Methods to Access the Condition of Post-Tension Seven Strand Wire Cables}

The use of post-tension members in structures provides durability and other structural benefits. However, older structures used cables and other tendon members without insuring the ingress of corrosive chlorides from the concrete. As a result, these members can fail causing a catastrophic loss of the structural member and perhaps the entire structure. As a result, there exists a tremendous need to perform nondestructive testing (NDT) on post tensioned tendons. Examples of post-tension structures include navigation locks, training walls, navigation and flood control dams, bridges, tieback retaining walls, mines, and many other types of large massive structures. These tendons may fail due to corrosion over time and high strain events such as earthquakes.

\subsection{Need within the Corps for Seven Strand Post Tension Cable Inspection}

There is a significant need within the U.S. Army Corps of Engineers (USACE) for methods to nondestructively test seven strand post tension cables. One such need was described in a Navigation Systems R\&D program Statement of Need (SON) 2009-N-1 by engineers at the Portland District who estimated the anchors to be designed into at least 10 percent of new construction. Additionally, these post tension strands are often involved in large repair and retrofit designs. These critical structural components are subject to failure for a variety of reasons. In older systems, primarily systems installed before the Post Tension Institute's 2004 Class II corrosion protection recommendations, the level of protection is inadequate. The intrinsically wet environment that these systems are installed in within the Corps navigation structures can often make these corrosion related failures even more problematic than seen in buildings and bridges. The problems at John Day Lock and Dam, which were discussed in report ERDC TR-13-3 (Ebeling et al. 2013), are a good example of this. Overloading from high strain events such as earthquakes and barge impacts is another potential source of cable failure within navigation structures. This problem was recently presented in 2013 when barges struck the tainter gates at Marseilles Lock and Dam in Grafton, Illinois. This impact destroyed the 
seven strand wire cable anchorage on one gate and brought into question the integrity of the cables in adjoining gates that were known to be part of the impact event.

\subsection{Boundary Conditions for Field Inspection in Mass Concrete}

Due to their continuously increasing global use, there is a tremendous need for seven wire strand inspection methods. The California Dept of Transportation now uses these cables in 90 percent of bridges, and they are also widely used in residential foundations, buildings, and retaining structures. The boundary conditions for deployment at the Corps navigation structures tend to be unique, and as a result many of the NDT technologies being pursued by other investigators will not transition for mass-concrete anchorages. In a mass-concrete anchorage, only one end of a cable is accessible with no shallow parallel access through the thick concrete cover. This eliminates two-sided access methods as well as methods which test through shallow concrete cover. This single-end access of the cables, coupled with the need to characterize the cable's condition along its length has resulted in our focusing on guided wave methods as the candidate inspection method, as initially discussed by Ebeling et al. (2013). Guided wave methods are intrinsically suited to remotely characterizing condition at great distances from only single or dual points of inspection. Single-end guided wave inspection of seven strand wire cable will be discussed in more detail in the remainder of this report; however, some mention will first be made of other approaches and their potential.

\subsection{NDT Technologies in General for Seven Strand Wire Cable Inspection}

In 2012, the Federal Department of Transportation published a large report, (Azizinamini and Gull 2012) where wide arrays of technologies were investigated on controlled bridges for seven strand inspection. These were divided into several groups by the condition being targeted such as breaks and cross-sectional loss, improper grout condition, active corrosion, tension, and duct location and condition. The methods which rely on having two-sided cable access, shallow concrete cover, or exposed tendon ducts are generally not applicable to mass concrete installations. These included the bulk of the investigated technologies and are magnetic flux leakage, radiography (x-rays), impact echo, acoustic sounding impulse response, ultrasonic imaging, half-cell potential, linear polarization, electro impedance spectroscopy, vibration of ducts, global vibration frequency 
monitoring, x-ray diffraction, infrared thermography, and impulse radar. This report also mentioned guided waves as a promising technology needing further investigation, but did not include the vendor/technology evaluations. Regarding guided wave testing, they addressed only low frequency guided waves. Inspection frequencies rarely address a large amount of the research that is aimed at longer inspection paths in grease/gout embedded cables. Some of the other investigated technologies, such as acoustic emission, were covered in more detail in a 2009 California Department of Transportation (CDOT) report (Bartoli et al. 2009). In the CDOT report, there is a significant focus on guided wave and nonlinear approaches applied from the cable ends; however, these system configurations were generally based on through transmission or two-sided cable access. In the CDOT report, a full scale multi-cable concrete test system was constructed and loaded to failure; in addition, numerous finite element and semianalytical finite element models were utilized. Some general findings from these investigations are in the rest of this section. Inter-wire leakage in the 400-500 KHz frequency range appeared to be a viable tension characterization approach with best performance achieved when the signal was injected on a perimeter wire and received on the central wire. Through careful application, this energy ratio measurement was determined to be base-line free. A second approach using the nonlinear beta parameter also provided base-line free tension estimation due to the decrease in acoustical nonlinearity as tension increased and the inter-wire forces increased. Lastly, acoustic emission monitoring as a real time approach was evaluated during the large scale model failure. Acoustic emission, which is applicable to single-side access, is established technology for non-embedded cables. An example is the Golden Gate Bridge Monitoring System. This system runs continuously to detect the acoustical energy created during material failures and has intrinsic deployment issues related to expense, large data volumes, extraneous noise sources, and they are not sensitive to pre-existing breaks or damage.

\subsection{Site Specific NDT}

In some cases, a seven wire strand anchorage problem or configuration may present either unique inspection capabilities or needs. At John Day Lock and Dam (Rufus, Oregon), installation and design problems led to ungrouted vent tubes from the lower stage grouting, and failure of the upper stage grout was due to a bad mix design (powdered rubber admixture). The result of these problems, discussed in Chapter 6 of ERDC TR-13-3 (Ebeling et al. 2013), are high water flow rates, which are occurring during lockages, directly to the anchor head and the region of failed grout. The obvious 
rehabilitation is to remove the failed grout, which has a mud like consistency, plug the vent tubes, and re-grout the upper stage. A logical NDT/monitoring approach would be to install moisture sensors in the 70 anchor heads to quantify the degree to which specific anchor heads are undergoing seepage and the effectiveness of rehabilitation. Generally, this type of moisture intrusion is not occurring, so this NDT/NDE approach would be site specific for the John Day Lock and Dam. Likewise, the potentially damaged tainter gate anchorages at Marseilles Lock and Dam terminate at the end of approximately 8-inch-square, 2-foot-long steel extrusions. The presence of these exposed elements enables methods such as acoustoelectric based stress measurements on the steel tubing to at least estimate the distribution and total load being carried. Such a process, when compared against gates not involved in the impact, would provide some reassurance that strands were not significantly damaged during the impact. These examples are presented to make the point that unique NDT needs or opportunities sometimes exist so some case-by-case considerations are often warranted.

\subsection{Ultrasonic Guided Wave Inspection}

In an ultrasonic guided wave inspection, the inspected structural element is a waveguide whose properties dictate which acoustical modes propagate, what their properties are, and how they interact with one another. Propagating modes change as a function of frequency, type of wave (compressional, torsional, and flexural), and the geometry and material properties of the waveguide and embedding medium. Unlike higher order modes in embedded rod structures, tension also has a significant effect and it must be taken into account when developing methods for cable inspection. This issue is discussed in more detail in this chapter under the section on embedded measurements. Because of the geometrical and inter-wire complexity of seven strand wire cables, embedded rods represent a simpler basis for a fundamental discussion of guided waves. The researchers in this effort are also involved in development of inspection methods for post tension trunion anchor rods and many overlapping concepts are more easily introduced for the case of the rod. The following section describes high frequency low-loss mode inspection of embedded rods to present simpler examples before going into cable guided waves. This approach is often used in cable journal articles before delving into cable specific behaviors. 


\subsection{Guided Waves in Rods}

A number of investigators have covered rod guided waves with the intent of solving problems such as rebar corrosion in concrete, rock anchor bolt bonding, and utility pole guide wire anchor corrosion in soils (Ervin et al. 2009; Beard et al. 2003). In general, these specific applications need high sensitivity at the rod surface, and therefore benefit from narrow band guided wave modes, such as low order longitudinal or torsional modes, that result in relatively higher levels of acoustical energy at or near the rod's surface. The drawback of these lower frequency modes is that energy leaks into the surrounding medium at a higher rate, producing correspondingly higher attenuation rates, and therefore reducing the maximum testable rod length. Low order attenuation cannot be overcome by simply continuing to apply more power because piezoceramic materials are limited by their dielectric breakdowns or depoling at extremely high voltages levels.

Testing long lengths of embedded rods with vertical or horizontal shear modes is likewise problematic as these modes produce higher leakage into the surrounding medium and additionally suffer from higher material attenuation rates. Pavlakovic et al. (2001) provides an excellent history of guided wave mode development for rods and proceeds to demonstrate that for long distance inspection, higher order longitudinal modes are the best solution. This is due to the fact that energy becomes progressively more centralized in the rod, and leakage rates at the surface are reduced proportionally. As frequency continues to increase, material attenuation rates also increase and so a point of diminishing return is encountered. Figure 29 illustrates the principles behind the high order low-loss propagation modes. The increased energy centralization that occurs at higher frequencies (i.e., higher longitudinal modes) minimizes surface displacements and energy leakage into the surrounding medium. The limitation of what can be gained from energy centralization occurs at higher frequencies where the frequency dependent material attenuation begins to impede ultrasonic propagation.

Figure 30 illustrates an experimentally collected broadband energy velocity curve for various embedded rod modes (left) and the higher frequency and sustained modes (right) that were captured in multiple reverberations. These higher frequency modes in the 1 to $3 \mathrm{MHz}$ range are the most practical for long distance trunion anchor rod testing. The timefrequency plot's A-Scan is shown above the spectrogram (right). 
Figure 29. Low-loss modes existing between centralization of guided wave energy at higher frequency and lower material attenuation at lower frequencies.

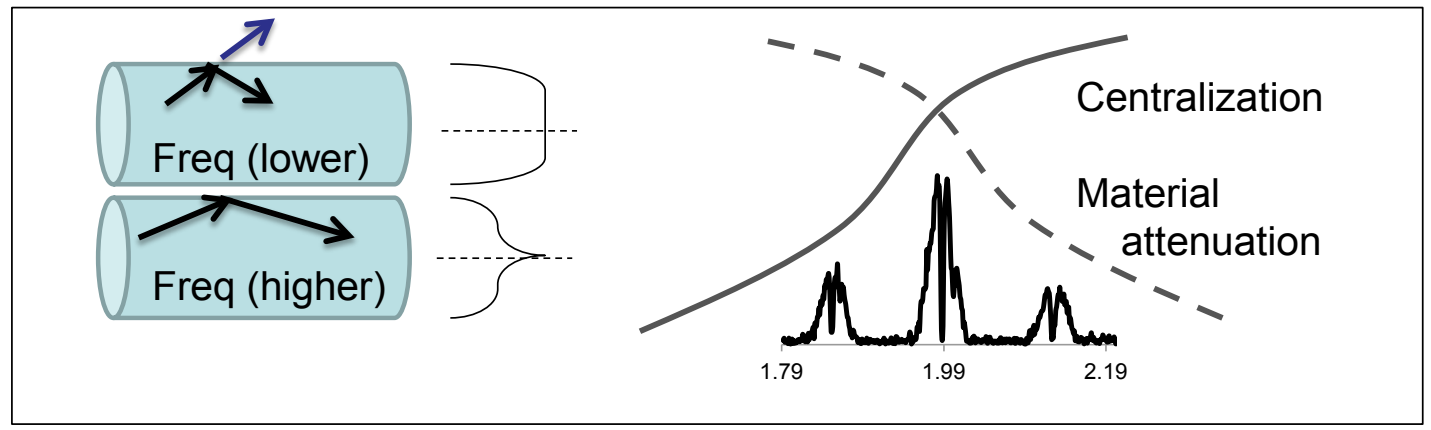

Figure 30. (Left)-Energy velocity curves showing compression and torsional modes. (Right)-Reverberation of high frequency low-loss modes and the associated A-scan.

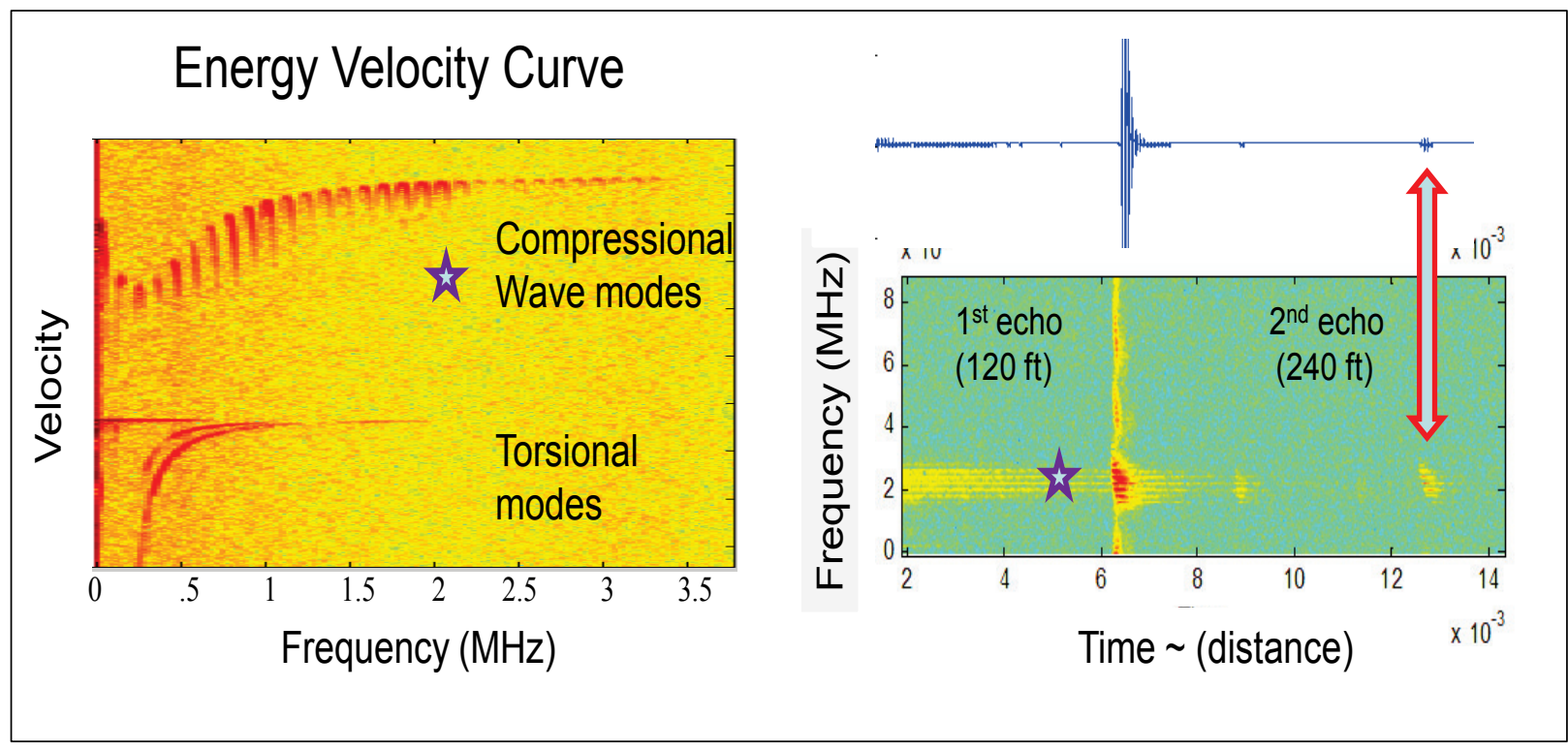

To evaluate the capabilities of shallow near surface defect detection with higher order modes, an experiment was performed where a progressively deepening cut was made, while monitoring the expected reflection region in the ultrasonic A-scan. This cut notch was detected with an approximate signal to noise ratio of two, using the low-loss narrow band inspection frequency at a depth of .1 inches and at a distance of 23 feet away from the free-end in a grease embedded 1.25 inch rod (Figure 31). As the cut was increased, the echo amplitude grew as expected at a very high rate due to both the increase rate of material removed from the rod's cross-section and the reflection of the higher energy concentrations as the cut moves towards the rod's center. The spectral signature of the cut (i.e., open crack) can serve a signature for monitoring purposes. 
Figure 31. Narrow band spectral reflections a .18-inch-deep cut and the rod end of a 1.31-inchdiameter grease embedded trunion anchor rod with concrete termination.

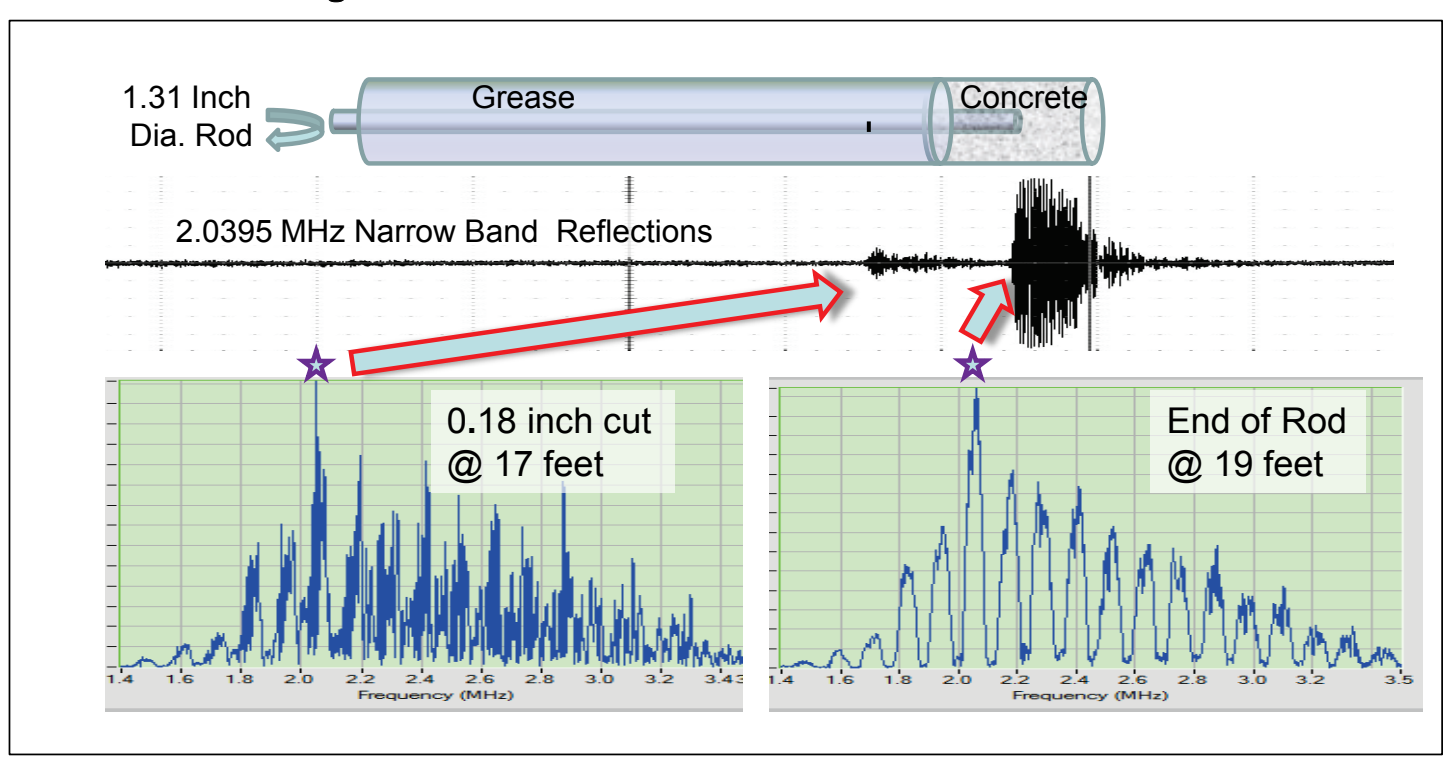

\subsection{Guided Wave Inspection of Cables}

A significant body of research exists on guided wave propagation in seven strand wire cables; however, many of these investigations have involved idealized configurations where the cable is not embedded or loaded and/or where the transducers have been placed in idealized locations such as between anchorages. While these investigations are informative in terms of understanding wave propagation in the cables, they do not generally holdup well for the NDT boundary conditions described in this chapter in section 3.2 (beginning of NDT section). Low frequency acoustoelastic (Chaki 2009; Washer 2001) notch frequency (Kwun et al. 1997; Treyssede and Laguerre 2010) measurements, for example, are promising approaches for tension assessment in two-sided measurements where the cable is surrounded by air, and have not been realizable for long sections of embedded cables with single point access. Therefore, we have focused our attention more on methods, which we believe have more promise for single point access embedded cable testing.

In the previous section on optimal low-loss longitudinal modes of embedded rods, low-loss frequencies suitable for long propagation distances were identified between 1.4 and $3 \mathrm{MHz}$. In the case of seven strand wire cables, this upper range of frequencies was observed to extend up to $5 \mathrm{MHz}$. The intrinsic material attenuation rate, which increases with frequency, limits practical high frequency testing to around $5 \mathrm{MHz}$. The net overall attenuation rate per distance traveled is an order of magnitude 
higher than the rate observed at $2 \mathrm{MHz}$ for the rod. For the grouted cable, an attenuation rate as high as $4 \mathrm{~dB} /$ foot of propagation has been observed at approximately $5 \mathrm{MHz}$ of narrowband inspection frequency (Beard et al. 2003; Laguerre 2009).

\subsubsection{Non-Embedded Cable}

When the seven strand wire cable is not embedded in grease or grout, then the lower order modes represent the best propagation mode for low-loss/ long range inspection. Initial experiments on a coiled cable that were made early in this project showed that over 210 feet of propagation could be received on a cable. Additionally, since this cable was coiled, it had periodic coupling to itself. In the A-scan shown in Figure 32, the signal first propagates through the 70 feet of cable producing the large signal shown with the left arrow, after reaching the receiver the signal then bounces between the receiver and transmitter once more. The small pulses shown to the left of the 70 feet received through transmission are energy that jumped across contact points in the coiled cable. Figure 33 shows the spectral response for the low order modes received using a spectrum analyzer. The spectrum analyzers response uses a band pass filtered continuous wave as opposed to the Ritec's spectral response, which is based on a time-gated, quadrature-phase heterodyne receiver.

An experiment was performed where a notch was cut in a perimeter wire and a .2-inch dual element transducer was placed on individual wires of the non-embedded/un-tensioned seven strand wire cable. The cut was only detected when the transducer was placed on the cut strand. The results of this experiment are shown in Figure 34.

Figure 32. $441 \mathrm{Khz}$ narrow band signal propagating in a non-embedded and non-loaded strand.

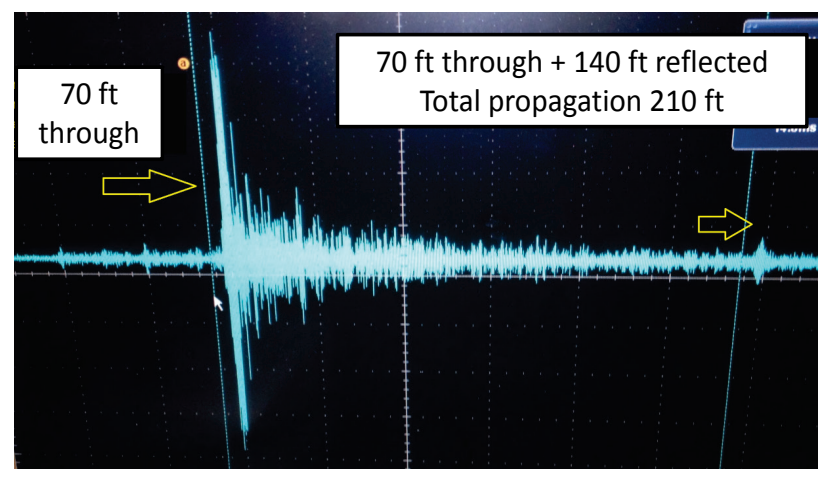


Figure 33. Continuous wave based low order spectral response for coiled cable test.

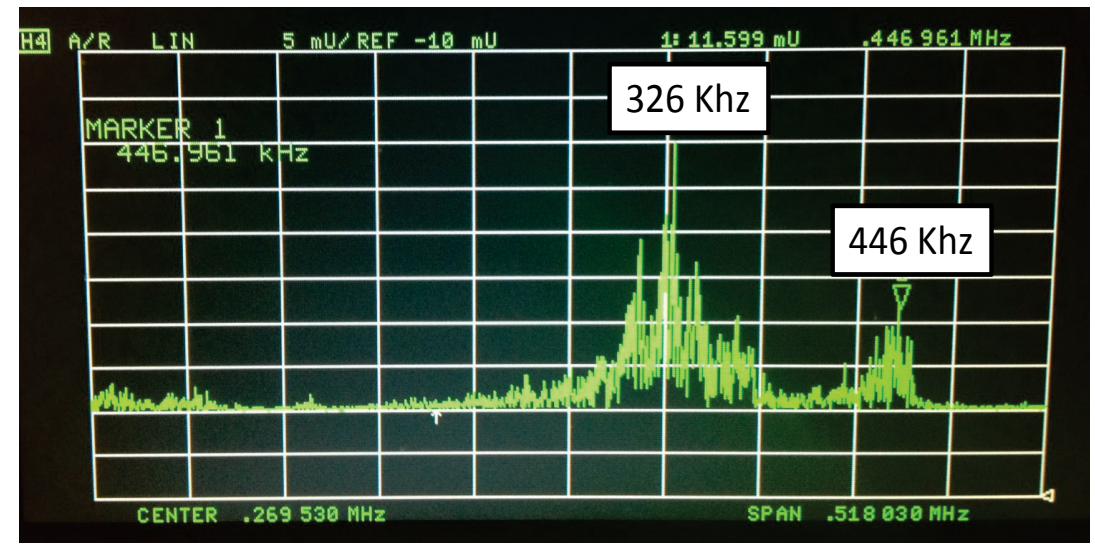

Figure 34. Cut detection in free strand using individual wire coupling.

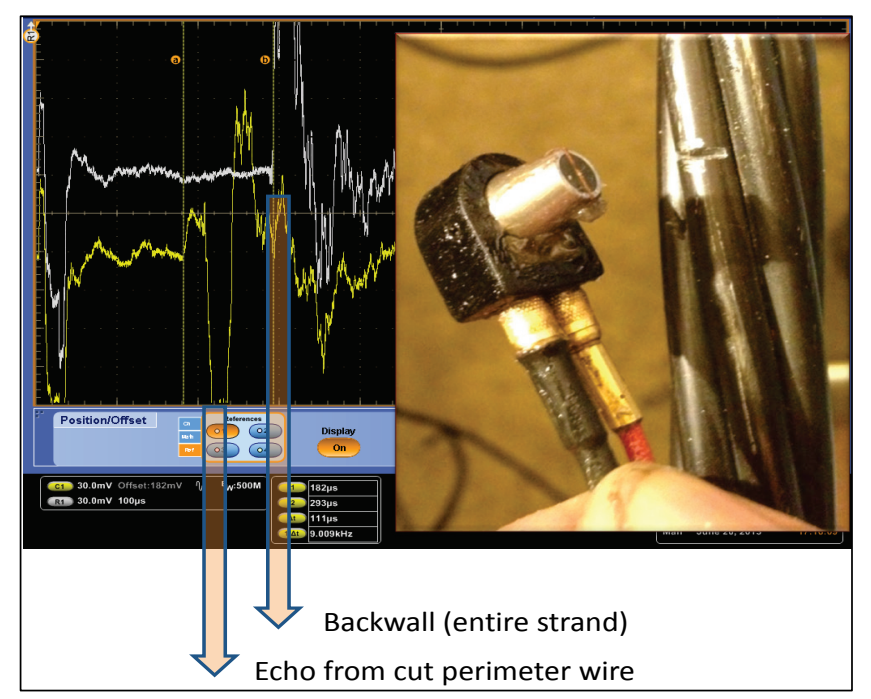

\subsubsection{Embedded Measurements:}

A number of cable sections were grouted in PVC pipe to look at the effect of embedding material on un-tensioned cables. Figure 35 shows the comparison of the propagation of the embedded rod and cable narrow band low-loss frequency modes. When the cable is not under tension, the seven strand wire cable behaves like seven individual waveguides. This effect is even more pronounced at higher inspection frequencies. A comparison of spectral modes and diameters is also shown in Figure 35. The calculations shown in this figure illustrates that the frequency spacing and diameter ratios are both 6.5 (note this is the individual wire diameter not the entire strand). 
Figure 35. Comparison of high frequency modes for embedded cable and rod (no tension).

Comparison of low-loss frequencies for embedded cable and rod

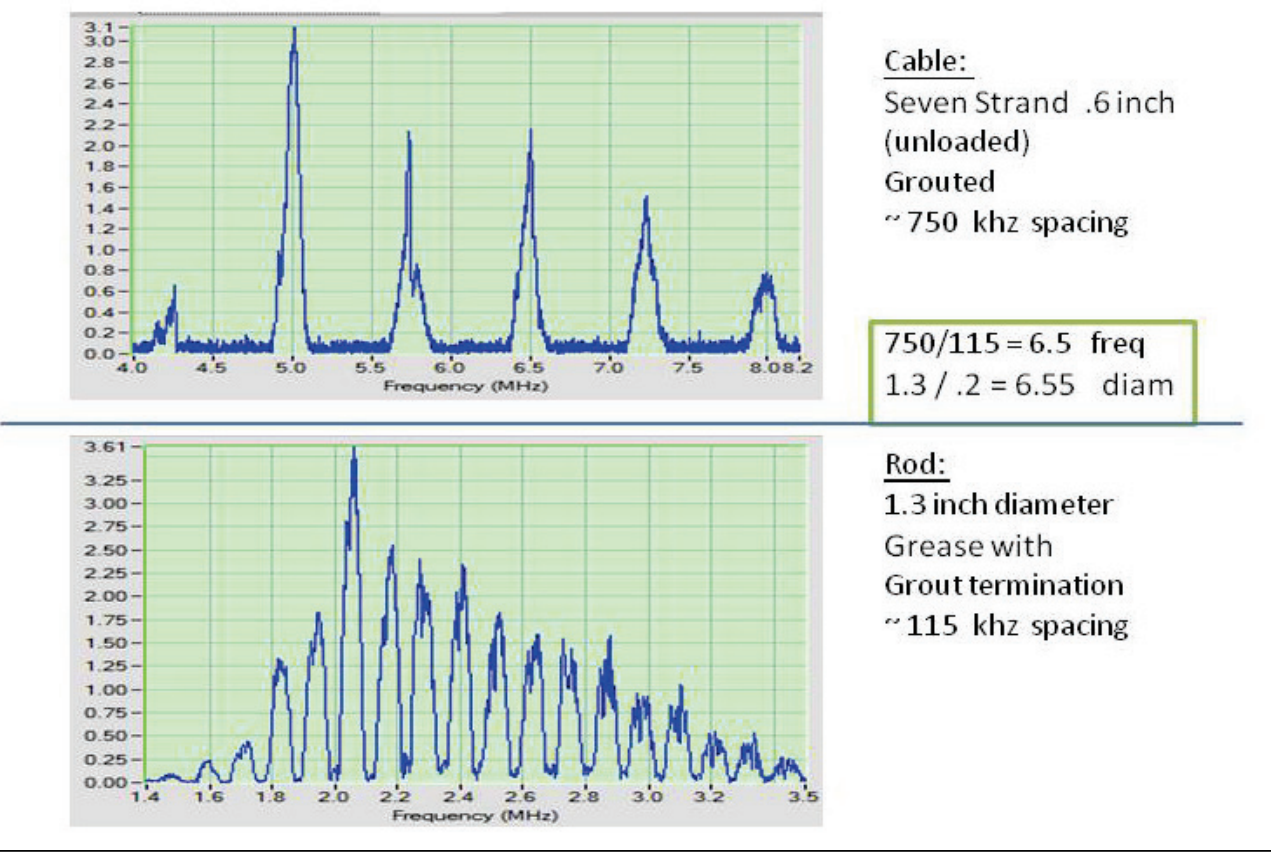

Figure 36 shows the embedded cable with ultrasonic reverberations in the embedded cable at an inspection frequency of 5.6 MHz. The total propagation distance shown here is 12 feet. In order to get a better handle on the dispersion influences of the seven strand wire cable, a perimeter wire was removed and embedded in a sulfur potting compound. A $2 \mathrm{MHz}, 0.2-$ inchdiameter transducer was glued to this wire to investigate variables of its spectral response. Figure 37 shows the configuration of the sulfur embedment.

Figure 36. Phase detected 5.6 MHz Ultrasonic Pulse Echo using magnetically coupled transducer on embedded cable.
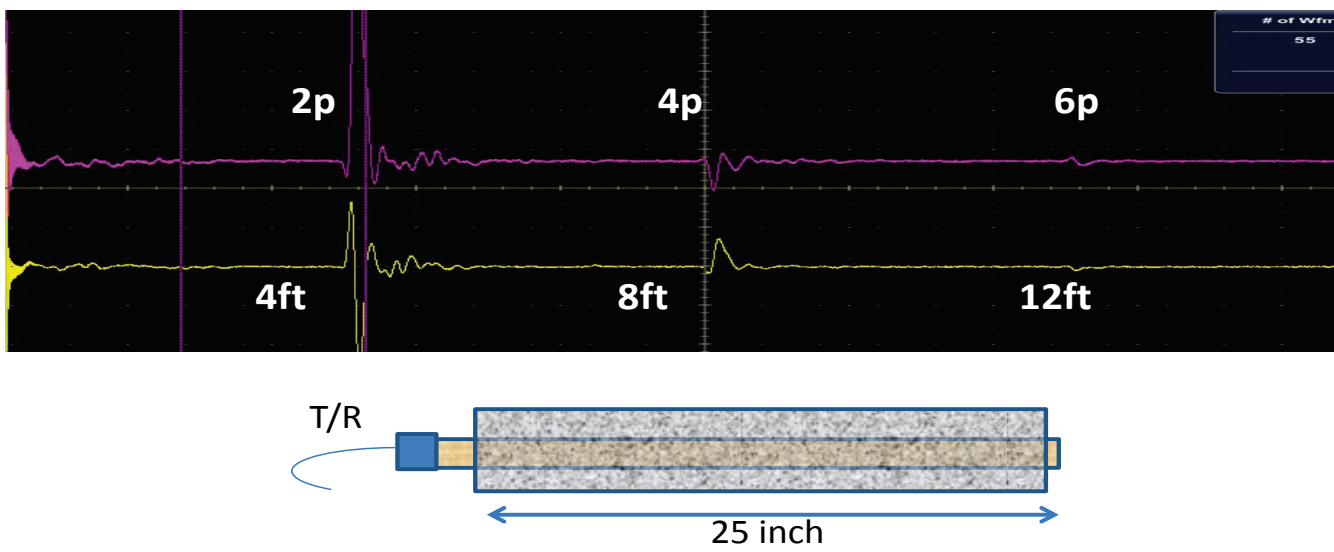
Figure 37. Helical (perimeter) wire embedded in potting compound.

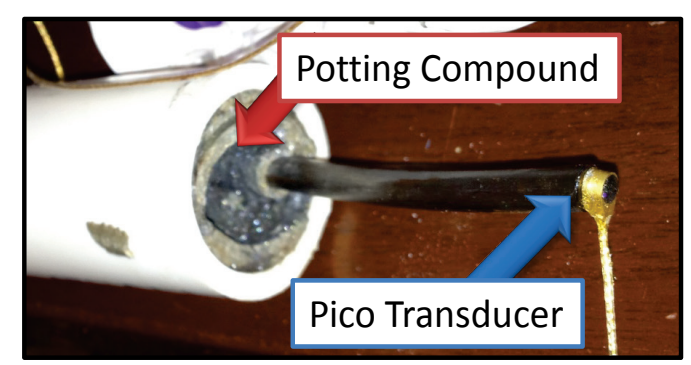

The Ritec SNAP System ${ }^{1}$ allows narrow band spectral scanning by setting time domain based gates in the received A-scans. In the configuration shown in Figure 37, it was observed that the reflected modes appeared to be significantly separated in time to the degree that they did not overlap. Rather than just setting a wide analysis window, two separate windows were configured to better understand this observation. The spectral response of these two integrator windows for the ultrasonic pulse echo configuration is shown in Figure 38. The later arrival of the higher frequency mode is unexpected and points towards an unexpected complexity for a single embedded helical wire. It is possible that this effect may be tied to scattering effects from the roughly 8 degree incidence angle on both ends.

Next, an experiment was constructed on a grouted seven strand wire cable where Pico transducers were used to look at the spectral differences between the center and perimeter wires through transmission. The results of these measurements are shown in Figure 39. In addition, the through transmissions vs. reflection spectrums are shown for the perimeter wire. Note that there are again differences here possibly due to the interface angle caused by the orthogonal cut of the helical wire.

Beard et al. (2003) took a detailed look at embedded and un-tensioned seven strand wire cables. Their experiments and modeling confirmed different propagating frequencies due to the slightly different wire diameters. The center (king) wire is $5.5 \mathrm{~mm}$ and the outer (helical) wire is $5.2 \mathrm{~mm}$, for which they calculate low-loss $\mathrm{L}(0,8)$ modes of $4.76 \mathrm{MHz}$ and $5.06 \mathrm{MHz}$, respectively. These experiments also showed the perimeter wire to be 3 times more attenuative, which they believe to be attributable to increased losses through the grout coupling, as well as curvature and cut angle incidence effects of destructive interference and mode conversion to

1 Ritec SNAP System, Ritec Inc., Warwick, RI. 
Figure 38. Embedded helical wire echo results from various gates.

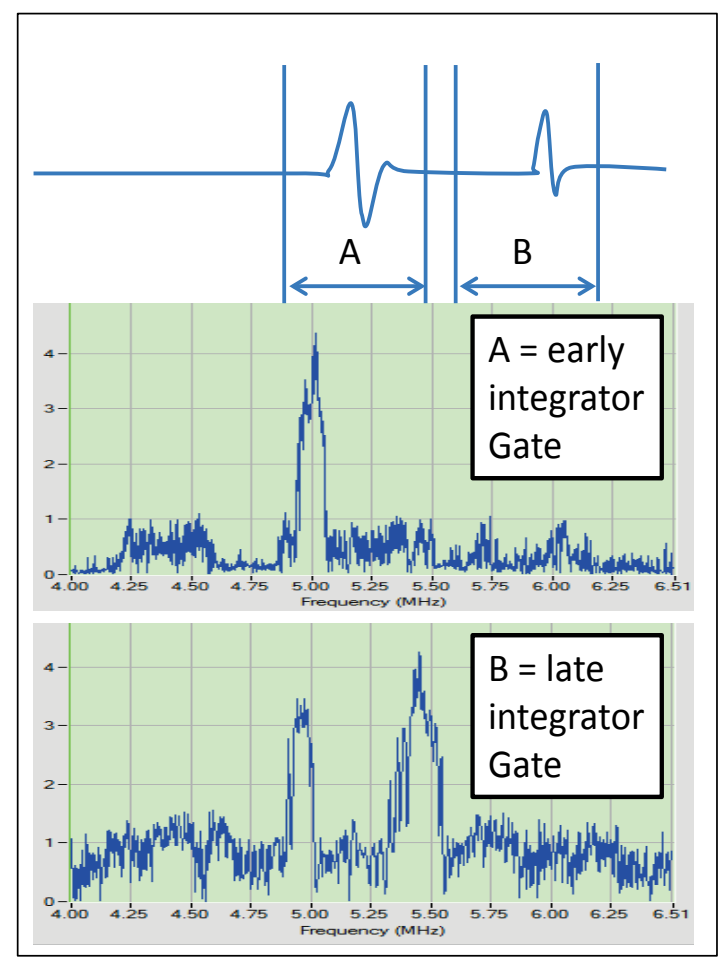

Figure 39. Spectral shifts observed between perimeter helical wire and center king wires.

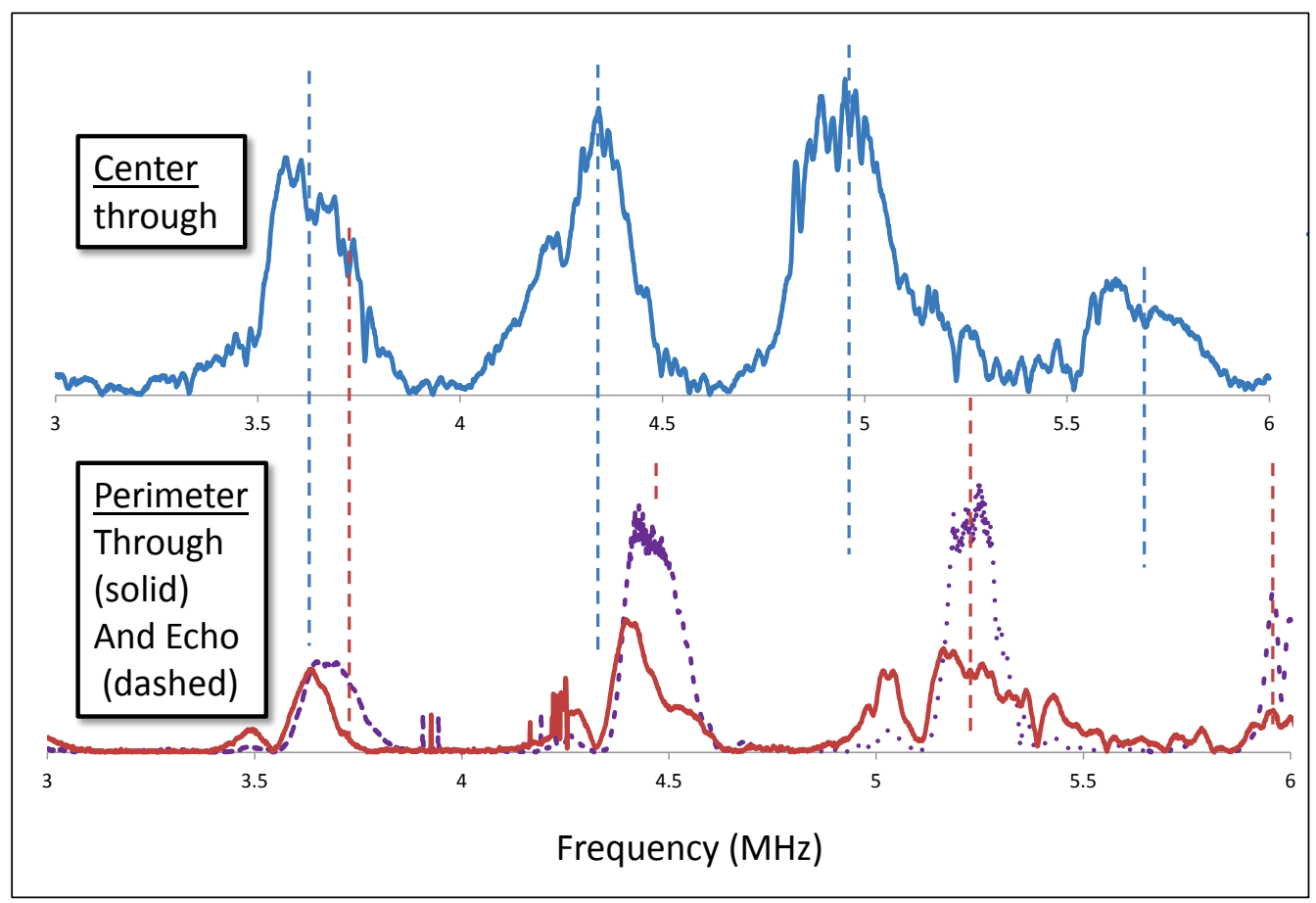


non-propagating modes. They also found the optimum low-loss mode to be $\mathrm{L}(0,10)$ centered around 6.5 MHz. These results only partially agree with our observations; for example, we found the optimum frequency to be lower (Figure 35 (cable)) and the overall attenuation to also be somewhat lower.

\subsection{Test Fixtures and Loading Mechanisms}

Published literature and laboratory investigations clearly point to the need for embedded cables in grease/grout and to control their load. Because grout embedment requires many dedicated specimens to be cast at varying loads, grease embedment was used in these studies so that the influence of tension variation could be considered on an embedded cable. Both a large scale test bed and a small scale test frame were constructed for the studies in this project. The large scale test bed is shown in Figure 40 and includes 6 single strand ports and 2 multistrand anchor heads. All conduits have side access to allow inclusion of grease, grout, or other media to embed the cable. A DSI ${ }^{1}$ hollow core rod tensioner was retrofitted with a standoff chair and set of slotted shims to allow tensioning and removal of tension on the large scale test bed. A close up of this is shown in Figure 41. It was also determined that a smaller and better load controlled test frame was needed. Towards this goal, an available testing frame, load cell, and hydraulic ram were integrated to create the open metal test frame shown in Figure 42. Note the applied load shown in Figure 42 is 18,700 lbs of tension.

Figure 40. A 15-foot concrete test bed after form removal.

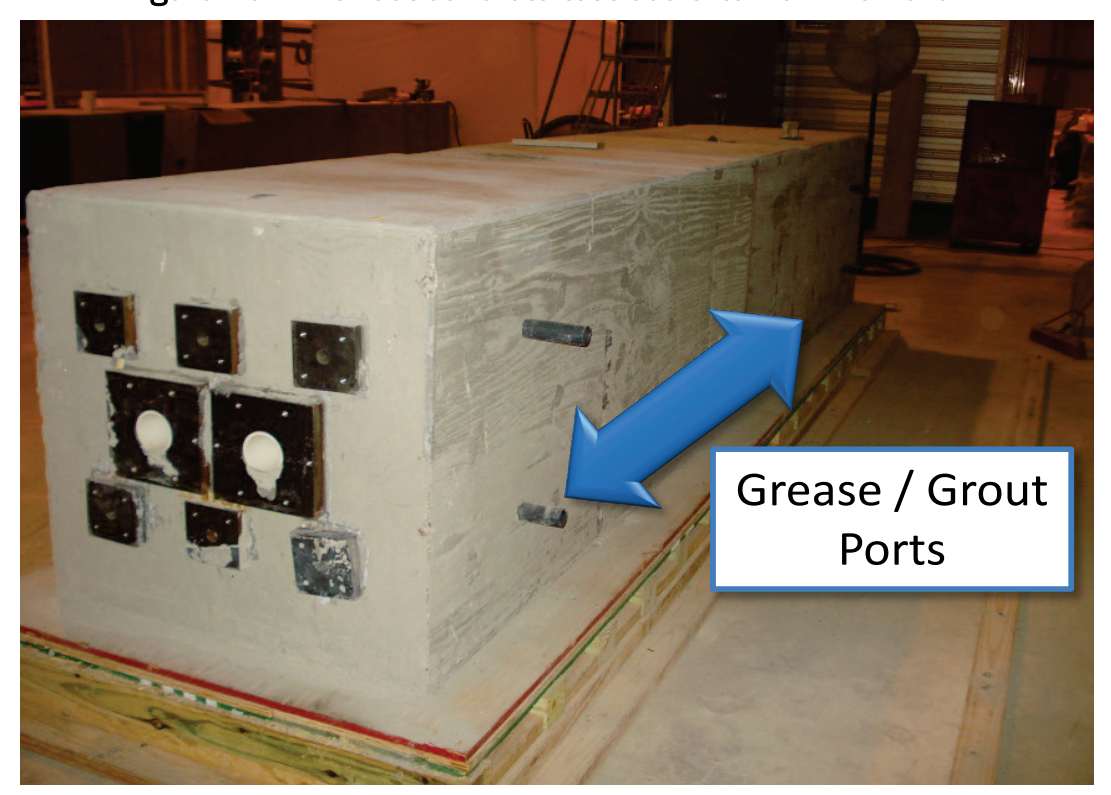

1 Dywidag-Systems Int. (DSI), http://www.dsiunderground.com 
Figure 41. Tensioner being used on concrete cable test bed.

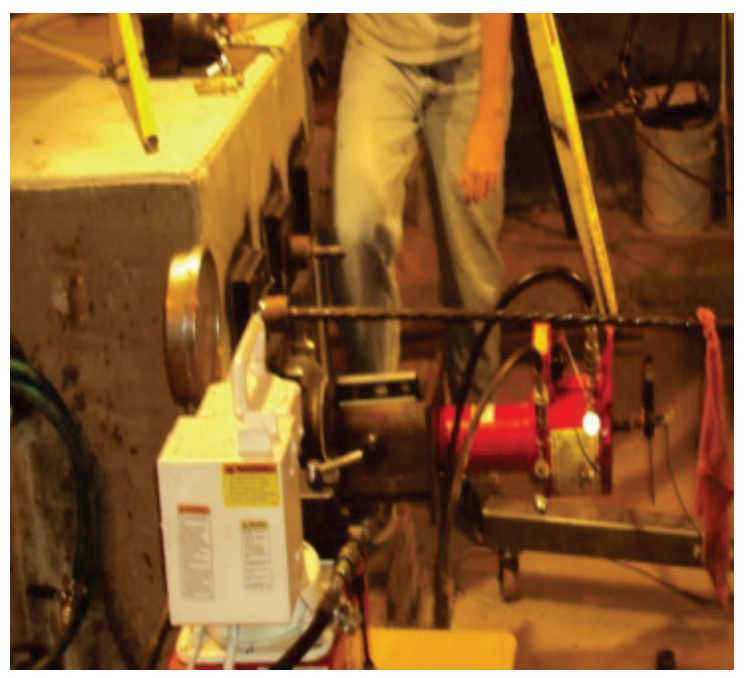

Figure 42. Small hydraulic load frame with fine control of applied tension.

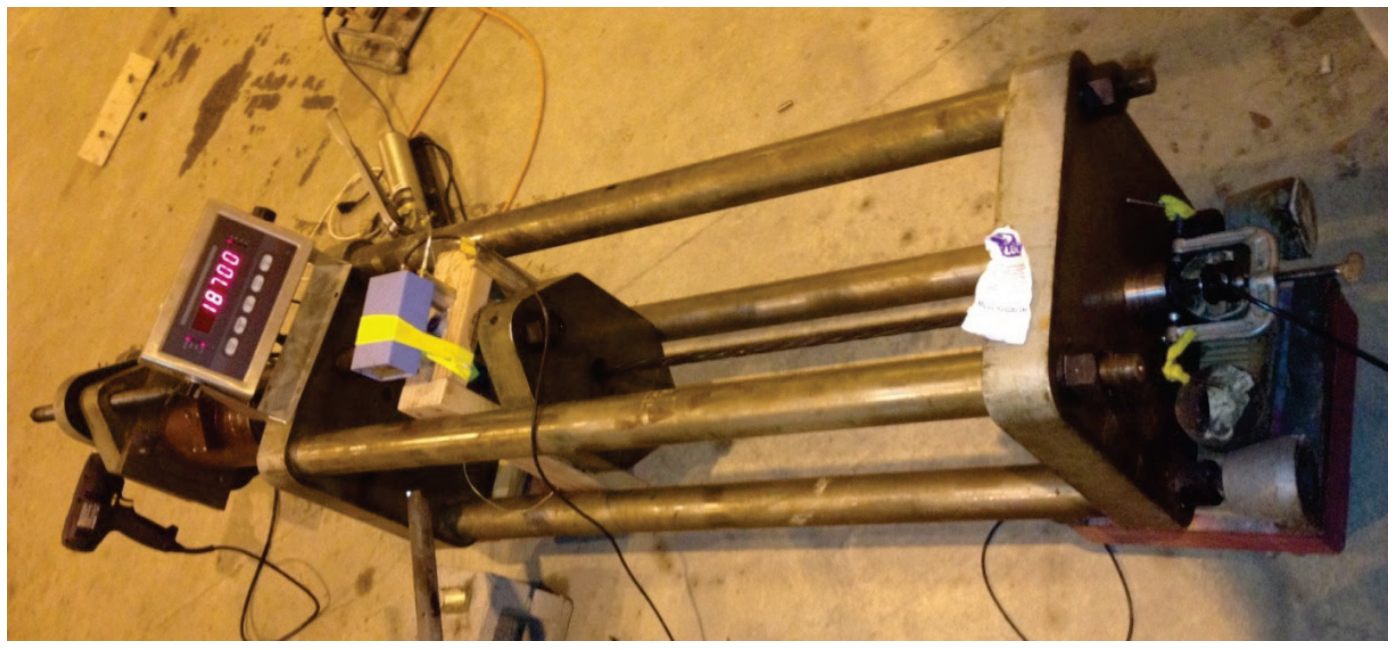

Two strands were tensioned in the concrete test bed (Figures 40 and 41). One of the two was encased in no-ox grease. It was observed that a strong 1.4 MHz mode existed in the through transmission spectrum of the strand, which was encased in grease. While this has been observed in nontensioned cases like the recovered John Day Anchor Heads with attached strands, it appears more consistently in tensioned cables. One issue that may be related to the consistency of observing this mode is that it appears dependent on how the transducer is coupled to the strand. Optimum generation and reception appear when the transducer is coupled to both the center and perimeter wires. This mode was observed and significantly attenuated by embedment in grease and grout, although at a lower rate than the fundamental modes. 
Figure 43 shows the received spectrum of the lower order modes and the approximately 1.4 MHz mode in the tensioned and ungreased 15-foot test bed. Another interesting observation of this mode, which indicates it may be torsional, is that it appears to be non-dispersive. In guided wave testing, this non-dispersive characteristic is often associated with the propagation of the fundamental torsional wave. This is illustrated by the top A-scan shown in Figure 44, in which the phase detected envelope retains its original shape after approximately 10 feet of propagation. The signals shown in Figure 44 are as follows:

- the top (yellow) trace is the phase detector output,

- the second from top (pink) trace is the reflected radio frequency signal,

- the green curve is the gain function for the time compensate gain circuit (to be discussed later), and

- the bottom (blue) trace is the post time compensated gain output.

Using the test frame shown in Figure 42 with the wire tensioned to 18,000 lbs and coated with grease, a broadband through transmission was made. The high energy source was a $\mathrm{CO} 2$ powered BB-Gun with a coupling tube and shroud; the BB directly struck the center wire and was trapped afterwards. On the receiving end, a Pico transducer ${ }^{1}$ was glued directly to the center (king) wire. Various time-frequency visualizations were explored in the visualization of this data with the Morlet transform (Grossmann and Morlet 1984), providing the best results for practical computational times. This data shown in Figure 45 illustrates various propagating modes in the cable. In addition to the low order modes, which are still present because of the short length and grease embedment, the higher order modes and their respective velocities (i.e., arrival times) are also shown. The spectrum shown on the left illustrates relative strength of both the approximately 1.4 and $5 \mathrm{MHz}$ modes (note that the impact source and the receiver response both bias this response towards the lower frequencies).

In the time-frequency visualization (Figure 46), the parameters of the Morlet Transform have been adjusted so that only the dominate propagation modes are visualized. In general, time-frequency transforms are selected based on a balance of resolution detail, transform artifacts, and signal characteristics. Some of the transformations tailored towards

\footnotetext{
1 Physical Acoustics Corporation, Pico transducer, Princeton Jct., NJ.
} 
narrow band signal visualizations were attempted with Ritec data; however, signal sampling requirements and computational expense proved problematic for the MATLAB transform code being used: the Time-Frequency Toolbox (Auger et al. 2005).

Figure 43. Low order modes and approximately $1.4 \mathrm{MHz}$ mode in a tensioned cable.

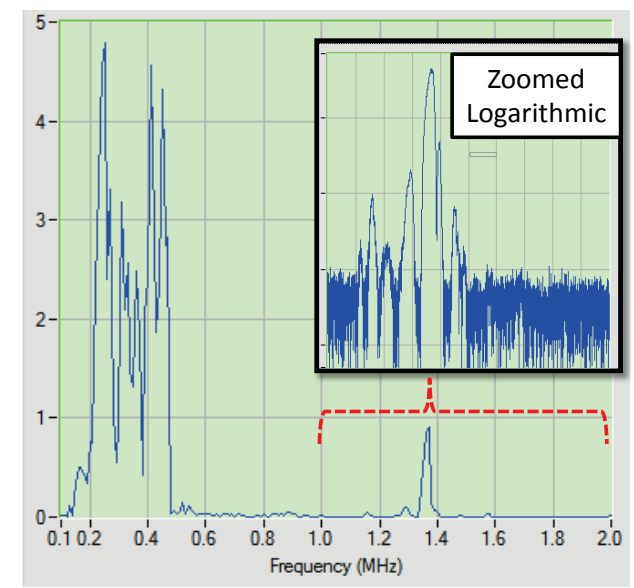

Figure 44. Reflection of approximately $1.4 \mathrm{MHz}$ mode through 5 -foot cable section.

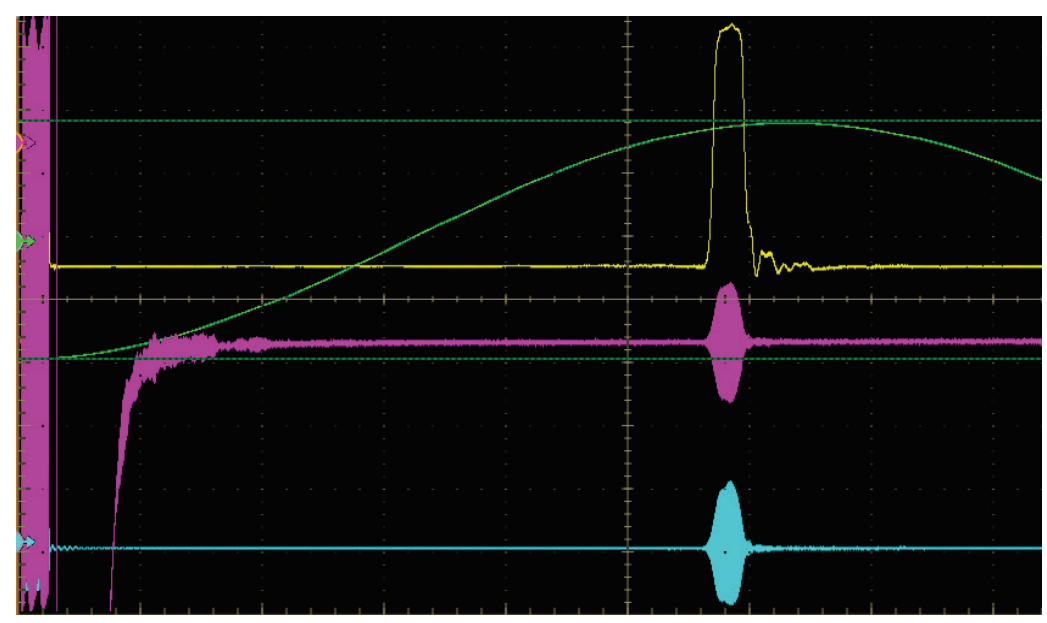


Figure 45. Time-frequency visualization of propagation in a tensioned and grease embedded cable.

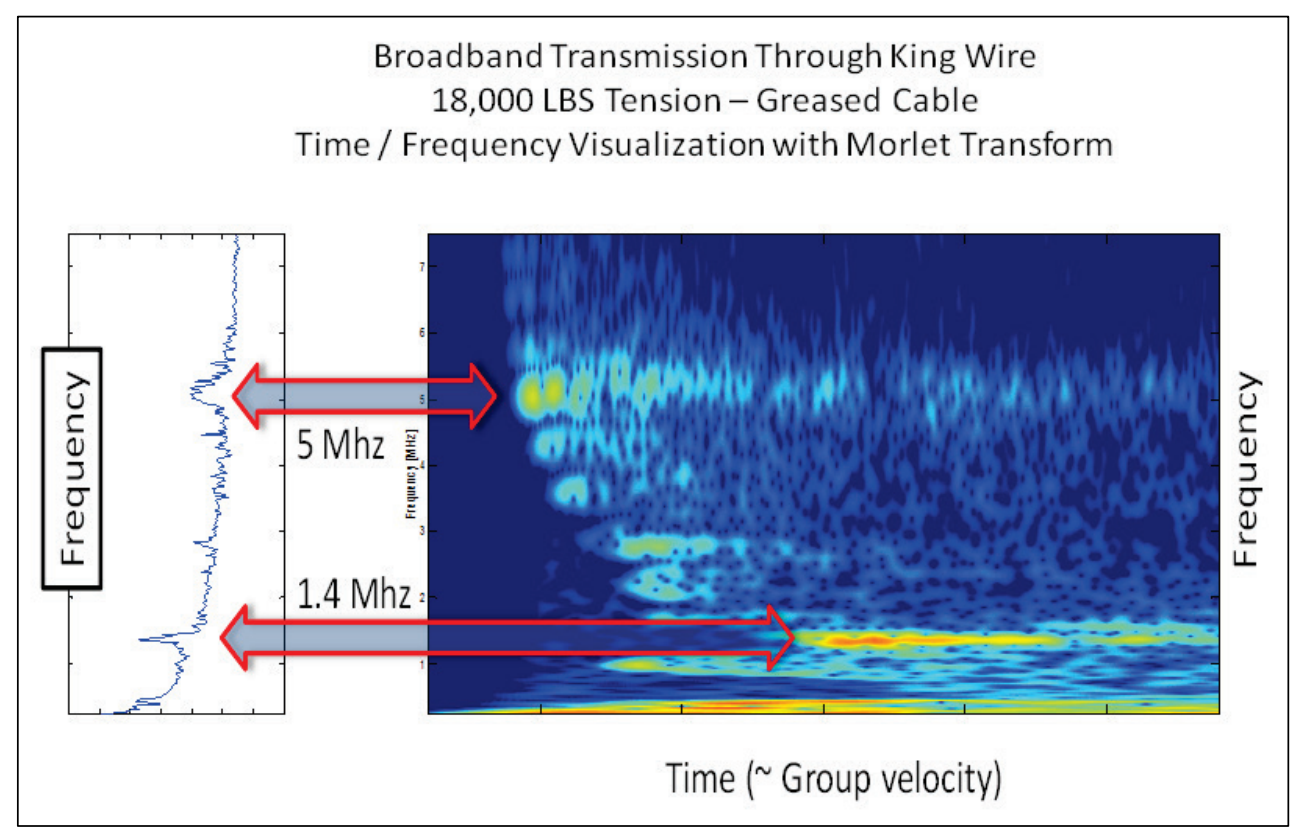

Figure 46. Alternate time-frequency visualization from the same data in Figure 45.

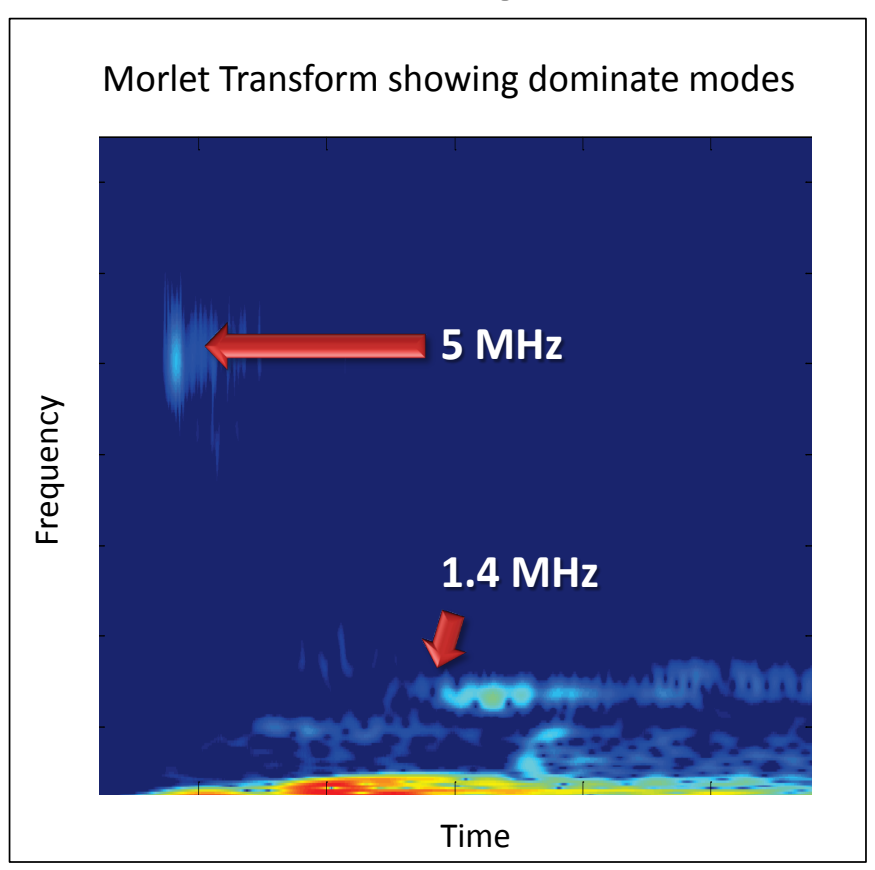

In Figure 47, a good comparison is observed between a narrow band Ritec scan of the cable and the broadband time-frequency visualization. This data shows the same discrete modes of propagation even though the Ritec scan was made on an un-tensioned cable. This is attributable to the fact that both measurement configurations are dominated by center wire propagation. 
Figure 47. Comparison of un-tensioned energy velocity from broadband stimulation (impact bottom) and narrowband (Ritec sweep - top) in center wire propagation.

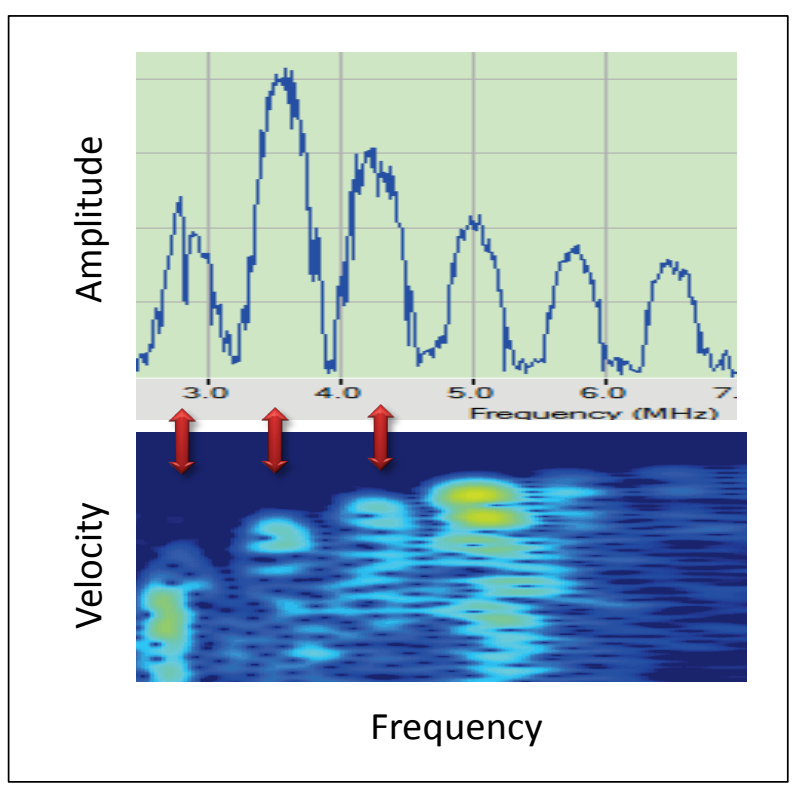

Moving from the mechanical broadband test on the load frame to more controlled narrowband measurements, through transmission and reflection data was collected before and after coating the exposed strand with a thick layer of grease. The results from that test illustrate how grease attenuates the non-dominate propagating modes in the cable. These results are shown in Figure 48.

Figure 48. Suppression of extraneous ultrasound by grease embedment (18,000 lbs tension).

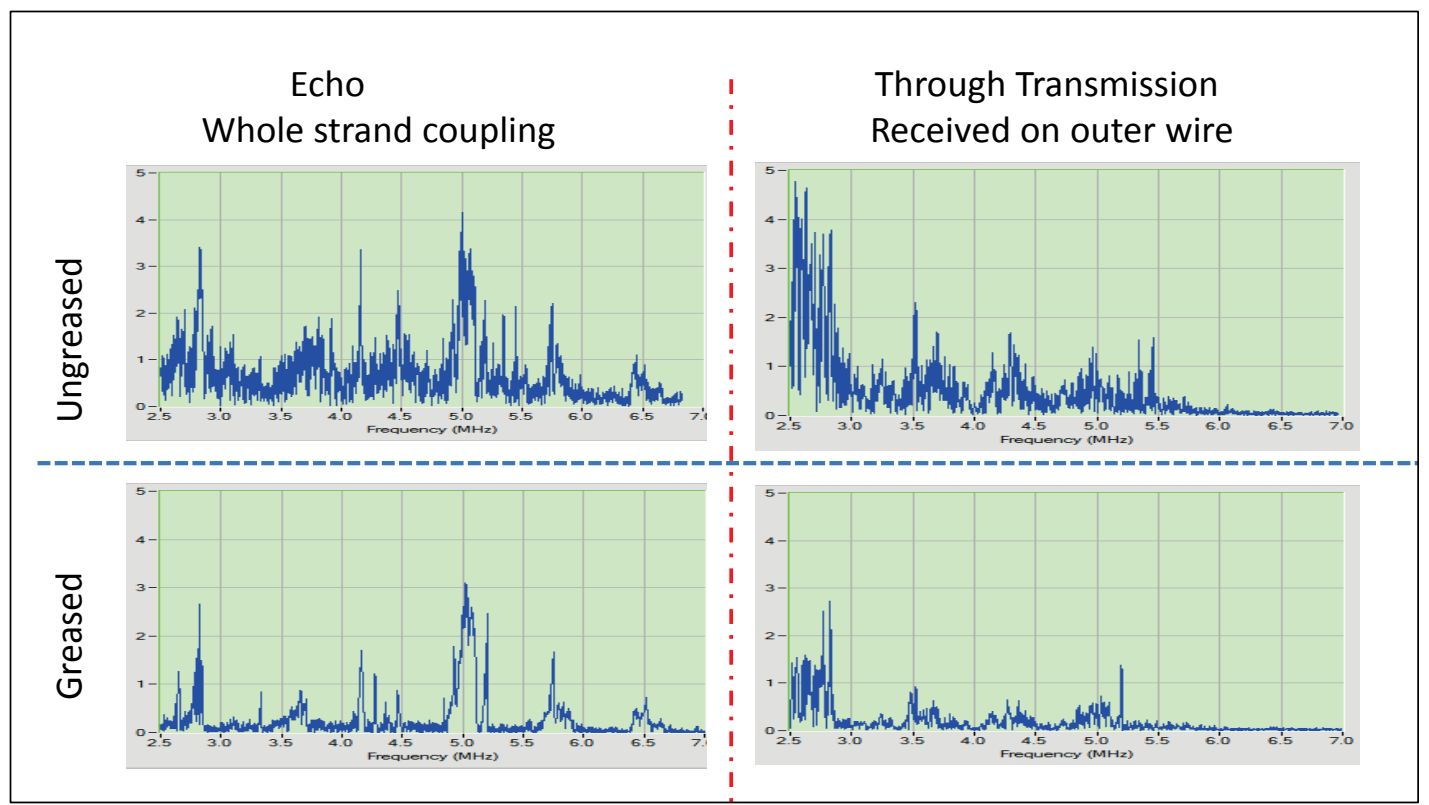


Figure 49 shows reflection data collected at two levels of tension. As expected, the inter-wire coupling increases and results in an increase in attenuation across all modes. In Figure 50, a more detailed scan is performed of the approximately $1.4 \mathrm{MHz}$ propagation mode at 27,000 lbs of applied tension.

Figure 49. Attenuation increase with tension due to inter-wire coupling.

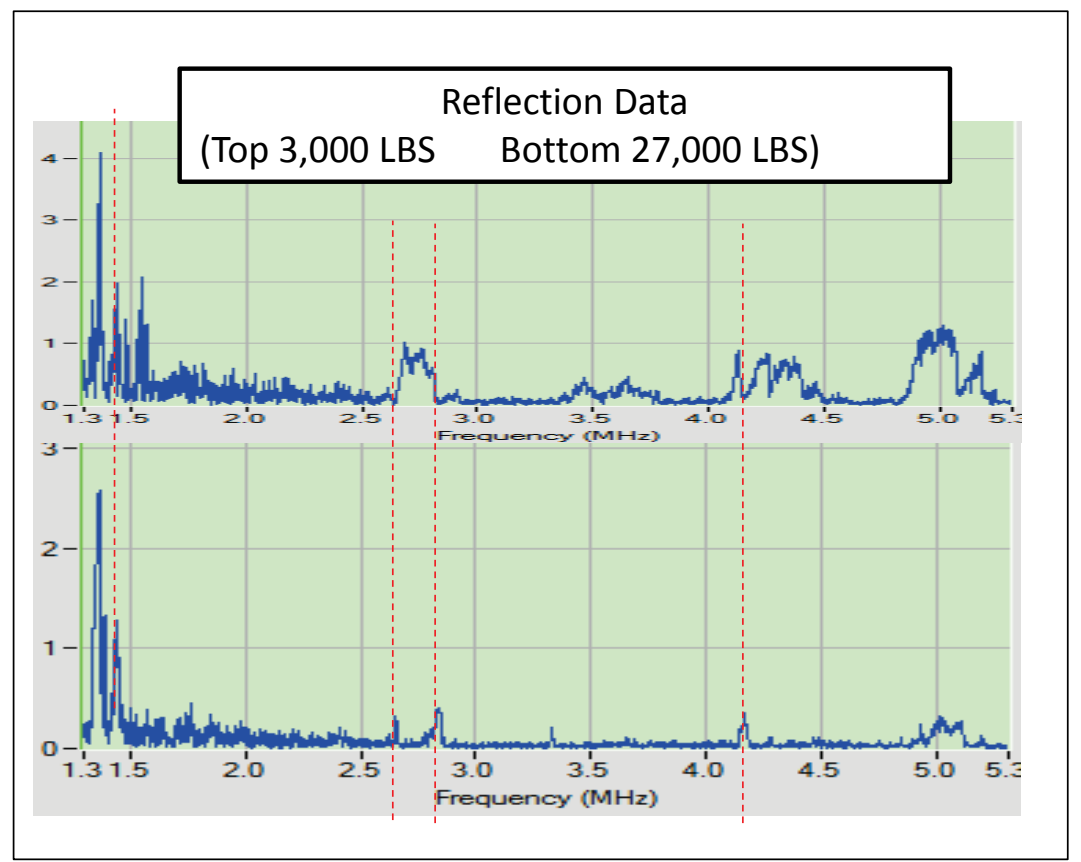

Figure 50. Scan of $1.4 \mathrm{MHz}$ mode at $27,000 \mathrm{lbs}$ of tension with grease embedment.

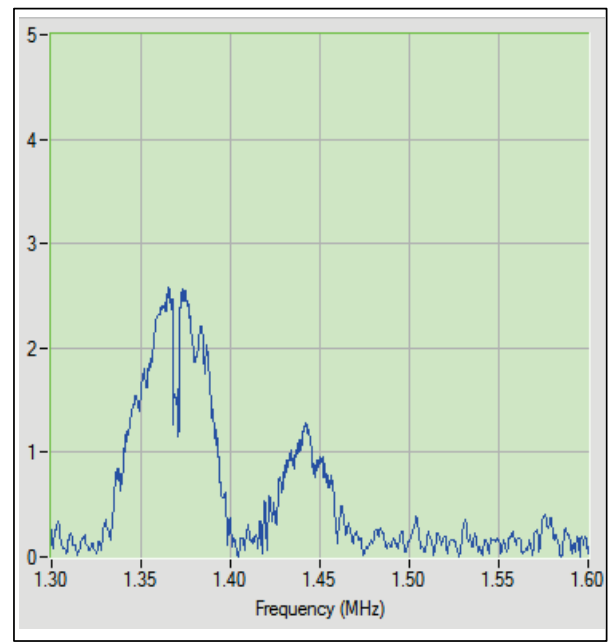




\subsection{Current system configuration and optimizations}

The system calls for an extremely demanding in-situ inspection of seven strand wire cables. Optimal low-loss modes occur in a range from 1.2 to 6.5 MHz. Even in these optimal modes, the attenuation rates are high and the limits of piezoceramic technology are pushed. Unlike low frequency ultrasonics, which can handle very high stimulation voltages, high frequency crystals are thinner and have lower dielectric breakdown and depoling voltages. Additionally, the cable presents only a very small coupling area of .2 or .6 inch diameter depending on the transducer coupling approach (i.e., single wire or whole strand). Towards the goal of breaking past this limit, new technology in the form of PMN-PT crystals (Luo et al. 2009) have been ordered for this project. Due to the very long fabrication lead time of 2-3 months, these materials were not received in time for inclusion into this report. The magnesium doped variant of these crystals is expected to produce an overall closed loop system gain of a factor of 8 improvement, which should increase the total possible inspection distance. Of the evaluated off-the-shelf transducers studied, a magnetically coupled .5-inch-diameter PZT crystal provided the best overall response and consistency of coupling to the wire. The .2-inchdiameter Picoducers ${ }^{1}$ are superior in their ability to couple directly to only an individual wire; however, these transducers are fragile and require special mounting consideration if they are to be integrated into any kind of field array system. Lastly, a clamped $5 \mathrm{MHz}$ Accuscan type transducer from Olympus ${ }^{2}$ provided the best broadband sensitivity though coupling performance was inconsistent and sometime affected by the clamping process itself as the sides of the cable were squeezed.

A number of time compensated gain circuits were evaluated. Optimum performance was achieved with one that had a $60 \mathrm{~dB}$ overall gain capability with $20 \mathrm{~dB}$ of the gain function being attenuation capability. These time compensate gain (TCG) circuits use arbitrary gain functions to optimize the response across the A-scan signal. This allows the application of both high power transducer stimulation and high gain at greater depths without the associated issues of ultrasonic backscatter in the near field or weak reflections at greater distances. This is a dynamic range system improvement. The optimal integration of this component into the Ritec system is shown in Figure 51. The optimal gain function tended to be a

\footnotetext{
1 Mistras Group, Inc., Princeton Jct., NJ.

2 Olympus NDT Inc., Waltham, MA.
} 
sine wave that started at -90-degree phase at pulse generation and ended with 90-degree phase over the maximum receivable depth. Time-gain application is shown in Figure 52, where additional inspection length is achieved on a non-saturated comparison. The top line is the TCG output and the middle trace is the raw output without TCG application.

Figure 51. Optimal system configuration of Ritec and TCG components.

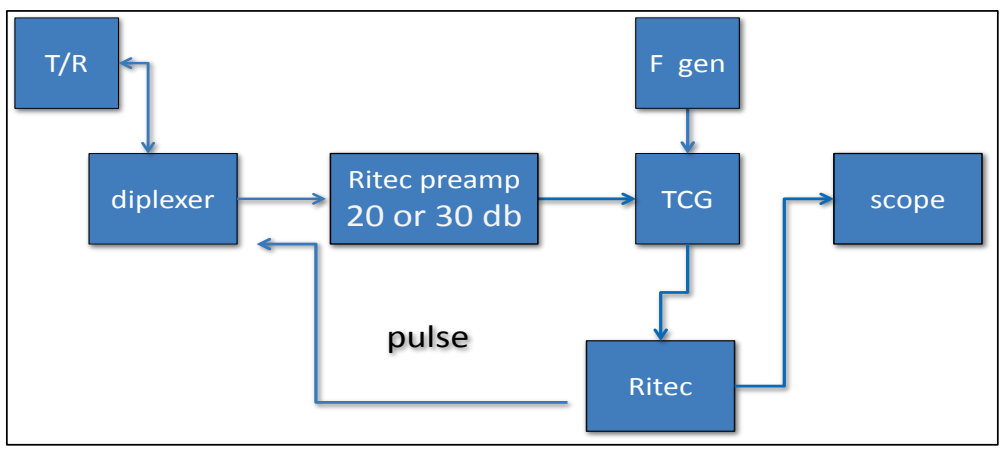

Figure 52. TCG application to reverberation in a 2-foot section of grouted cable.

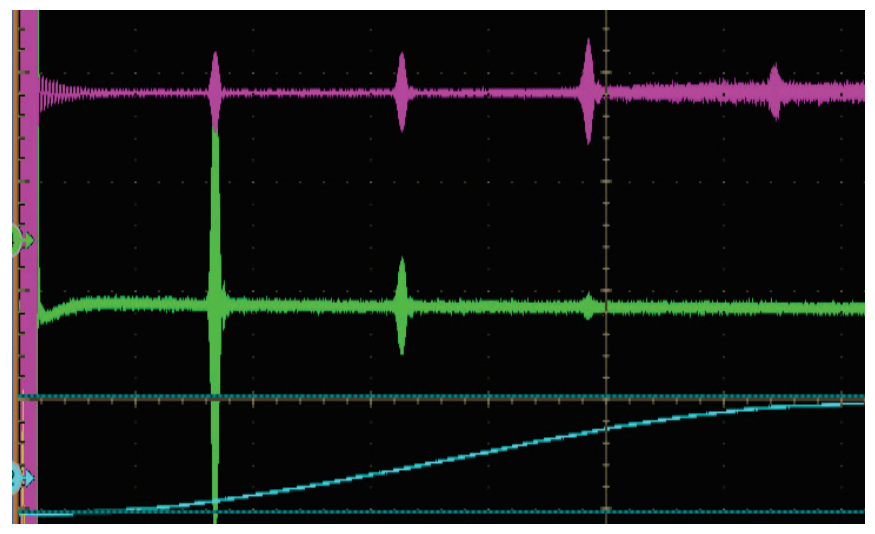

Additional system aspects and their contribution to performance are described in Table 2.

\subsection{NDT Results and Conclusions}

Investigations revealed that for a single point access of embedded seven strand wire cables, higher order low-loss modes show the most promise for detecting defects and characterizing damage. The high attenuation rates combined with typical post tension cable lengths makes the detection of the far end of cable reflection unlikely. This creates a problematic NDT scenario of not having a reference marker. This reference marker is typical 
Table 2. System Requirements.

\begin{tabular}{|c|c|}
\hline System Component or Method & Benefit or Contribution \\
\hline Signal averaging & $\begin{array}{l}\text { Reduction in non-stationary noise, which is } \\
\text { largely due to high system gain }(\sim 100 \mathrm{db}) \text {. }\end{array}$ \\
\hline Narrow band signal (70-200 cycles) & $\begin{array}{l}\text { Concentrates energy in desired propagation } \\
\text { mode, and improves response of PZT } \\
\text { transducer. }\end{array}$ \\
\hline High output/sensitivity PZT or PMN-PT & $\begin{array}{l}\text { Maximum performance transduction } \\
\text { technologies. }\end{array}$ \\
\hline $\begin{array}{l}\text { Time corrected gain amplifier with nonlinear } \\
\text { ramp }\end{array}$ & $\begin{array}{l}\text { Extends detectability to entire rod length, } \\
\text { while still allowing high gain and high pulsar } \\
\text { voltages. }\end{array}$ \\
\hline Medium damped transducer & $\begin{array}{l}\text { Maintains high output levels and sensitivity, } \\
\text { while eliminating undesired in transducer } \\
\text { reverberations experienced with low damped } \\
\text { (high response) transducers. }\end{array}$ \\
\hline Superhetrodyne phase detector & $\begin{array}{l}\text { Improved detection of narrowband signal } \\
\text { amplitude and phase information in the } \\
\text { presence of stationary noise. }\end{array}$ \\
\hline Very fast recovery preamplifier & $\begin{array}{l}\text { Prevents preamplifier saturation of diplexer } \\
\text { output from masking rod defects that may be } \\
\text { located near the transducer. }\end{array}$ \\
\hline High pass and low pass filtering & Reduction of unwanted noise sources. \\
\hline Tunable diplexer & $\begin{array}{l}\text { Optimizes pitch-catch operation and takes } \\
\text { advantage of limited injection area. }\end{array}$ \\
\hline $\begin{array}{l}\text { On-site, Pre-Inspection Scanning with gated } \\
\text { narrowband signals }\end{array}$ & $\begin{array}{l}\text { Allows determination of optimum low-loss } \\
\text { inspection modes at each site if coherent } \\
\text { backwall exists. }\end{array}$ \\
\hline
\end{tabular}

in ultrasonic NDT and provides assurance of coupling integrity, inspection range, and defect severity. It is clear that any comprehensive study towards the goal of the NDT of seven strand wire cables needs to address grout embedded specimens of varying tension and curvature. An overview and recommendation for future efforts is described below.

Specific challenges related to the NDT system development for seven strand wire cable are outlined in Table 3.

An additional investigation of the effects of grease as a boundary media is underway and being conducted by FBS Inc. ${ }^{1}$ This research effort is being led by Professor Joseph L. Rose of Pennsylvania State University, one of the few researchers who investigate high frequency, guided waves.

1 FBS Inc., State College, PA. 
Table 3. Challenges of the NDT system development of seven strand wire cables.

\begin{tabular}{|l|}
\hline Challenge \\
\hline High attenuation rates \\
\hline Difficult coupling \\
\hline Tension influence \\
\hline Limited injection area \\
\hline Attenuation and frequency differences between inner and outer wires \\
\hline Cable curvature in multistrand systems \\
\hline $\begin{array}{l}\text { Influence from bulkhead, wedge, and tension variation between injection point and inspection } \\
\text { range }\end{array}$ \\
\hline
\end{tabular}

The current guided wave knowledge gained in the ERDC test bed, combined with the research being performed by Professor Rose, will form the starting point for the next phase of a field deployable NDT developmental effort. This development will make use of the ordered PMN-PT transducer material. Techniques focused on pitch-catch implementation such as phased arrays, coupling strategies, leakage effects, nonlinear measurements, and time reversal methods will be evaluated. 


\section{Overall Results and Conclusions}

Technical results and conclusions from the non-destructive system development phase are given at the end of Chapter 3. Section 4.1 and 4.2 will briefly give an overview of past and current efforts as well as describe the path forward that is planned.

\subsection{Summary of NDT Findings to Date}

Older post tension systems are a significant area of concern due to the fact that they were constructed with standards and methods considered unacceptable by today's standards. Additionally, these inferior and less corrosion resistant systems have now been in service for decades and many have undergone deterioration to the point of partial or complete failure. The complexity of the seven strand wire cable, coupled with its restricted accessibility due to embedment, creates a very challenging demand for inspection and assessment technologies. Additionally, inspection methods which may one day work for bridges and other shallow covered seven strand wire cables are not likely to translate well to mass concrete applications. Generally, these systems are more prone to fail at or near the anchorages due to factors such as stress concentration, poor corrosion protection near the wedge, and increased susceptibility to environmental mechanisms. Inspection technologies providing feedback on even the first few meters under the anchor head would provide valuable condition information. Case-by-case consideration of seven wire strand systems can yield localized inspection solutions. For example, at John Day Lock and Dam where construction problems produced poor grout and ungrouted/capped vent tubes for large water migration, moisture probes under the anchor heads will likely provide valuable information on the degree to which the various anchor heads are being affected. This information could be correlated with past pull testing to further improve the overall assessment. In cases like Marseilles Dam, where barge impact may have damaged protruding post tension anchorages of the tainter gates, measurements such as acoustoelastic tension assessment of the protruding beams, can likely help quantify and characterize condition of the inaccessible portions of the cable.

A global NDT solution, which operates on the exposed end of the cable, will require additional research and development efforts before being 
realized. The ultrasonic guided wave NDT development effort performed in FY13 demonstrated the influence of condition parameters such as embedment and tension that identified candidate inspection frequencies for future development, and identified system performance of various components such as time corrected gain, magnetic transducer coupling, and heterodyne phase detection. This research has helped lay the groundwork necessary for future development of a broadly applicable NDT tool for seven strand wire cable inspection.

\subsection{Summary of progress relating cable condition to performance}

This work unit effort has three objectives. The first objective is to conduct fundamental research leading to the correlation of cable condition with an NDT measurement. Chapter 3 discussed the ongoing accomplishments of this fundamental research effort and laid out future research direction.

The second research objective is the creation of condition estimation tools based on attainable risk and condition factors for in-situ seven strand wire cables over time. Understanding how corrosion material loss affects cable performance remains a key aspect of this project. Chapter 2 summarized the process being developed from initial pull test results for seven strand wire cables with various levels of corrosion. A newly developed process involves the determination of cross-sectional morphological data at the point of failure for these specimens. Additional data continues to be collected and examined to better understand how the corroded geometry of the cable relates to its degraded engineering performance.

The final objective, and the next stage of research and development, is the creation of risk-based civil engineering software for reliability and lifecycle analyses of anchored hydraulic structures for use in major rehabilitation studies. This risk-based software will incorporate the condition assessment tools and correlation of corrosion to degraded engineering performance with statistical uncertainty.

\subsection{Results and Conclusions}

This interim report along with ERDC TR-13-3 (Ebeling et al. 2013) reflects the progress made to date. In FY13, the authors were able to develop a cable corrosion and characterization system. The characterization system was composed of both pull test performance and measurement of cable condition. Because cable properties varied significantly at different locations 
along the cable, a decision was made to characterize cross-sectional properties at the failure locations. A digital imaging system was developed for this purpose. Imaging the cables at the failure locations involved determining the failure location; cutting and polishing the ends orthogonal to the cable axis near the failure location; collecting and calibrating image data; segmenting the individual wires in the calibrated image data; and performing morphological analysis of the final segmented, calibrated image data. This process has been created and tested with a select set of existing data. This process will be used with the remaining data to better understand the influence of corrosion on cable performance. A second batch of corroded specimens is currently scheduled and will be processed in a similar manner. This second batch will fill data gaps observed in the first batch results. 


\section{References}

Auger, F., P. Flandrin, P. Goncalves, and O. Lemoine. 2005. Time Frequency Toolbox for use with MATLAB, CNRS, (Centre National De La Recherche Scientifique), Rice University, http://www.nongnu.org/tftb/tutorial.pdf.

Azizinamini, Atorod, and Jawad Gull. 2012., Improved inspection techniques for steel prestressing/post-tensioning strand, FDOT Contract No BDK80-977-13, Final Report, Volume I, Miami, FL: Florida International University, http://ntl.bts.gov/lib/46000/46100/46173/FDOT_BDK80_977-13_rptvol1.pdf

Bartoli, I., S. Salamone, R. Phillips, C. Nucera, and F. L. D. Scalea. 2009. Health monitoring to detect failure of prestressing (PS) cables in segmental box girder bridges, San Diego La Jolla, California: Final Report Submitted to California Department of Transportation (Caltrans) by The Department of Structural Engineering University of California, http://cdm16255.contentdm.oclc.org/cdm/fullbrowser/collection/p266401coll4/id/4788/rv/ singleitem

Beard, M. D., M. J. S. Lowe, and P. Cawley. 2003. Ultrasonic guided waves for inspection of grouted tendons and bolts. American Society of Civil Engineers Journal of Materials in Civil Engineering 15(3):212-218, http://ascelibrary.org/doi/pdf/10.1061/\%28ASCE\%290899$1561 \% 282003 \% 2915 \% 3 A 3 \% 28212 \% 29$.

Chaki, S., Gerard Bourse. 2009. Non-destructive evaluation of the stress levels in prestressed steel strands using the acoustoelastic effect, BP 10838, 59508, Douai Cedex, France: Ecole des Mines de Douai, Department Technologie des Polymeres et Composite et Ingenierie Mecanique (TPC \& IM) 941 Rue Charles Bourseul, http://www.ndt.net/article/ndtce2009/papers/155.pdf.

Ebeling, R. M., M. Azene, and R. W. Strom. 2002. Simplified procedures for the design of tall, flexible anchored tieback walls, ERDC/ITL TR-02-9, Vicksburg, MS: US Army Engineer Research and Development Center.

Ebeling, R. M., Ralph W. Strom, John E. Hite Jr., R. W. Haskins, and James A. Evans. 2013. Assessing corrosion damage and corrosion progression in multistrand anchor systems in use at Corps projects, Multistrand Research Project, ERDC TR-13-3, Vicksburg, MS: US Army Engineer Research and Development Center, http://acwc.sdp.sirsi.net/client/default/index.assetbox.assetactionicon.view/1028160;jsession id=755CB8E9AB 17854C8D2B54CE9D0D9FFC.enterprise15000 ? $r$ =ENGINEER+RESEA0\%7C\%7C\%7C1\%7C\%7C\%7C0\%7C\%7C\%7Ctrue.

Ebeling, R. M., R. W. Haskins, D. Scofield, J. Hite, and R. Strom. 2012. Post-tensioned multistrand anchorage capacity deterioration due to corrosion, John Day Lock Project, ERDC/CHL CHETN-IX-28, Vicksburg, MS: US Army Engineer Research and Development Center, http://acwc.sdp.sirsi.net/client/search/asset/1006201. 
Ervin, B. E., J. T. Bernhard, D. A. Kuchma, and H. Reis. 2009. Monitoring general corrosion of rebar embedded in mortar using high frequency guided mechanical waves, Urbana, IL: Department of Industrial and Enterprise Systems Engineering, http://www.researchgate.net/publication/238179474_Monitoring_Corrosion_of_Rebar_Embed ded_in_Mortar_Using_High-Frequency_Guided_Ultrasonic_Waves.

Grossmann, A., and J. Morlet. 1984. Decomposition of hardy functions into square integrable wavelets of constant shape, Marseille, France: Centre de Physique Theorique, Section II, Centrre national de La Recherche Scientifique.

Headquarters, US Army Corps of Engineers (HQUSACE). 2005. Stability analysis of concrete structures. EM 1110-2-2100. Washington, DC: US Army Corps of Engineers.

Kwun, H., K. A. Bartels, and J. C. Hanley. 1997. Effects of tensile loading on the properties of elastic-wave propagation in a strand, San Antonia, Texas: Southwest Research Institute.

Laguerre, Laurent. 2009. Non-destructive evaluation of seven wire strands using ultrasonic guided waves, BP 4129,44341 Bonuguenais, France: Laboratoire Centeral des Ponts et Chaussees, Route de Bouaye, http://www.ndt.net/article/ndtce2009/papers/189.pdf.

Luo, J., W. Hackenberger, S. Zhang, and T. R. Shrout. 2009. The progress update of relaxor piezoelectric single crystals, In Proceedings, Ultrasonics Symposium (IUSo, 2009 IEEE International), http://ieeexplore.ieee.org/xpl/abstractKeywords.jsp?arnumber=5441884.

Pavlakovic, B. N., M. J. S. Lowe, and P. Cawley. 2000. High-frequency low-loss ultrasonic modes in imbedded bars, Journal of Applied Mechanics, 68(1) 67-75, http://appliedmechanics.asmedigitalcollection.asme.org/article.aspx?articleid=1555318.

Strom, R. W., and R. M. Ebeling. 2002. Methods used in Tieback Wall Design and Construction to Prevent Local Anchor Failure, Progressive Anchor Failure, and Ground Mass Stability Failure. ERDC/ITL TR-02-11. Vicksburg, MS: U.S. Army Engineer Research and Development Center.

Treyssede, F., and L. Laguerre. 2010. Investigation of elastic modes propagating in multi-wire helical waveguides, BP 4129 44341, Bouguenais, France: Laboratoire Central des Points et Chaussees, http://www.sciencedirect.com/science/article/pii/S0022460X0900933X.

Washer, Glenn. 2001. The acoustoelastic effect in prestressing tendons. PhD dissertation, Johns Hopkins University. 


\title{
Appendix A: Cable End View Imager Code (MATLAB IMAGE PROCESSING \#2 code)
}

\author{
$\%$ image Processing code for evaluation of cut cable cross sections \\ $\%$ Written by : Rick Haskins 10/31/13 \\ $\%$ requires image processing and statistics toolboxes \\ $\%$ input cable images are 15 Megapixel and calibration dots are 3/4 inch ref \\ $\%$ dots : Code segments and analyzes individual wires from a seven strand \\ $\%$ bundle. Automatic and manual segmentation options are presented. All \\ $\%$ operations are GUI based with right and center mouse buttons for manual \\ $\%$ cutting process. Fixes matlab 'problem' with zoom and imfreehand being \\ $\%$ used together
}

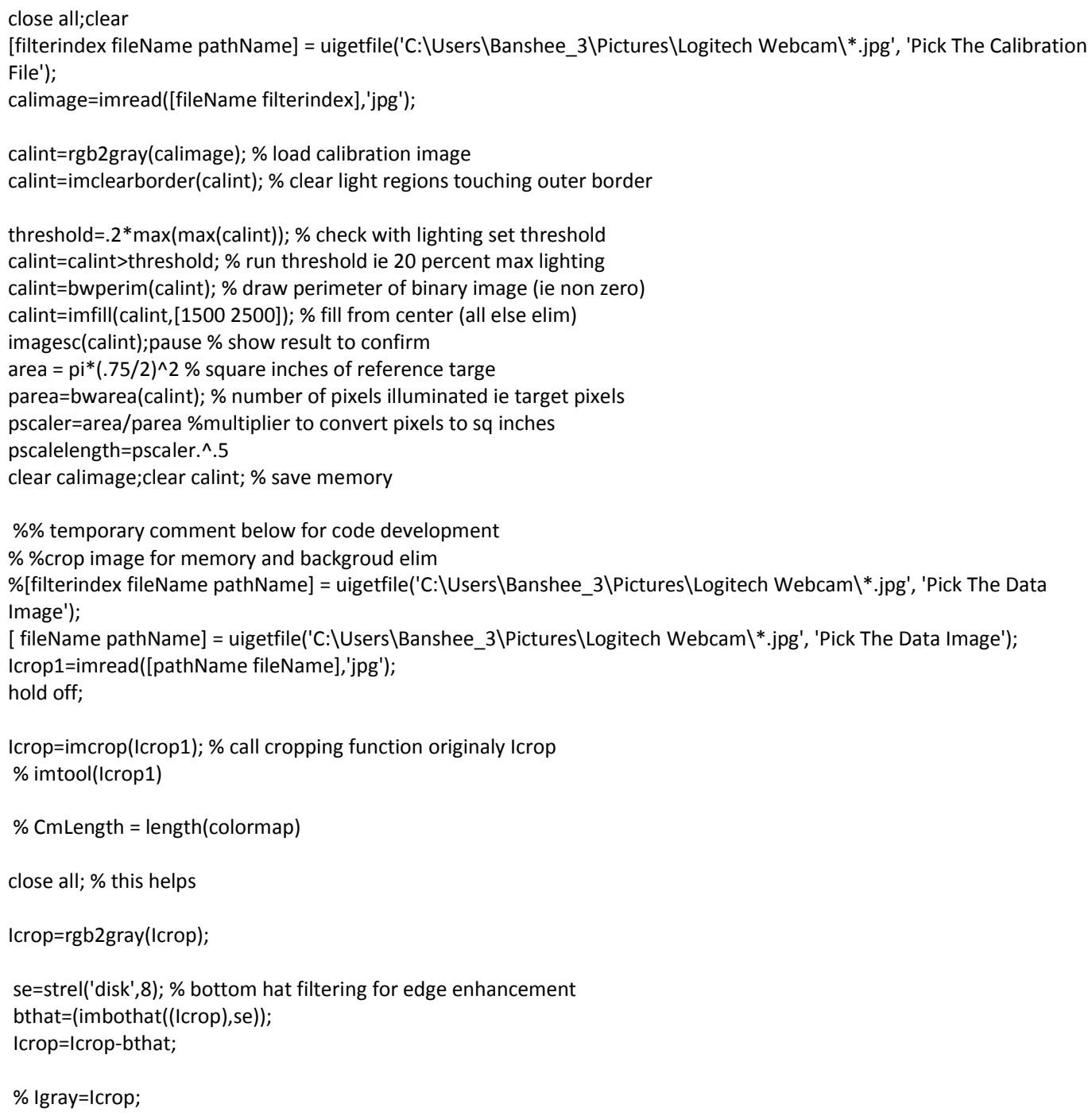




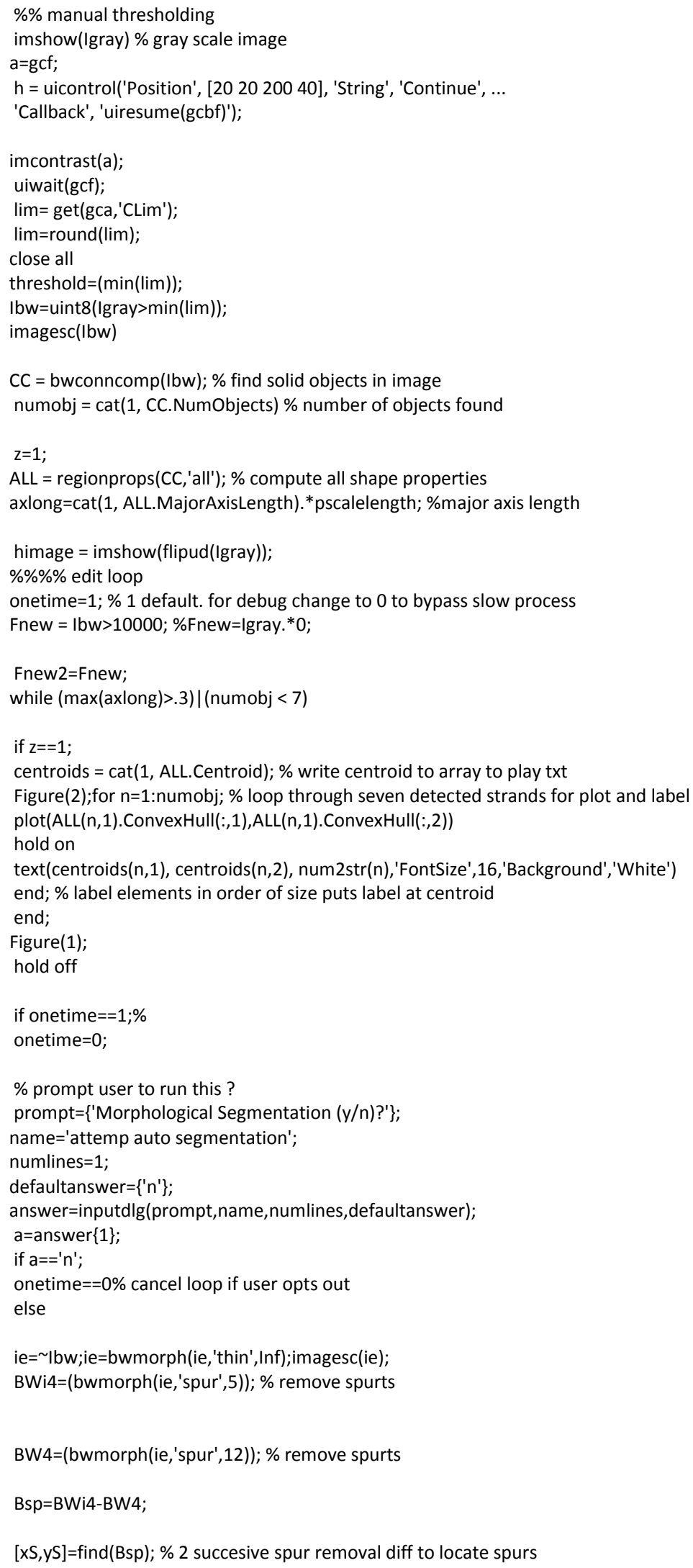


BW5=bwmorph(BW4,'branchpoints'); \% find branch point $[x, y]=f i n d(B W 5)$;

$\%$ imagesc(BW5);

$\% \operatorname{plot}\left(x(\operatorname{cat}(1, \mathrm{idx}\{:\})), y(\operatorname{cat}(1, \mathrm{idx}\{:\})),{ }^{\prime} \mathrm{o}\right) ; \%$ knnsearch plot

[idx2,d2]=knnsearch([x y],[x y],'IncludeTies',true,'K',6);

pts=cat(1,d2\{:\}); \% 1st 2nd 3rd connected distance

$F=$ false $(\operatorname{size}(l b w))$;

Fnew2=F;

for $\mid p=1: \max (\operatorname{size}(x))$;

$\mathrm{pts}=(\operatorname{cat}(1, \mathrm{idx} \times\{\mid \mathrm{p}\}))$;

for inlp=2:6; \% inner loop 3 connected neighbot

$\%$ hold off;

$\% \operatorname{plot}([y(\mid p) y(p t s($ inlp) $)],[x($ Ip) x(pts(inlp))],'o'); hold on

$m n x=\min ([x(\mid p) x(p t s($ inlp $))]) ;$

$\max x=\max ([x(\operatorname{lp}) x(p t s($ inlp $))])$;

$\operatorname{mny}=\min ([y(\mid p) y(p t s($ inlp) $))]) ; \%$ ORDER ENDPOINTS

$\max =\max ([y(\mid \mathrm{lp}) \mathrm{y}(\mathrm{pts}(\mathrm{in} \mid \mathrm{p}))])$;

$\mathrm{Idx}=(\operatorname{find}((\mathrm{xS}>\mathrm{mnx}) \&(\mathrm{xS}<\max \mathrm{x}))) ; \%$ FIND $x$ CONTAINED BETWEEN ENDPT

$I d y=($ find $((y S>m n y) \&(y S<\max y))) ;$

if $\max (\operatorname{size}(\mathrm{Idx}))>\max (\operatorname{size}(\mathrm{Idy})) ; \%$ get smallest subset of contained $\mathrm{pts}$

$\mathrm{c}=\mathrm{Idx} ; \mathrm{c}(\sim$ ismember $(\mathrm{Idx}, \mathrm{Idy}))=0$;

else;

$c=I d y ; c(\sim$ ismember $(I d y, I d x))=0$;

end;

[indx]=find(c);\%indes point

$\mathrm{c}=\mathrm{c}($ ind $\mathrm{x}) ; \%$ actural index value in $\mathrm{yS}, \mathrm{xS}$

if $\max (\operatorname{size}(c))==1$; continue;end;

$\% \operatorname{plot}\left(\mathrm{yS}(\mathrm{c}), \mathrm{xS}(\mathrm{c}),{ }^{\prime}+{ }^{\prime}\right)$;

$\% \%$ check for linear $\mathrm{P}=\operatorname{polyfit}(\mathrm{X}, \mathrm{Y}, \mathrm{N}) \mathrm{Y}=\operatorname{polyval}(\mathrm{P}, \mathrm{X})$

Ply=polyfit([y(lp) y(pts(inlp))],[x(Ip) x(pts(inlp))],1);

$\% \%$ check for linear $\mathrm{P}=\operatorname{polyfit}(\mathrm{X}, \mathrm{Y}, \mathrm{N}) \mathrm{Y}=\operatorname{polyval}(\mathrm{P}, \mathrm{X})$

$\mathrm{YY}=\operatorname{polyval}(\mathrm{Ply}, \mathrm{yS}(\mathrm{c}))$;

$\% \operatorname{plot}\left(y S(c), Y Y,{ }^{\prime} r o '\right) ;$

err=(sum((YY-xS(c)).^2))./max(size(YY)); \% compute error from line

if err>1.5e3; continue;end; \% error outside linear fit

err

$\mathrm{P} 01=([y S(c) x S(c)]) ;$

D11 = round $([0 ;$ cumsum $(\operatorname{sum}(\operatorname{abs}(\operatorname{diff}(P 01)), 2))]) ; \%$ Need the distance between points...

$\mathrm{P} 1=$ interp1(D11,P01,D11(1):.5:D11(end)); \% ...to close the gaps

$P 1=$ unique $\left(\right.$ round $(P 1)$, 'rows' $\left.^{\prime}\right)$;

$\mathrm{S} 1$ = sub2ind(size(Igray),P1(:,2),P1(:,1));

$\mathrm{F}(\mathrm{S} 1)=$ true;

$\% \mathrm{~F}(\mathrm{P} 1(:, 2), \mathrm{P} 1(:, 1))=1$;

Fnew2=Fnew2 $\mid F$; 


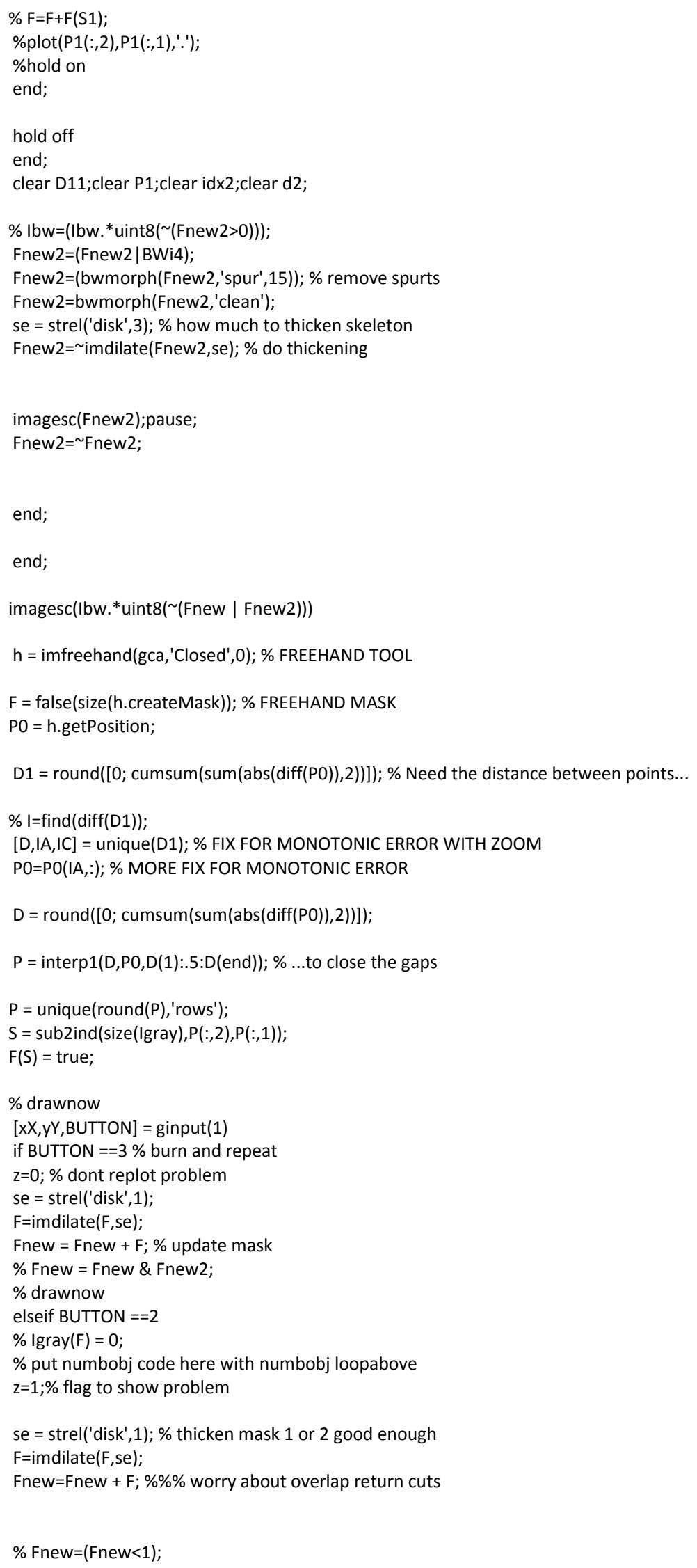


$\% \operatorname{Igray}($ Fnew $)=0$;

$\%$ Igray=Igray. ${ }^{*}$ (uint8(Fnew));

$\%$ Ibw=lgray>threshold; \% convert to binary everything above $20 \% \%$

$\% \mathrm{Ibw}=\mathrm{Ibw} \&$ Fnew2 \& Fnew;

$\% \mathrm{Ibw}=($ imerode(Ibw,se)); \% make drawn lines thicker \% ** FIX this removing image

$\% \% \% \% \% \% \% \% \% \% \% \%$ Ibw=imfill(Ibw,'holes'); \%fill interior holes

$\mathrm{CC}=$ bwconncomp $($ Ibw. *uint8( (Fnew2 | Fnew $))) ; \%$ find solid objects in image

numobj = cat $(1$, CC.NumObjects) $\%$ number of objects found

$\mathrm{ALL}=$ regionprops $\left(\mathrm{CC}, \mathrm{\prime}^{\prime} \mathrm{all}\right) ; \%$ compute all shape properties

axlong=cat(1, ALL.MajorAxisLength).*pscalelength; \%major axis length

end;

end;

$\mathrm{ALL}=$ regionprops $\left(\mathrm{CC}, \mathrm{Ill}^{\prime}\right) ; \%$ compute all shape properties

Figure('Position',[100 100520640$])$;

$\%$ subplot(211)

axes('Position',[.27 .54 .5 .4]);

title(filterindex);

hold on

area $=\operatorname{cat}(1$, ALL.ConvexArea); \% get array of areas

[sortedValues,sortIndex] = sort(area,' 'descend'); \%sort with index descend

maxIndex = sortIndex(1:7); \% seven largest objects detected in image

centroids = cat(1, ALL.Centroid); $\%$ write centroid to array to play txt

\%draws hulls

for $n=1: 7 ; \%$ loop through seven detected strands for plot and label plot(ALL(maxIndex(n),1).ConvexHull(:,1),ALL(maxIndex(n),1).ConvexHull(:,2))

hold on

$\%$ below writes size order at centroid

text(centroids(maxIndex(n),1), centroids(maxIndex(n),2), num2str(n),'FontSize',16, 'Background','White')

end; \% label elements in order of size puts label at centroid

hold off

$\%$ start extracting properties from ALL -dont forget order of maxIndex

$\%$ also don't forget scaling from calibration

perim $=$ cat $(1$, ALL.Perimeter $) .{ }^{*}$ pscalelength; $\%$ length extracted and scaled

area=area*pscaler; \% area scaled from pixel calibration th;

eccentr=cat(1, ALL.Eccentricity); \% 1 round 0 line

axlong=cat(1, ALL.MajorAxisLength). *pscalelength; \%major axis length

axshort=cat(1, ALL.MinorAxisLength).*pscalelength;

colnames $=\{$ 'area', 'perim', 'eccentr','Axis long', 'Axis short' $\}$;

rowname=\{'1st','2nd','3rd', '4th','5th','6th','7th','outer mean','outer std','totals 1-7'\};

data=[area(maxlndex,1) perim(maxIndex,1) eccentr(maxIndex,1) axlong(maxIndex,1) axshort(maxIndex,1) ];

$\operatorname{data}(8,:)=$ mean $(\operatorname{data}(2: 7,:)) ; \%$ next to last row mean perim wires

$\operatorname{data}(9,:)=\operatorname{std}(\operatorname{data}(2: 7,:)) ; \%$ last row std dev perim wire

data(10,:)=sum(data(1:7,:));\% last row std dev perim wire

$\%$ pos=[2 47500250$]$

pos=[14 63500 209];

$\%$ subplot(212)

t=uiTable('Data', data, 'ColumnName',colnames, 'RowName',rowname,'Position', pos)

len=length(fileName);\% get length of string to cut the jpg part and replace $w$ csv

fileName=fileName(1:len-4);

csvwrite_with_headers(fileName,data,colnames);

Figure(1) ; 
hfigs = get $(0$, 'children') $; \%$ Figure handle

saveas(hfigs(1), [fileName '.fig']) \%Matlab .FIG file

saveas(hfigs(1), [fileName '.emf']) \% enhanced metafile 


\section{Appendix B: Axial Scanner Theory and Operation}

\section{Measuring Surface Variations on Stranded Cable with a Laser}

\section{Theory of Operation}

By projecting a plane laser onto a surface and observing the intersection point of the laser and the surface from an angle offset from the plane of the laser, variations in the surface that fall in the plane of the laser may be observed and quantified. Recording the surface with a digital camera, the variations in the surface can be measured by shifts in the image where the laser occurs. Figure B.1 contains an image obtained in such a manner. As seen in Figure B.1, light reflecting on the cable surface matches the intensity of the laser. By removing the artificial lighting in the room, the intersection point of the laser and the cable surface becomes easily distinguishable as seen in Figure B.2. The straight vertical surfaces are part of the test apparatus and are ignored during processing. Projecting the laser onto a surface with known variations in elevation, the camera image can be calibrated to provide accurate elevation change measurements in the surfaces to be scanned.

\section{System Implementation}

In order to characterize the surface variations of multi-stranded cables, a scanning system utilizing a plane laser and a digital camera was implemented. The system is shown in Figure B.3. It consists of four major components. They are a plane laser, a 2 Megapixel digital camera (1600 x 1200), a motorized carriage on which the laser and camera are mounted, and a channel to secure the cables in a straight line while being scanned. Figure B.4 shows a close-up of the camera and laser portions of the system.

The plane laser was aligned perpendicular to the cable to be measured. By utilizing this orientation of the laser, it was assured that the observed elevation changes in the cable surface are in the same cross-sectional area of the cable. The digital camera was aligned at an angle such that the observed changes in the laser line would be spread over a large portion of the image to maximize resolution. The angle between the camera and the plane of the laser could not be so great that the laser would be blocked from the camera image by the elevation changes to be measured. 
Figure B.1. Camera image obtained by projecting a plane laser onto a stranded cable.

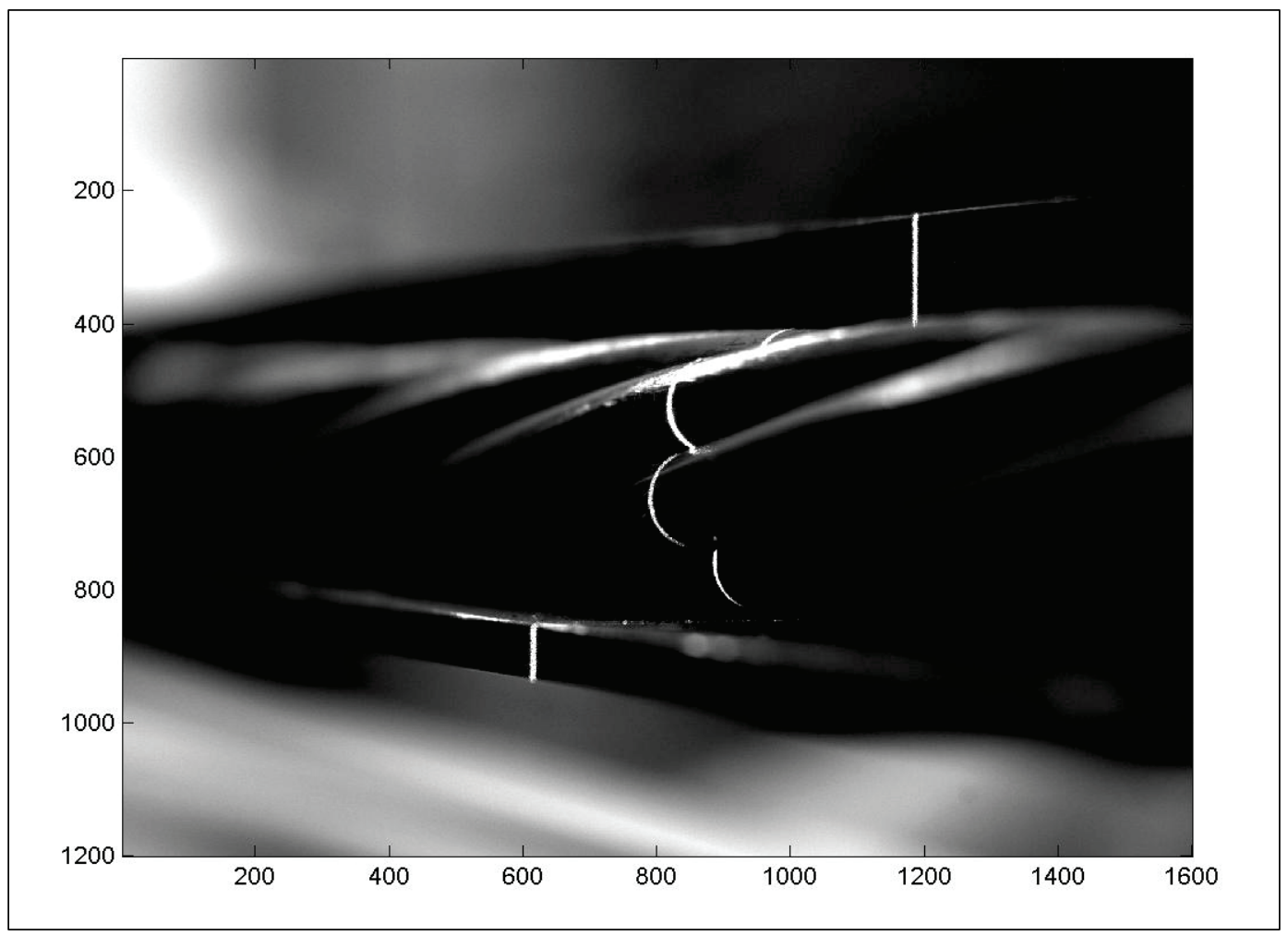

Figure B.2. Camera image obtained in a darkened room.

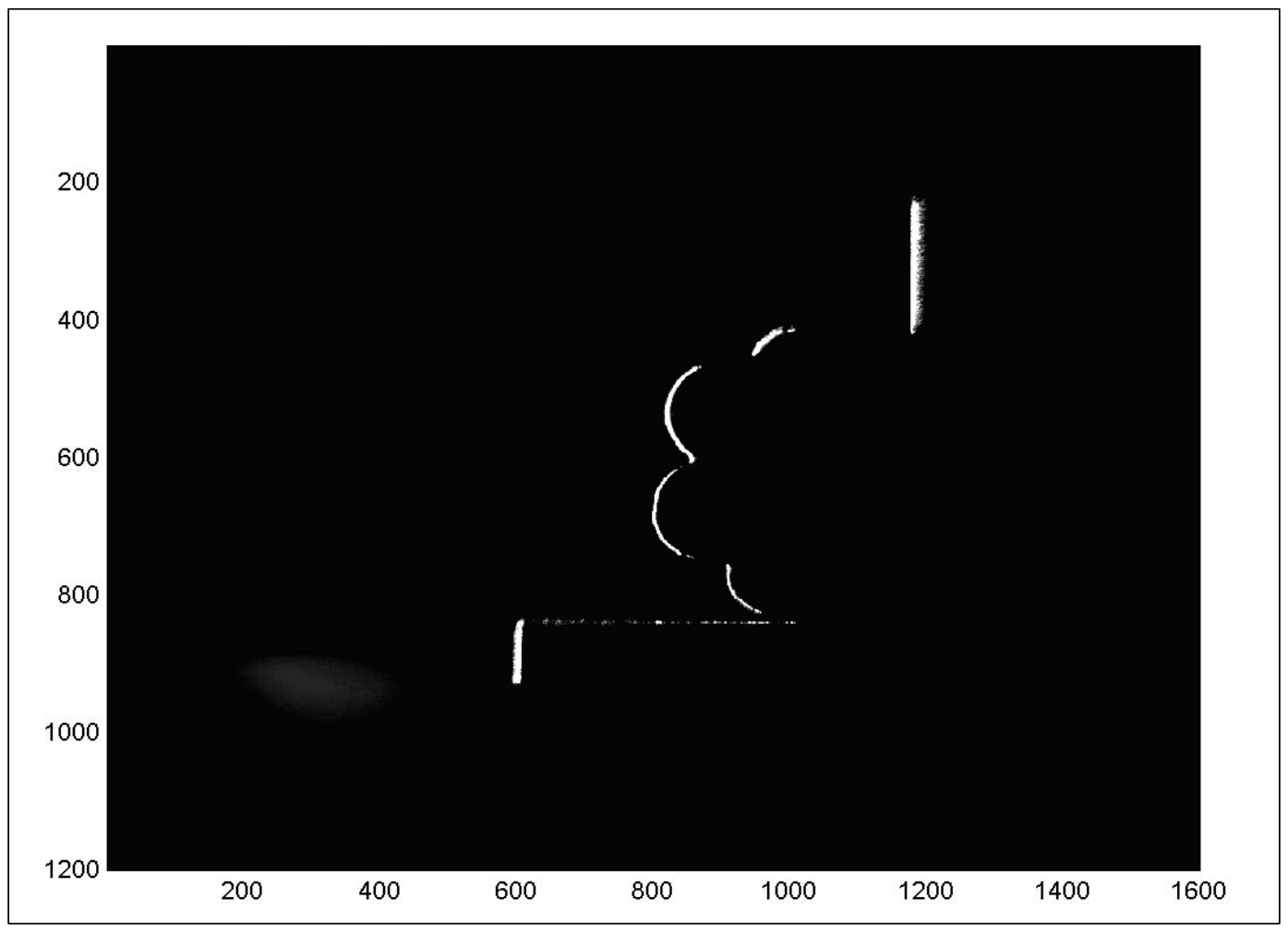


Figure B.3. Cable scanning system.

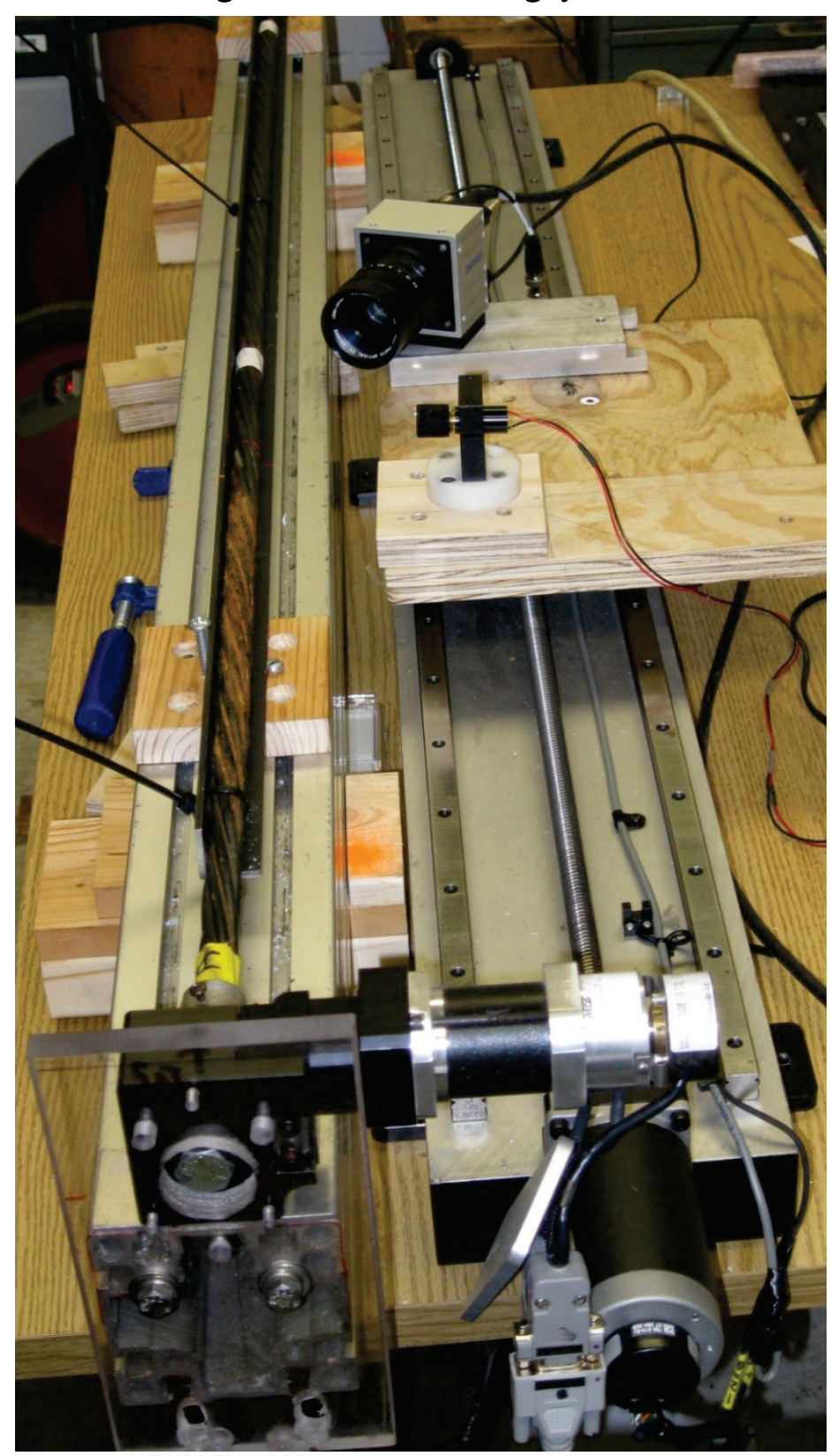


Figure B.4. Camera and plane laser aligned to scan a stranded cable.

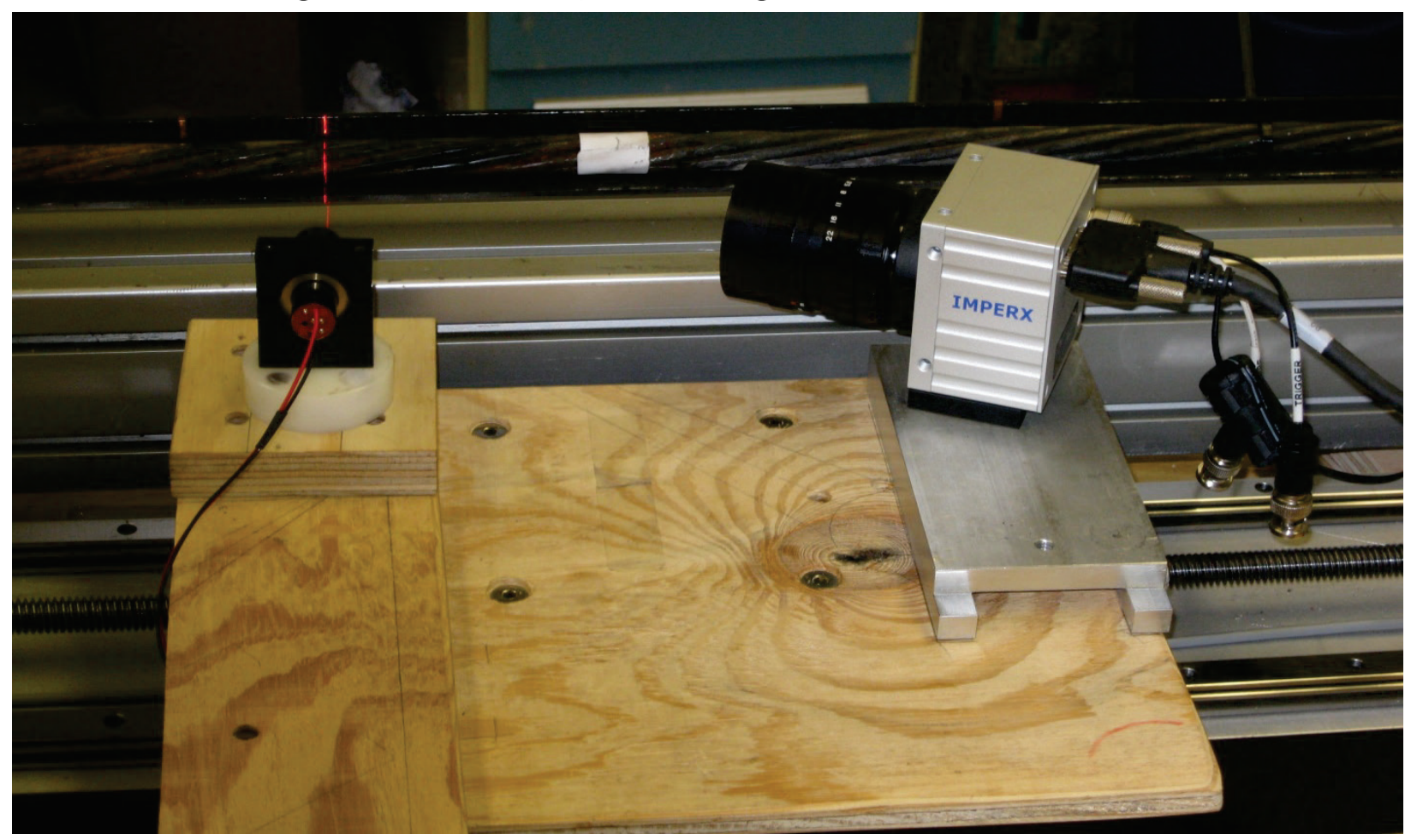

\section{Measurement Procedure}

Two types of scans are performed using this system. One type was a rotation scan in which the laser/camera platform was moved along the length of the stranded cable, while the cable was also rotated around its longitudinal axis at a rate that matched the period of the cable winding as depicted in Figure B.5. Figure B.5 shows the laser/camera platform moving from left to right, while the cable is rotated clockwise when looking along the length of the cable from left to right. By doing so, individual cable strands were straightened in a virtual sense, so they could be mapped the length of the scanned section.

The other type of scan was performed by moving the laser/camera platform along the length of the stranded cable without rotating the cable. This allows a surface map of the cable to be made that provides a picture of the variations of the cable in a more natural manner, while providing a means of viewing portions of all strands in a single scan. This is referred to as a non-rotational scan. 


\section{Results Obtained}

Figure B.6 shows a 3-dimensional image of a rotational scan of the multistrand cable labeled 47A. Figure B.7 contains a line graph that shows the amount of surface variation along a single line of a cable strand. The graph in Figure B.7 shows a change in surface elevation of 0.017 inches in the section of cable shown.

Figure B.5. Rotation Method of Scanning.

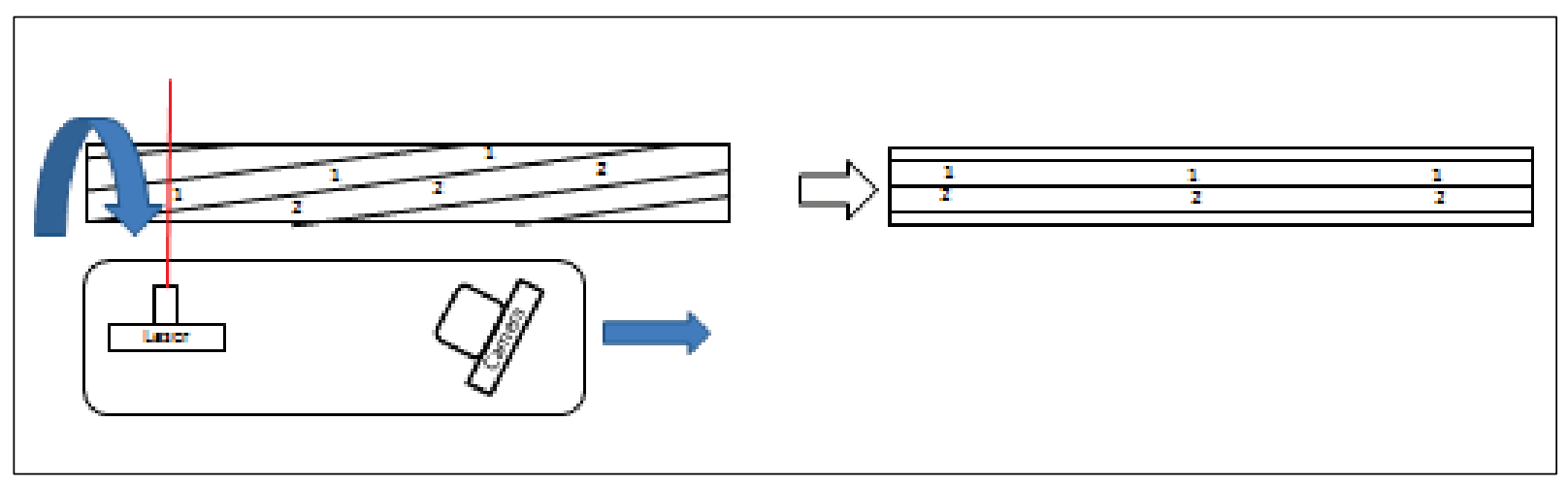

Figure B.6. 3-D display of data obtained while rotating stranded Cable 47A about the longitudinal axis.

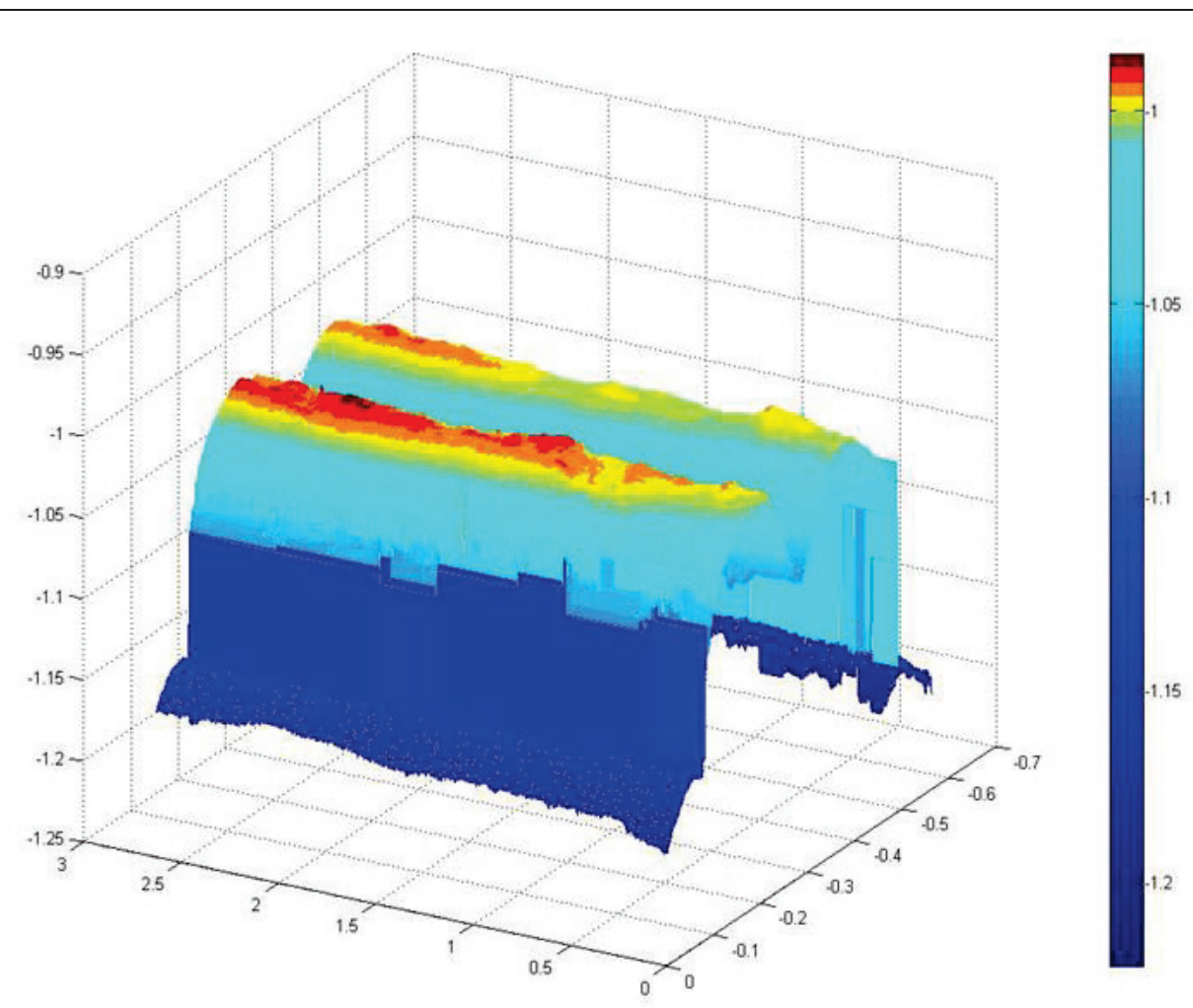

Dimensions are in inches. 
Figure B.7. Surface magnitude variations along a single line of a cable strand.

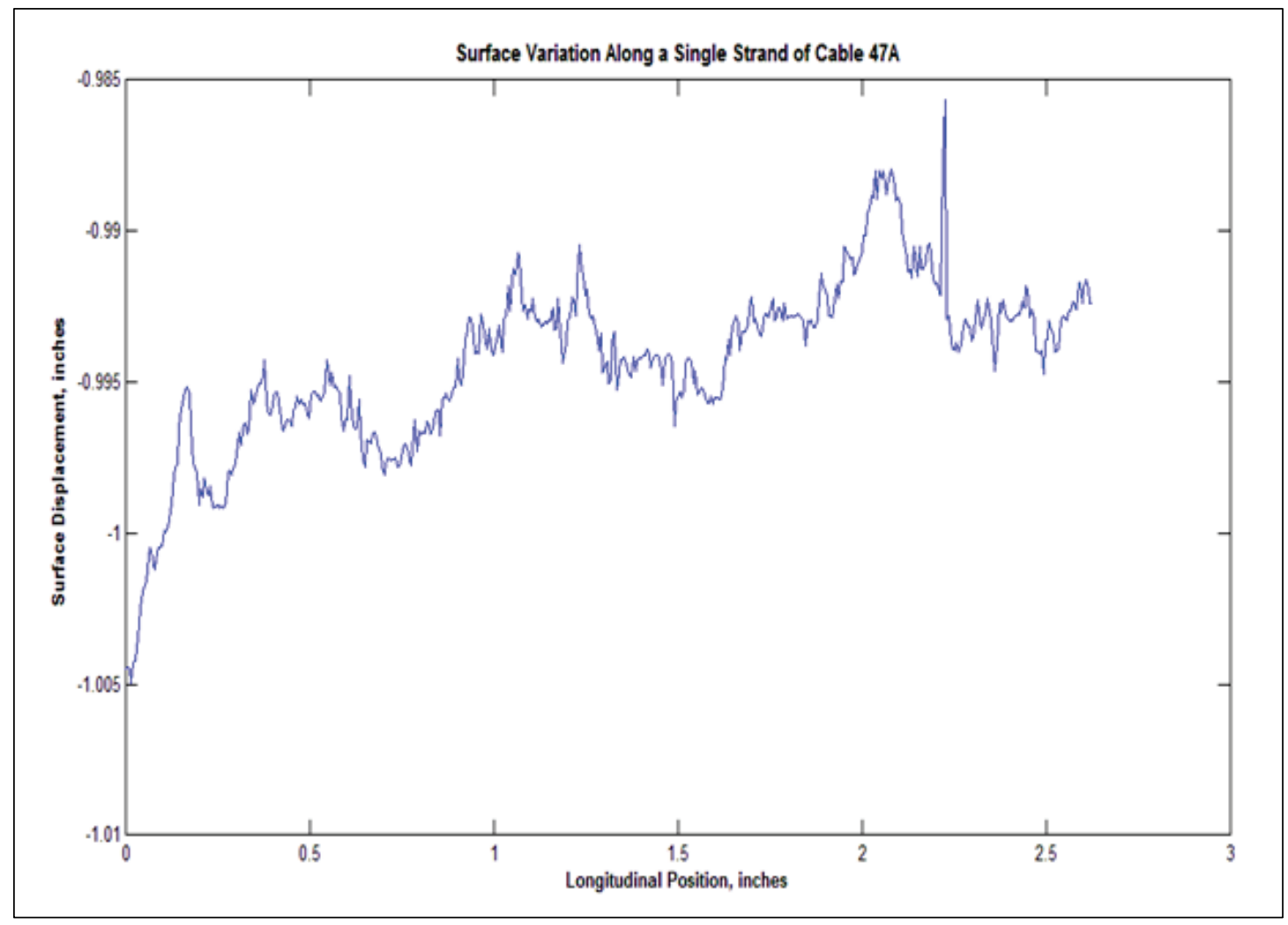

Figure B.8 presents a 3-dimensional representation of a section of the data obtained from a non-rotational scan of Cable 47A. Figure B.9 shows an intensity mapping of a non-rotational scan of a section of Cable 47A. Figure B.10 contains a comparison of surface displacements measured along a single pixel row on Cable 47A and the same pixel row on a pristine cable. The pixel row to map was selected by finding the maximum value of each scan (column in the data). By computing the mean value of the rows where the maximum values occurred, the longitudinal center line of the cable was located. Both cables yielded the same result. The longitudinal center is located along pixel row 618. Note the overall reduced diameter and the irregularity in the surface profile of Cable $47 \mathrm{~A}$ due to the corrosive methods applied. 
Figure B.8. 3-D representation of data obtained with a non-rotational scan of Cable 47A.

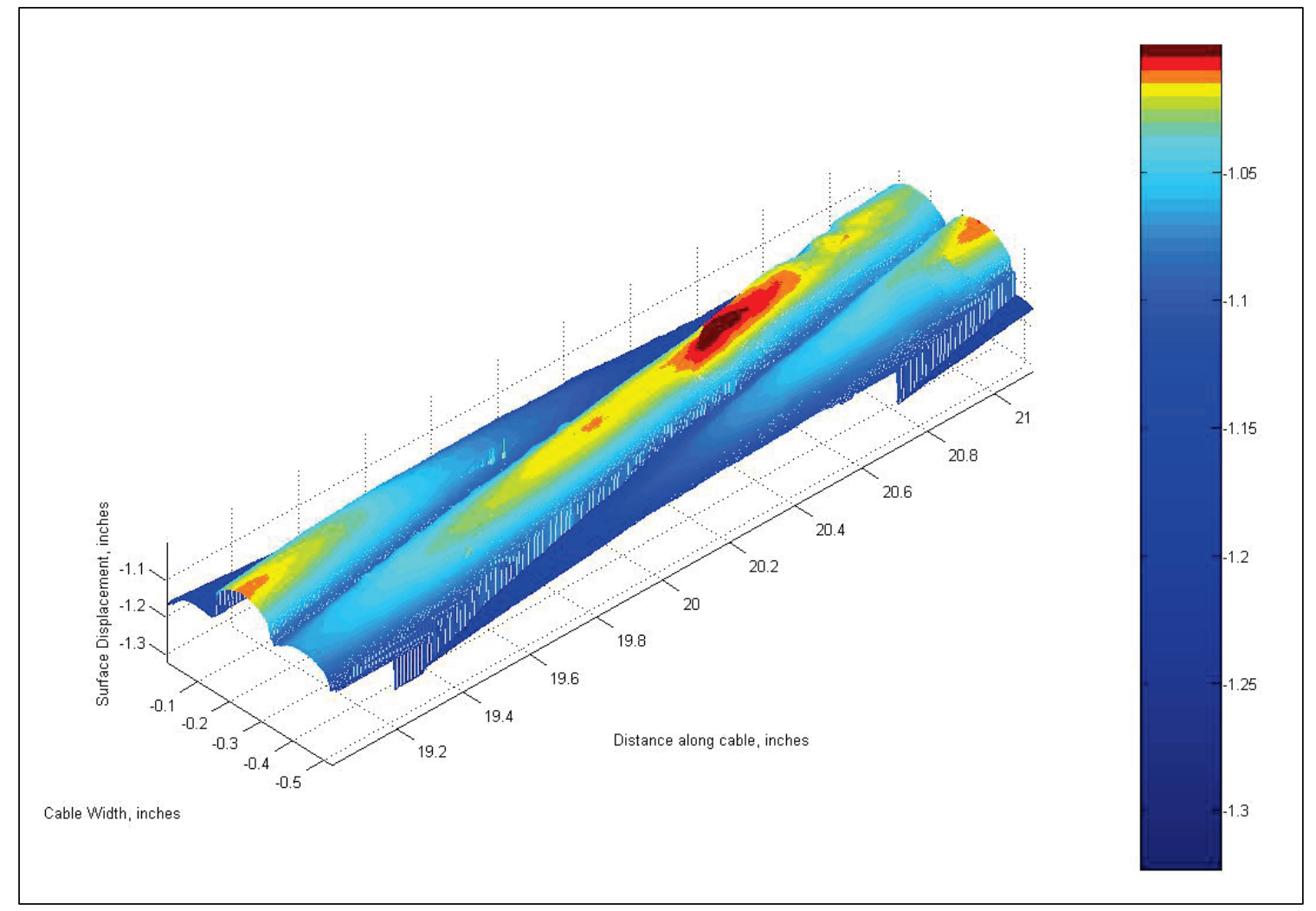


Figure B.9. Surface displacement mapping of a non-rotational scan of Cable 47A.

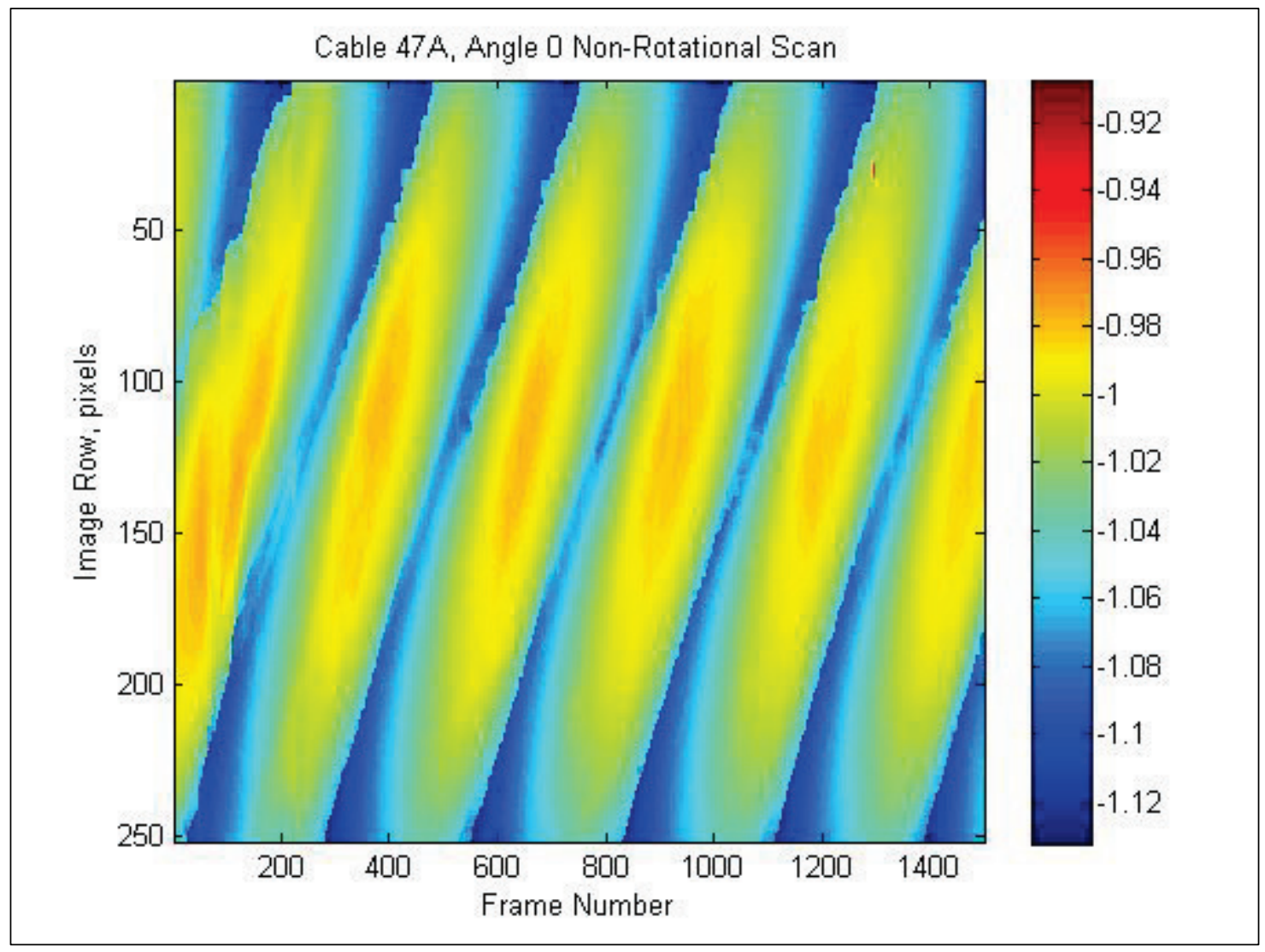

Figure B.10. Surface displacements measured at pixel row 618 along the length of a section of Cable 47A as compared to a pristine cable section.

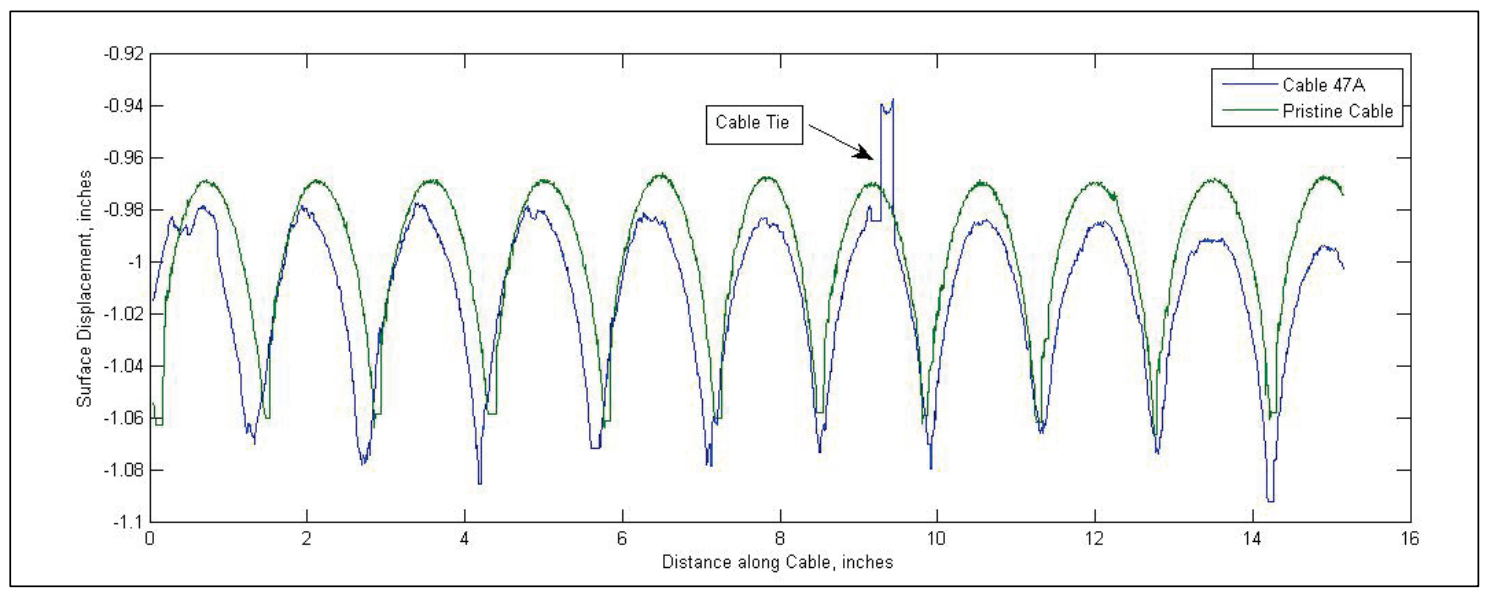




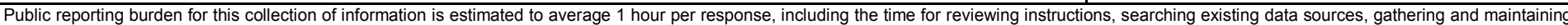

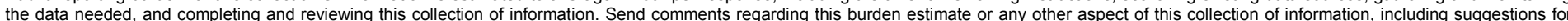

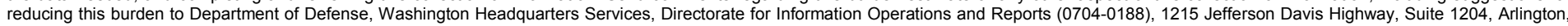

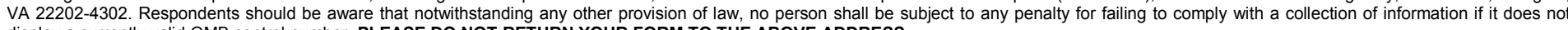
display a currently valid OMB control number. PLEASE DO NOT RETURN YOUR FORM TO THE ABOVE ADDRESS.
1. REPORT DATE (DD-MM-YYYY)
August 2014
2. REPORT TYPE
Final Report

\section{TITLE AND SUBTITLE}

Corrosion Induced Loss of Capacity and Development of a Guided

Wave Condition Assessment Method for Multistrand Anchor Systems

Used in Corps Projects

\section{AUTHOR(S)}

Richard W. Haskins, James A. Evans, and Robert M. Ebeling
3. DATES COVERED (From - To)

\section{5a. CONTRACT NUMBER}

5b. GRANT NUMBER

5c. PROGRAM ELEMENT NUMBER

\section{5d. PROJECT NUMBER}

5e. TASK NUMBER

5f. WORK UNIT NUMBER

\section{PERFORMING ORGANIZATION REPORT} NUMBER

ERDC/ITL TR-14-2
Information Technology Laboratory

US Army Engineer Research and Development Center

3909 Halls Ferry Road

Vicksburg, MS 39180-6199

\section{SPONSORING / MONITORING AGENCY NAME(S) AND ADDRESS(ES)}

US Army Corps of Engineers

441 G. Street, NW

Washington, DC

20314-1000

\section{DISTRIBUTION / AVAILABILITY STATEMENT}

Approved for public release; distribution is unlimited.

\section{SUPPLEMENTARY NOTES}

\section{ABSTRACT}

Over the past five decades, the US Army Corps of Engineers has worked to upgrade its projects by installing high-capacity, post-tensioned foundation anchors. These stressed steel tendons have been used to strengthen hydraulic structures and to improve their serviceability and stability. The goal has been to achieve structural stability for Corps hydraulic concrete structures and/or to remediate cracked concrete monoliths. Substantial improvements to protect multistrand anchor systems from corrosion have been made since they were first used in Corps projects more than 50 years ago, but the corrosion of older multistrand anchor systems is still a major concern. As a result of needs within the USACE, researchers at the US Army Engineer Research and Development Center (ERDC) are developing engineering procedures to estimate the current state of load-carrying capacity and to estimate the remaining service life of these tendons. These tools also aim to establish the rate of deterioration of anchorage capacity (with time), so costly replacement of ground anchorage can be delayed until absolutely needed. Analytical, laboratory, and field-testing efforts will be used to develop a methodology and analytical models to predict deterioration and loss of strength. Probabilistic procedures will be used to quantify uncertainties for the primary variable resulting in loss of strength of the post tensioned tendon. These uncertainty parameters will be carried into the risk-based analytical model. Procedures to extend the life of deteriorating multistrand tendons will be investigated. This report discusses the progress made since publication of the authors' first research report, ERDC TR-13-3. This report discusses ERDC's recent advances in the initial phase of a laboratory testing program to estimate seven strand wire cable strength as a function of cross sectional material loss. Cable strength is measured by performing a pull test to failure on corroded specimens, as well as specimens with manufactured defects. An innovative morphological procedure using digital photography was developed for quantifying the geometrical properties of cable near their failure locations. Fundamental research into Nondestructive testing (NDT) methods to assess the condition of post-tensioning seven strand wire cables is also discussed, with a focus on the guided wave approach.

\section{SUBJECT TERMS}

Corrosion

Multistrand anchor systems
Seven strand wire cables

Seven wire strand cables

Wire pull tests
16. SECURITY CLASSIFICATION OF: Unclassified

a. REPORT

Unclassified b. ABSTRACT

Unclassified c. THIS PAGE

Unclassified
Digital photography

Morphological processing

Nondestructive testing (NDT)

\section{LIMITATION} OF ABSTRACT

\section{NUMBER OF PAGES}

83

\section{9a. NAME OF RESPONSIBLE} PERSON

19b. TELEPHONE NUMBER (include area code) 